\title{
2005 Hydrographic Survey of South San Francisco Bay, California
}

By Amy C. Foxgrover ${ }^{1}$, Bruce E. Jaffe ${ }^{1}$, Gerald T. Hovis ${ }^{2}$, Craig A. Martin ${ }^{2}$, James R. Hubbard $^{3}$, Manoj R. Samant ${ }^{2}$, and Steve M. Sullivan ${ }^{4}$

${ }^{1}$ U.S. Geological Survey Pacific Science Center, Santa Cruz, CA

${ }^{2}$ NOAA National Ocean Service CO-OPS, Silver Spring, MD

${ }^{3}$ Retired, formerly with NOAA National Ocean Service CO-OPS, Silver Spring, MD

${ }^{4}$ Sea Surveyor, Inc., Benicia, CA

Open-File Report 2007-1169

U.S. Department of the Interior

U.S. Geological Survey 


\section{U.S. Department of the Interior Dirk Kempthorne, Secretary}

\section{U.S. Geological Survey Mark Myers, Director}

U.S. Geological Survey, Reston, Virginia 2007

Revised and reprinted: 2007

For product and ordering information:

World Wide Web: http://www.usgs.gov/pubprod

Telephone: 1-888-ASK-USGS

For more information on the USGS-the Federal source for science about the Earth, its natural and living resources, natural hazards, and the environment:

World Wide Web: http://www.usgs.gov

Telephone: 1-888-ASK-USGS

Suggested citation:

Foxgrover, A.C., Jaffe, B.E., Hovis, G.T., Martin, C.A., Hubbard, J.R., Samant, M.R., and Sullivan, S.M., 2007, 2005 Hydrographic Survey of South San Francisco Bay, California, U.S. Geological Survey Open-File Report 2007-1169 113 p. [URL:

http://pubs.usgs.gov/of/2007/1169]

Any use of trade, product, or firm names is for descriptive purposes only and does not imply endorsement by the U.S. Government.

Although this report is in the public domain, permission must be secured from the individual copyright owners to reproduce any copyrighted material contained within this report. 


\section{Contents}

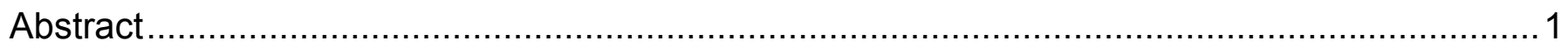

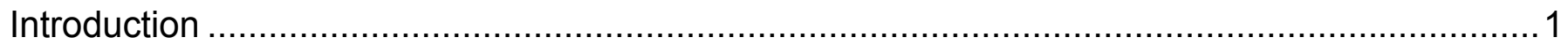

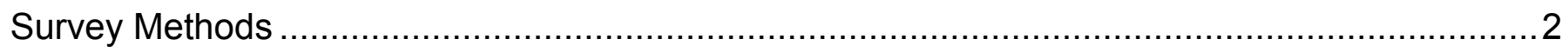

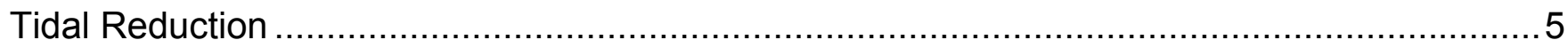

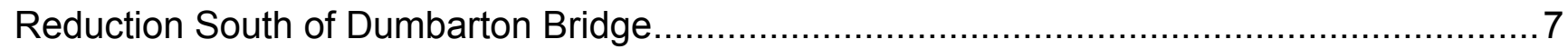

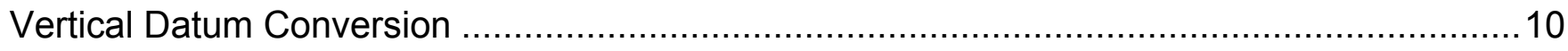

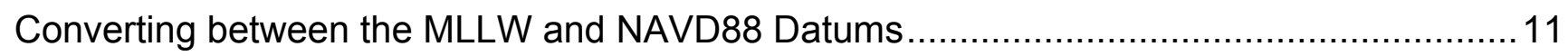

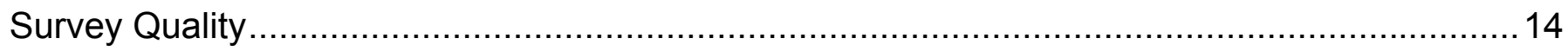

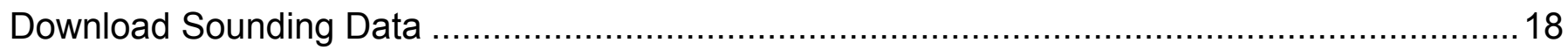

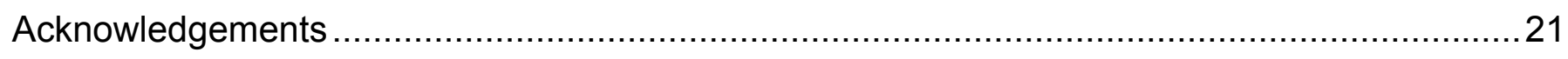

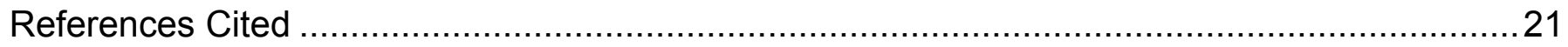

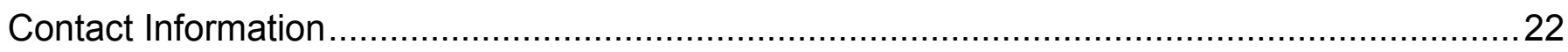

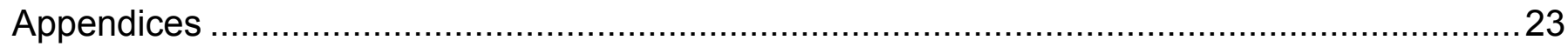

I. Hydrographic Survey of South San Francisco Bay by Sea Surveyor, Inc ..........................24

Sub-Appendix A - Boundary Coordinates for Tide Zones .............................................65

Sub-Appendix B - Acoustic Classification Survey South San Francisco Bay ..................71

II. Draft summary of procedures and results - South San Francisco Bay vertical datum determination and conversion study by NOAA Center for Operational Oceanographic Products and Services 


\section{Abstract}

An acoustic hydrographic survey of South San Francisco Bay (South Bay) was conducted in 2005. Over 20 million soundings were collected within an area of approximately $250 \mathrm{sq} \mathrm{km}(97 \mathrm{sq}$ mi) of the bay extending south of Coyote Point on the west shore, to the San Leandro marina on the east, including Coyote Creek and Ravenswood, Alviso, Artesian, and Mud Sloughs. This is the first survey of this scale that has been conducted in South Bay since the National Oceanic and Atmospheric Administration National Ocean Service (NOS) last surveyed the region in the early 1980s. Data from this survey will provide insight to changes in bay floor topography from the 1980s to 2005 and will also serve as essential baseline data for tracking changes that will occur as restoration of the South San Francisco Bay salt ponds progress. This report provides documentation on how the survey was conducted, an assessment of accuracy of the data, and distributes the sounding data with Federal Geographic Data Committee (FGDC) compliant metadata. Reports from NOS and Sea Surveyor, Inc., containing additional survey details are attached as appendices.

\section{Introduction}

The largest wetland restoration project on the west coast of the U.S. is underway in South San Francisco Bay (South Bay), California. Fifteen thousand acres (approximately $61 \mathrm{sq} \mathrm{km}$ or 23 sq mi) of industrial salt ponds are slated for restoration to mixed intertidal habitats (http://southbayrestoration.org). This effort is complicated by the fact that during the decades of commercial salt production some of these ponds have subsided as much as $2 \mathrm{~m}$ beneath natural marsh levels as a result of excessive ground water withdrawal that occurred from the 1930s to 1960s (Poland and Ireland, 1988). Without careful planning, opening these subsided ponds (potential sediment sinks) to tidal influence could have detrimental impacts to the adjacent tidal flats which help to protect the shoreline from erosion and serve as critical habitat for wintering waterfowl and shorebirds (San Francisco Bay Joint Venture, 2001).

Understanding long-term sediment dynamics is a crucial component for developing successful restoration strategies. Foxgrover, et al., (2004) performed an analysis of the series of five National Oceanic and Atmospheric Administration (NOAA) National Ocean Service (NOS) hydrographic surveys collected in South Bay from 1858 to 1983 however, this left a critical data gap from 1983 to the present. With the large fluctuations between periods of net deposition and net erosion recorded between 1858 and 1983 in Foxgrover, et al., (2004) it was important to determine how sedimentation rates have changed in South Bay since 1983. The hydrographic survey conducted in 2005 provides insight to changes in bay floor topography from the 1980s to 2005 (Jaffe and Foxgrover, 2006a; Jaffe and Foxgrover, 2006b) and also serves as essential baseline data for tracking changes that will occur as restoration efforts progress.

The 2005 hydrographic survey was collected from January 10 to April 5, 2005 using the same procedures and to the same standards as recent NOS surveys. The survey extends south of Coyote Point on the west shore, to the San Leandro marina on the east, including Coyote Creek and Ravenswood, Alviso, Artesian and Mud Sloughs (Figs. 1, 2). Over 20 million soundings were collected within an area of approximately $250 \mathrm{sq} \mathrm{km}$ (97 sq mi). 

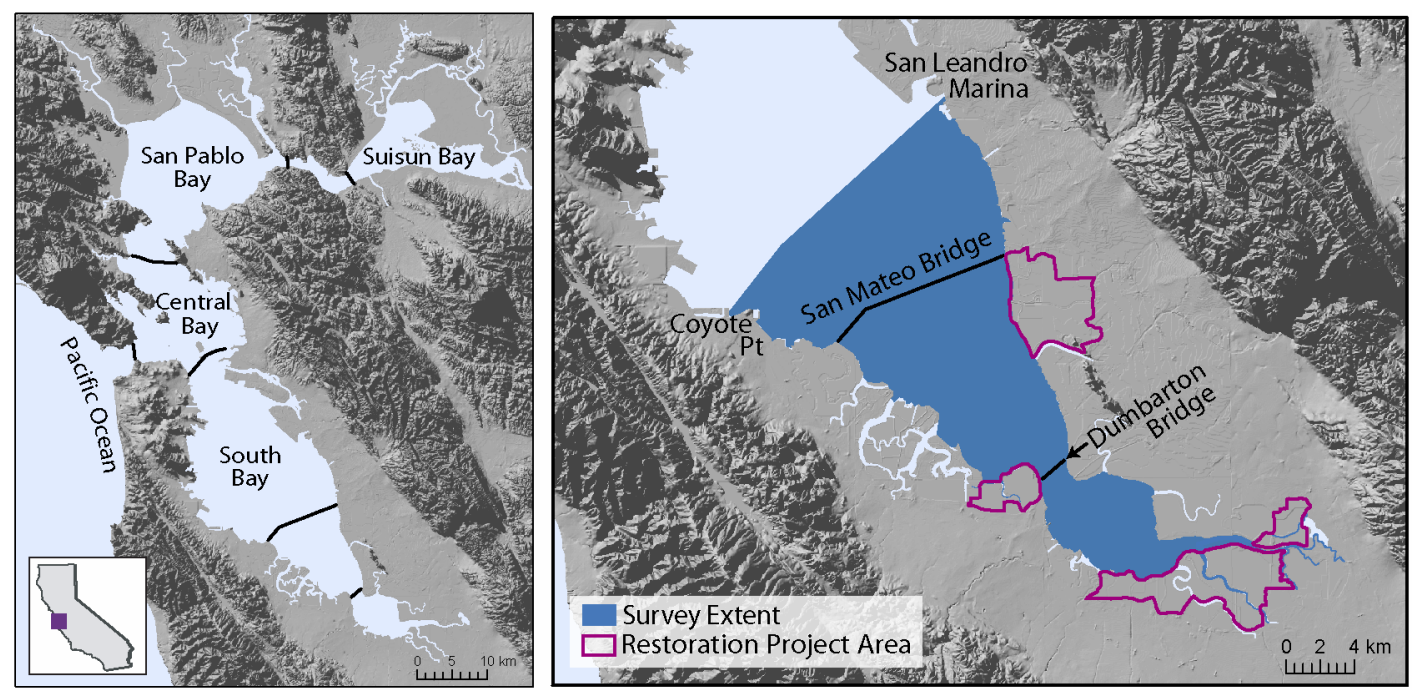

Figure 1. Location and extent of 2005 South San Francisco Bay hydrographic survey. Pond complexes slated for restoration are delineated for reference.

\section{Survey Methods}

Order 1 hydrographic surveys are conducted under the stringent standards established by the International Hydrographic Organization (IHO, 1998) and the National Oceanic and Atmospheric Administration (NOAA, 2006). Sea Surveyor, Inc., was contracted by the California Coastal Conservancy to conduct an Order 1 hydrographic survey of South Bay (Appendix I). A singlebeam, $200-\mathrm{kHz}$ depthfinder was used to collect depths at a nominal spacing of $0.15 \mathrm{~m}$ along and $100 \mathrm{~m}$ between tracklines, resulting in approximately 20 million soundings (or 2.7 million when thinned to $1 \mathrm{~m}$ spacing). Nearshore soundings were collected during extreme high tides and captured elevations of $+0.3 \mathrm{~m}$ Mean Lower Low Water (MLLW) or higher in order to overlap topographic lidar data collected in May of 2004 (Foxgrover and Jaffe, 2005). Tracklines are generally oriented in a southwest-northeast direction (perpendicular to the morphology of the bay floor). A few crossing lines were run in a northwest-southeast direction for assessing the quality of the survey through differences in sounding values at the intersections of tracklines (Fig. 2). 


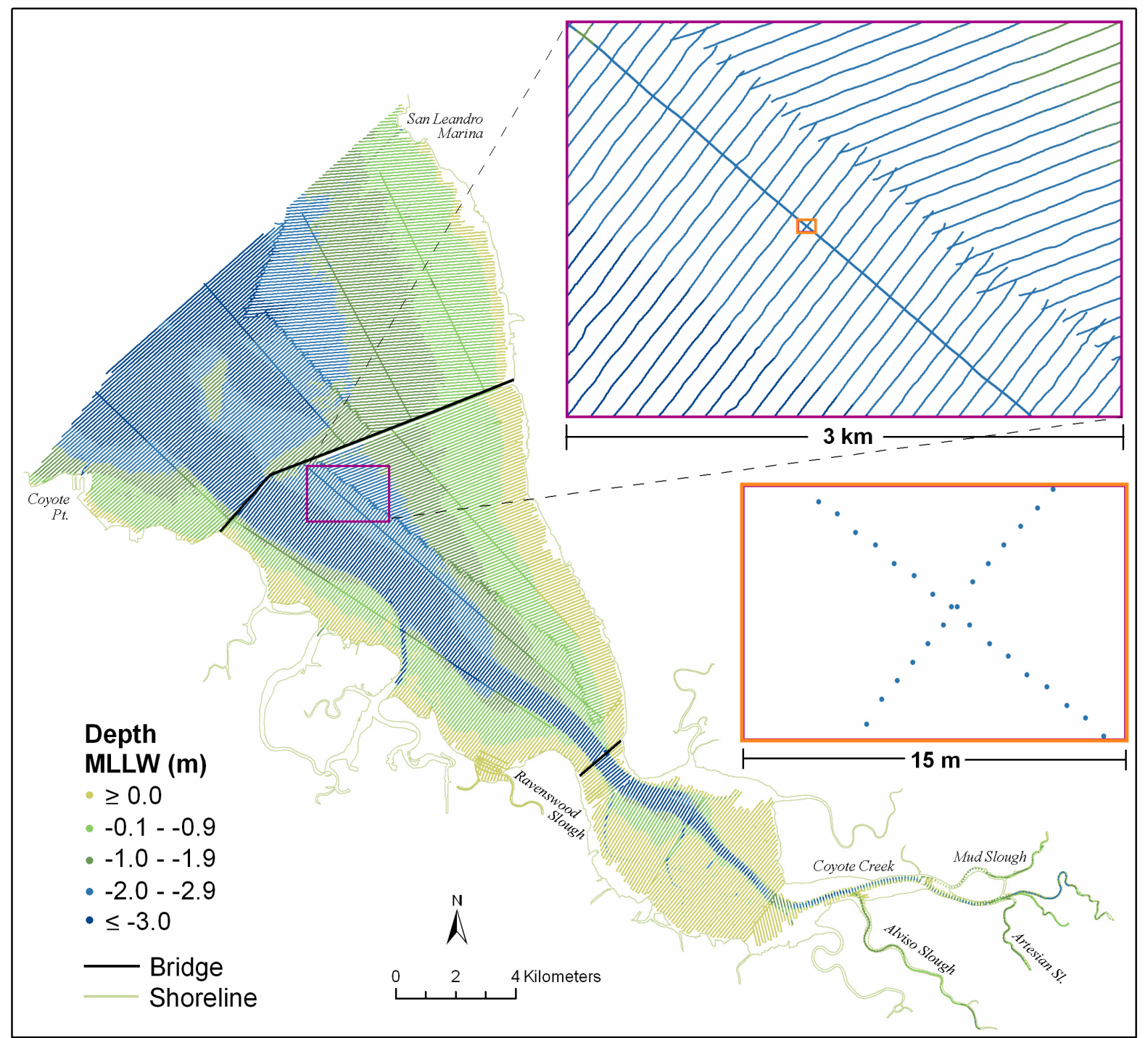

Figure 2. Extent and orientation of soundings collected for 2005 hydrographic survey. Note that the primary trackline orientation is perpendicular to the morphology of the bay floor. A few survey tracklines run parallel to the morphology of the bay floor (and perpendicular to the primary tracklines) for error analyses. (MLLW values approximated for upper sloughs.)

Three different vessels were used for surveying the bay: (1) a 29-ft aluminum vessel for north of the Dumbarton Bridge; (2) a 25-ft vessel with a fiberglass hull for the shallow-water area between the Dumbarton Bridge and Coyote Creek and; (3) a 14-ft aluminum skiff for the shallow creeks and sloughs (Fig. 3). Each vessel was equipped with an INNERSPACE Model 455 surveygrade depthfinder with 3-degree $(200 \mathrm{kHz})$ transducer, a TSS DMS-05 motion sensor, and an OMNISTAR GPS receiver with differential subscription service. Data were collected from a second, low-frequency, $(50 \mathrm{kHz})$ transducer and processed by Questor Tangent to determine the acoustic character of the bay floor (Appendix 1). This information was used in combination with over 150 surface sediment samples to produce a map of seabed classification (Fregoso, et al., 2005). 

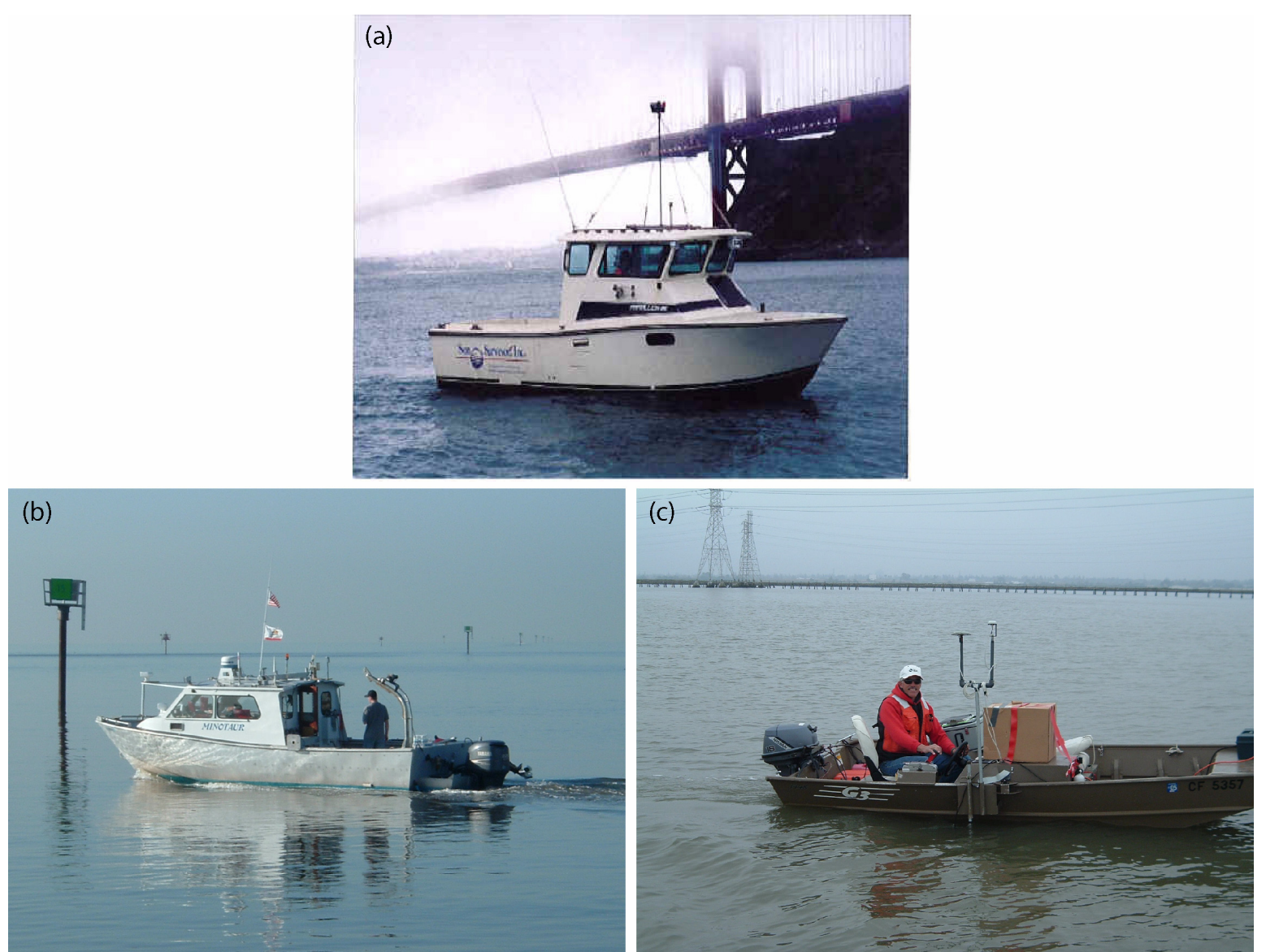

Figure 3. Vessels used in collecting bathymetry for the various regions of South Bay. (a) 25-ft Betty Jo used between the Dumbarton Bridge and Coyote Creek. (b) 29-ft Minotaur used in all areas north of the Dumbarton Bridge. (c) 14-ft aluminum skiff used in shallow creeks and sloughs.

Tides were measured at several locations in South Bay throughout the duration of the survey. In addition to the continuously operating NOS primary tide primary tide station at Alameda (9414750), temporary subordinate tide stations consisting of Model 9210 Aquatrak acoustic water level sensors with Sutron 8210 data loggers that transmitted to a GOES satellite were installed at the San Leandro Marina (9414688), the west side of the San Mateo Bridge (9414458), and the east side of the Dumbarton Bridge (9414509) (Figs. 4, 5). A fourth acoustic tide gauge was installed in Coyote Creek (9414575), but produced no data due to mechanical failure.

The three operational acoustic tide gauges began data collection in early January 2005 , recording water level data processed to six-minute intervals. The tide data were transmitted via GOES satellite to the NOS Center for Operational Oceanographic Products and Services (CO-OPS) Silver Spring, Maryland headquarters for real-time monitoring, quality assurance, and processing to MLLW of the 1983-2001 National Tidal Datum Epoch (NTDE) (Appendix II). CO-OPS provided the MLLW offsets at each gauge site for determining the original staff zero or datum of tabulation, allowing the new tide data to be compared directly with the historic data series. Differential leveling surveys with official published tidal bench mark elevations were run to each tide gauge upon installation and removal to assure stability during operation. The quality of the tide data 
obtained from these three acoustic gauges was assured through a datum recovery procedure that compared the computed datums from the one-month long data set in January, 2005 to the long-term accepted datums used in the reduction of soundings. The datum recovery was $0.1 \mathrm{ft}(3 \mathrm{~cm})$ or less at all three stations, which is within the expected generalized accuracy limits of $+/-0.13 \mathrm{ft}(4 \mathrm{~cm})$ for a one-month long data series on the West Coast (Swanson, 1974).

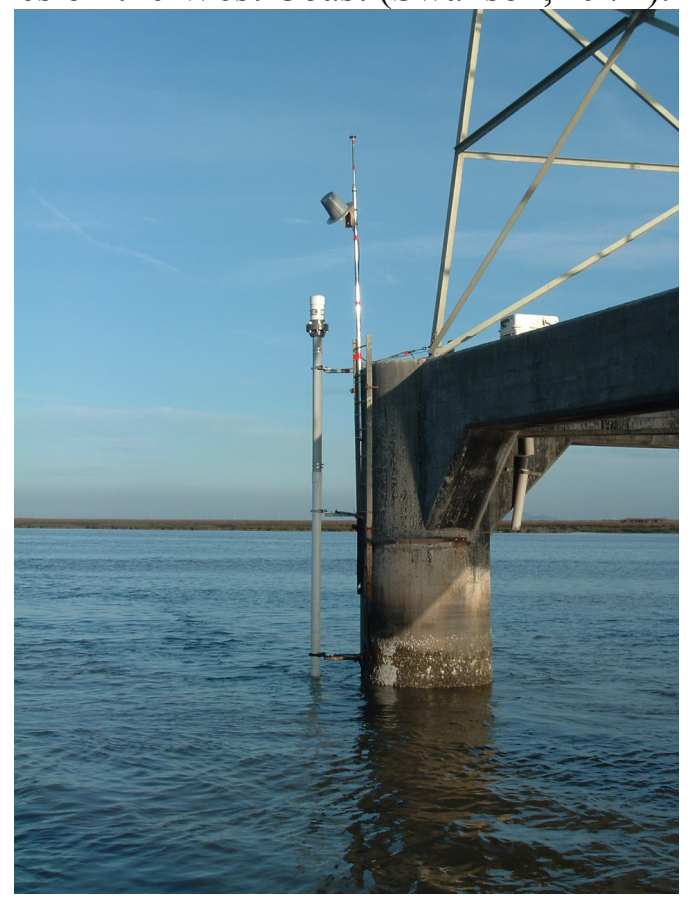

Figure 4. Air-acoustic tide gauge, stilling well, data logger and antenna used to record and transmit tide data to a GOES satellite.

Four pressure-sensing tide gauges referenced to the North American Vertical Datum, 1988 (NAVD88) by precision surveying served as short-term tide stations south of the Dumbarton Bridge in Coyote Creek and the adjacent sloughs. One tide gauge was placed in Artesian Slough, one in Alviso, and two in Coyote Creek. This tide gauge data was calibrated primarily during high tides and only on days during when surveying in the sloughs took place (Appendix I).

\section{Tidal Reduction}

To account for spatial and temporal changes in the tides throughout the survey area, a tidal zoning scheme was developed by CO-OPS prior to the survey for reducing bathymetric soundings to MLLW. MLLW is a tidal datum derived from the arithmetic mean of all lower low water values observed over a 19-year NTDE. MLLW pertains to local water levels and should not be confused with fixed geodetic datums such as NAVD88. The bay was divided into 59 discrete tidal zones bounding areas of common tidal characteristics. Each zone has a designated tide control reference station and specific time and range corrections to reduce the soundings to MLLW for the 1983-2001 NTDE (Table 1, Fig. 5). The height of tide in each zone is calculated by applying the time corrector and range multiplier for that zone to the actual tides measured at the controlling gauge. The NOAA primary control station at Alameda (9414750) was used as the reference station for adjusting tidal datums at subordinate or short term stations to the NTDE through standard mathematical comparison procedures (NOAA, 2003). 


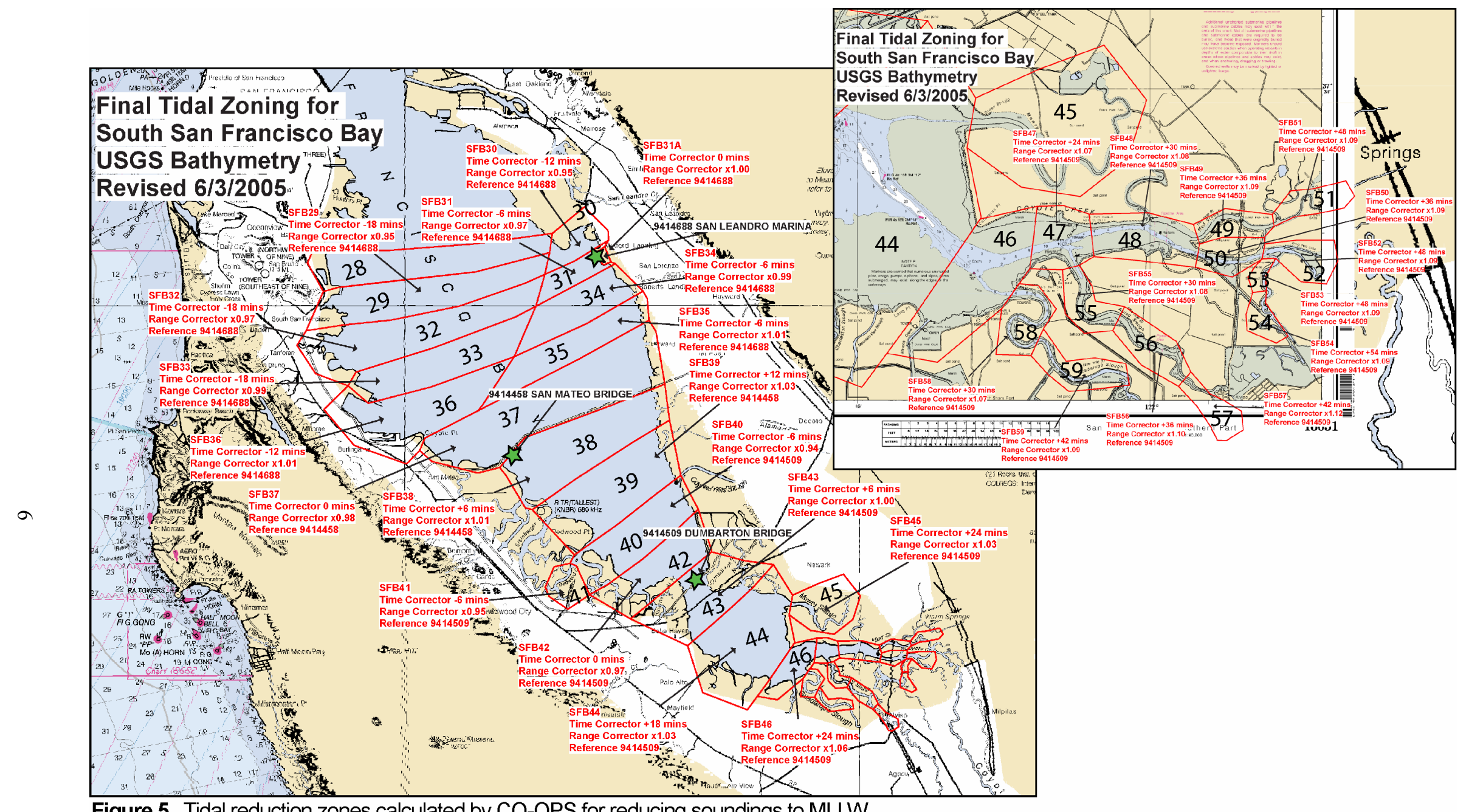

Figure 5. Tidal reduction zones calculated by CO-OPS for reducing soundings to MLLW. 
Table 1. Tidal reduction zone values calculated by CO-OPS for reducing soundings in South San Francisco Bay to MLLW.

\begin{tabular}{|c|c|c|c|c|c|c|c|}
\hline Zone & $\begin{array}{c}\text { Time } \\
\text { Corrector } \\
\text { (min) }\end{array}$ & $\begin{array}{c}\text { Range } \\
\text { Corrector }\end{array}$ & $\begin{array}{c}\text { Tide } \\
\text { Station }\end{array}$ & Zone & $\begin{array}{c}\text { Time } \\
\text { Corrector } \\
\text { (min) }\end{array}$ & $\begin{array}{c}\text { Range } \\
\text { Corrector }\end{array}$ & $\begin{array}{c}\text { Tide } \\
\text { Station }\end{array}$ \\
\hline SFB28 & -24 & $\times 0.93$ & 9414688 & SFB44* & +18 & $\times 1.03$ & 9414509 \\
\hline SFB29 & -18 & $\times 0.95$ & 9414688 & SFB45* & +24 & $\times 1.03$ & 9414509 \\
\hline SFB30 & -12 & $\times 0.95$ & 9414688 & SFB46* & +24 & $\times 1.06$ & 9414509 \\
\hline SFB31 & -6 & $\times 0.97$ & 9414688 & SFB47* & +24 & $\times 1.07$ & 9414509 \\
\hline SFB31A & 0 & $\times 1.00$ & 9414688 & SFB48* & +30 & $\times 1.08$ & 9414509 \\
\hline SFB32 & -18 & $\times 0.97$ & 9414688 & SFB49* & +36 & $\times 1.09$ & 9414509 \\
\hline SFB33 & -18 & $\times 0.99$ & 9414688 & SFB50* & +36 & $\times 1.09$ & 9414509 \\
\hline SFB34 & -6 & $\times 0.99$ & 9414688 & SFB51* & +48 & $\times 1.09$ & 9414509 \\
\hline SFB35 & -6 & $\times 1.01$ & 9414688 & SFB52* & +48 & $\times 1.09$ & 9414509 \\
\hline SFB36 & -12 & $\times 1.01$ & 9414688 & SFB53* & +48 & $\times 1.09$ & 9414509 \\
\hline SFB37 & 0 & $\times 0.98$ & 9414458 & SFB54* & +54 & $\times 1.09$ & 9414509 \\
\hline SFB38 & +6 & $\times 1.01$ & 9414458 & SFB55* & +30 & $\times 1.08$ & 9414509 \\
\hline SFB39 & +12 & $\times 1.03$ & 9414458 & SFB56* & +36 & $\times 1.10$ & 9414509 \\
\hline SFB40 & -6 & $\times 0.94$ & 9414509 & SFB57* & +42 & $\times 1.12$ & 9414509 \\
\hline SFB41 & -6 & $\times 0.95$ & 9414509 & SFB58* & +30 & $\times 1.07$ & 9414509 \\
\hline SFB42 & 0 & $\times 0.97$ & 9414509 & SFB59* & +42 & $\times 1.09$ & 9414509 \\
\hline SFB43 & +6 & $\times 1.00$ & 9414509 & & & & \\
\hline
\end{tabular}

*Zones 44 through 59 are preliminary time and range correctors based upon historic tide data. Failure of the acoustic tide gauge in Coyote Creek prevented CO-OPS from being able to finalize values for these zones based upon tide data collected at the time of the survey. Information from the pressure-sensing tide gauge in Coyote Creek suggests that the time correctors provided for zones 44 through 47 may be too long. For zones 44 and higher we have used an alternate approach for reducing soundings (detailed in the "Reduction South of Dumbarton Bridge" section, and in Table 2 and Figure 6).

\section{Reduction South of Dumbarton Bridge}

The standard procedure CO-OPS uses in developing a tidal reduction scheme to accompany a hydrographic survey is to first develop preliminary tidal zones with time and range corrections based upon available historic tide data (Appendix II). After the completion of the survey, a final zoning scheme is created using correctors derived from subordinate tide stations installed during the survey. This procedure was followed for the 2005 South Bay survey; however, with the failure of the Coyote Creek gauge (9414575), the reduction scheme could not be finalized for data south of the Dumbarton Bridge. Instead, correctors were derived from tide data from the more distant Dumbarton Bridge gauge (9414509) and from the four short-term pressure-sensing tide gauges that were located in Coyote Creek and the adjacent sloughs (Table 2, Fig. 6).

Data from the pressure-sensing gauge that was installed at the same location as the NOS Coyote Creek gauge (9414575) confirmed that the range correction provided in the preliminary reduction scheme was correct, but that the time corrector was larger than needed. For zone 47, COOPS provided a preliminary time corrector of +24 minutes from the Dumbarton Bridge gauge (9414509). The pressure-sensing gauge revealed that the time lag between these two stations is actually +9 minutes. Therefore, for zones 44 and 46 we used the range correctors provided by COOPS in Table 1, but used time correctors of +7 and +8 minutes, respectively.

For zones 47 and higher, the pressure-sensing gauges located in Coyote Creek near the entrance of Alviso Slough, the Railroad Bridge over Coyote Creek, and in Alviso and Artesian 
Sloughs were used to reduce the soundings to NAVD88 (Fig. 6). Soundings collected along Alviso Slough were reduced using a linear interpolation between tide elevation at the Coyote Creek gauge and the gauge at the end of Alviso Slough. Similarly, soundings in Artesian Slough were reduced using tide elevations interpolated linearly between the Railroad Bridge gauge and the gauge at the end of Artesian Slough. The Coyote Creek gauge was used directly for reducing soundings in zone 47.

As a check of how the two reduction methods compared, for zone 47, tidal elevations from the pressure gauge were converted to MLLW and compared to results using the CO-OPS reduction values based upon the Dumbarton Bridge gauge (9414509) with a time correction of +9 minutes. During flooding high tides, the heights from the two methods agreed within $0.1 \mathrm{ft}(3 \mathrm{~cm})$; however, for the few sounding lines collected as the tide began to ebb, the values using the Dumbarton Bridge gauge were as much as $0.5 \mathrm{ft}(15 \mathrm{~cm})$ lower than readings at the Coyote Creek gauge.

Except for the small portion within Mud Slough, all of the soundings in zone 48, and soundings in zone 50 west of the Railroad Bridge, were collected on March 11, 2005 prior to the installation of the pressure gauge at the Railroad Bridge (Fig. 6). For these two areas, linear interpolation of tide data between two gauges was not possible. An evaluation of tide data from March 25, 2005, for both Coyote Creek and the Railroad Bridge reveals a six-minute time lag and a range correction of $\times 1.02$ between the two gauges. For soundings in zone 50 collected on March 11, 2005 (east of the Railroad Bridge), Coyote Creek gauge data were used with a range correction of $\times 1.02$ and a time corrector of +6 minutes. For soundings in zone 48 collected on March 11, 2005 , a range correction of $\times 1.01$ and a time corrector of +3 minutes was used.

For Mud Slough, soundings west of the Railroad Bridge (in zones 48 and 49), linear interpolations between Coyote Creek and the Railroad Bridge were used. All soundings east of the Railroad Bridge (in zones 49-52) were directly referenced using measurements from the Railroad Bridge gauge. Every effort was made to collect these soundings at high tide, when the difference in tidal height between the Coyote Creek gauge and Railroad Bridge was minimal. However, this still entails some assumptions regarding how the tides travel up slough, and as a result may contain slightly larger errors. Soundings in the southern tributary of Coyote Creek (zone 52) and soundings in zones 49 and 50, were collected as the tides began to ebb and measurements at the Railroad gauge were 0.2-0.3 $\mathrm{ft}(6-9 \mathrm{~cm})$ higher than at the Coyote Creek gauge. Soundings in these reaches may slightly underestimate depths. 


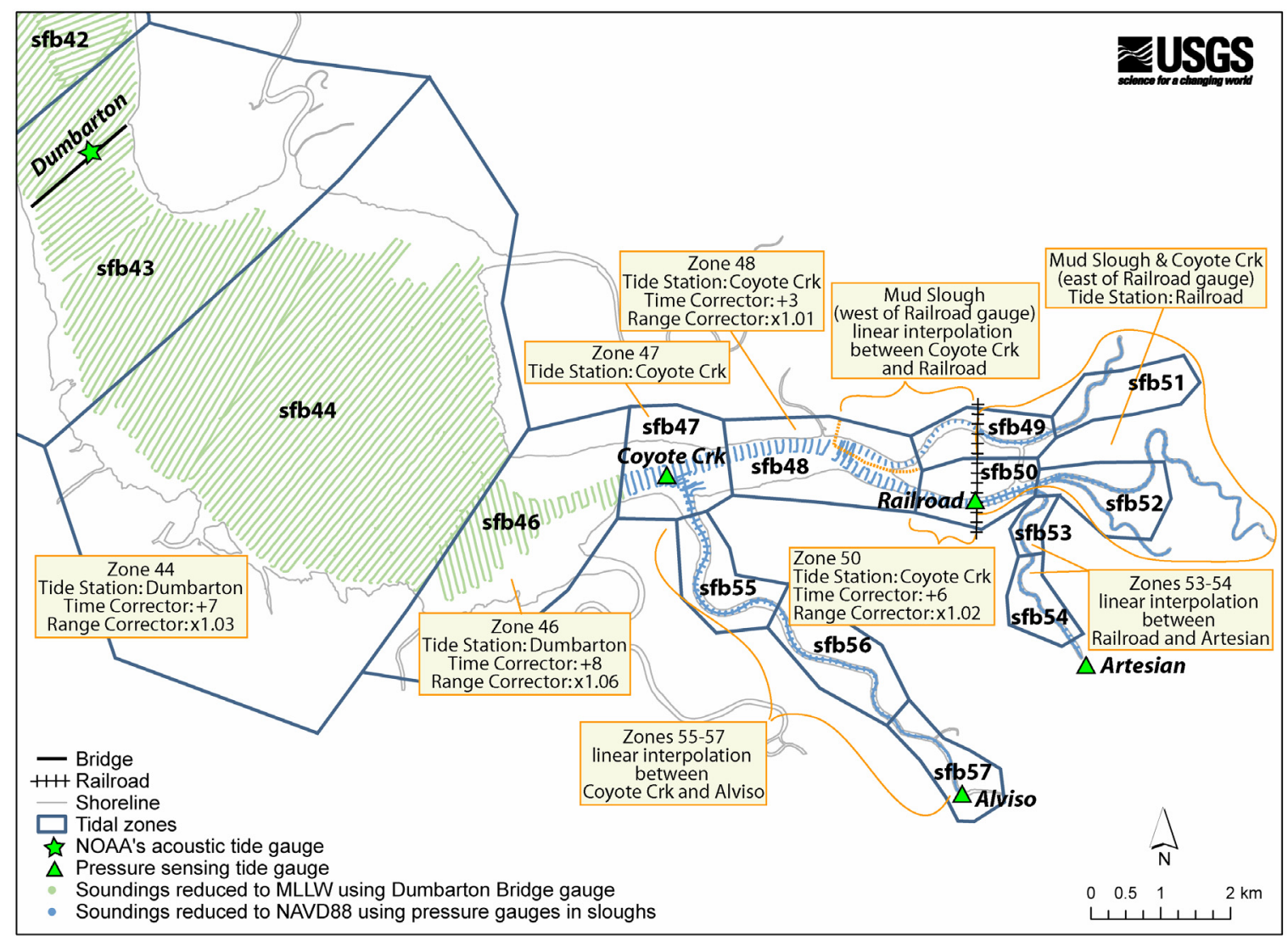

Figure 6. Tidal reduction methods and parameters used for zones south of the Dumbarton Bridge.

Table 2. Values used to reduce soundings in zones south of the Dumbarton Bridge. Gauges: $\mathrm{DB}=$ Dumbarton, $\mathrm{CC}=$ Coyote Creek, $\mathrm{RR}=$ Railroad, -- indicates that time and range correctors were not applied directly as with the CO-OPS tidal reduction scheme rather, values were interpolated from nearby pressure-sensing gauges.

\begin{tabular}{|c|c|c|c|c|c|}
\hline ZONES & $\begin{array}{c}\text { TIDE } \\
\text { STATION }\end{array}$ & $\begin{array}{l}\text { STATION } \\
\text { DATUM }\end{array}$ & $\begin{array}{c}\text { TIME } \\
\text { CORRECTOR }\end{array}$ & $\begin{array}{c}\text { RANGE } \\
\text { CORRECTOR }\end{array}$ & NOTES \\
\hline 44 & $\mathrm{DB}$ & MLLW & +7 & $\times 1.03$ & $\begin{array}{l}\text { time corrector shortened } \\
\text { from value in Table } 1\end{array}$ \\
\hline 46 & DB & MLLW & +8 & $\times 1.06$ & $\begin{array}{l}\text { time corrector shortened } \\
\text { from value in Table } 1\end{array}$ \\
\hline 47 & $\mathrm{CC}$ & NAVD88 & -- & -- & used CC gauge directly \\
\hline 48 (CC portion) & $\mathrm{CC}$ & NAVD88 & +3 & $\times 1.01$ & $\begin{array}{l}\text { time corrector derived from } \\
\text { March } 25^{\text {th }} \text { tide data } \\
\end{array}$ \\
\hline $\begin{array}{c}48 \text { (Mud portion) \& } \\
49 \text { (west of RR) }\end{array}$ & $C C \& R R$ & NAVD88 & -- & -- & $\begin{array}{c}\text { linear interpolation } \\
\text { between CC \& RR gauges }\end{array}$ \\
\hline $\begin{array}{c}50 \text { (portion west of } \\
\text { RR) }\end{array}$ & $\mathrm{CC}$ & NAVD88 & +6 & $\times 1.02$ & $\begin{array}{l}\text { time corrector derived from } \\
\text { March } 25^{\text {th }} \text { tide data }\end{array}$ \\
\hline $\begin{array}{c}49 \& 50 \text { (portion } \\
\text { east of RR), } 51 \& 52\end{array}$ & $\mathrm{RR}$ & NAVD88 & -- & -- & used RR gauge directly \\
\hline $53-54$ & $\begin{array}{c}\text { RR \& } \\
\text { Artesian }\end{array}$ & NAVD88 & -- & -- & $\begin{array}{c}\text { linear interpolation } \\
\text { between RR \& Artesian }\end{array}$ \\
\hline $55-57$ & $\begin{array}{l}\text { CC \& } \\
\text { Alviso }\end{array}$ & NAVD88 & -- & -- & $\begin{array}{l}\text { linear interpolation } \\
\text { between CC \& Alviso }\end{array}$ \\
\hline
\end{tabular}




\section{Vertical Datum Conversion}

The conversion of soundings from the tidal datum of MLLW to the geodetic datum of NAVD88 makes it possible to utilize data referenced to both tidal and geodetic datums, respectively, and will enable us to merge the bathymetry with a topographic lidar survey collected in 2004 (Foxgrover and Jaffe, 2005) to create a continuous elevation map of the bay floor and surrounding terrain. CO-OPS personnel made the vertical datum conversion by computing NAVD88-MLLW offsets for each tide zone in the hydrographic survey based on analyses of all available tide and geodetic data in the South Bay.

Using a combination of new GPS surveys (performed under contract to Sea Surveyor, Inc.; Appendix I) and National Geodetic Survey (NGS) Height Modernization bench marks at historic NOS tide stations, a linear interpolation was modeled between 11 stations around South Bay with known NAVD88-MLLW relationships and adjusted for changes in diurnal tide range. The resulting offsets are provided in Table 3 as the height that the datum of NAVD88 is above the datum of MLLW. To convert data referenced to MLLW to the geodetic datum of NAVD88, subtract the value listed in Table 3 from soundings within the zone of interest. For example, a sounding in zone 32 with a value of $-1.0 \mathrm{~m}$ relative to MLLW would have a value of $-1.15 \mathrm{~m}$ relative to NAVD88.

Conversions from MLLW to NAVD88 could not be computed for the regions of lower Coyote Creek (zones 49-54) using this method because the tide gauges were not installed low enough to capture a substantial number of lower low water observations at existing NOS stations in the area. The processing of tide data collected in February and March of 2004 by Moffatt \& Nichol Engineers enabled CO-OPS to calculate a NAVD88-MLLW offset of $1.7 \mathrm{ft}(52 \mathrm{~cm})$ for zones 49 and 50 and to estimate a range of 1.8-2 ft $(55-61 \mathrm{~cm})$ for zones 51 through 54.

Table 3. South San Francisco Bay vertical datum corrections.

\begin{tabular}{|c|c|c|c|c|c|c|c|}
\hline $\begin{array}{l}\text { TIDAL } \\
\text { ZONE }\end{array}$ & \multicolumn{2}{|c|}{$\begin{array}{c}\text { NAVD88 ABOVE } \\
\text { MLLW } \\
\text { (FT) }(\mathrm{CM}) \\
\end{array}$} & \multirow{2}{*}{$\begin{array}{c}\text { CONTROL } \\
\text { STATION } \\
9414688 \\
\end{array}$} & \multirow{2}{*}{$\begin{array}{l}\text { TIDAL } \\
\text { ZONE } \\
\text { SFB44 } \\
\end{array}$} & \multicolumn{2}{|c|}{$\begin{array}{c}\text { NAVD88 ABOVE } \\
\text { MLLW } \\
\text { (FT) } \quad(\mathrm{CM})\end{array}$} & \multirow{2}{*}{$\begin{array}{c}\text { CONTROL } \\
\text { STATION } \\
9414509 \\
\end{array}$} \\
\hline SFB28 & 0.4 & 12 & & & 1.3 & 40 & \\
\hline SFB29 & 0.5 & 15 & 9414688 & SFB45 & 1.4 & 43 & 9414509 \\
\hline SFB30 & 0.5 & 15 & 9414688 & SFB46 & 1.4 & 43 & 9414509 \\
\hline SFB31 & 0.5 & 15 & 9414688 & SFB47 & 1.5 & 46 & 9414509 \\
\hline SFB31A & 0.5 & 15 & 9414688 & SFB48 & 1.6 & 49 & 9414509 \\
\hline SFB32 & 0.5 & 15 & 9414688 & SFB49 & 1.7 & 52 & 9414509 \\
\hline SFB33 & 0.6 & 18 & 9414688 & SFB50 & 1.7 & 52 & 9414509 \\
\hline SFB34 & 0.6 & 18 & 9414688 & SFB51 $^{1}$ & $1.8-2.0$ & $55-61$ & 9414509 \\
\hline SFB35 & 0.6 & 18 & 9414688 & SFB52 $^{1}$ & $1.8-2.0$ & $55-61$ & 9414509 \\
\hline SFB36 & 0.6 & 18 & 9414688 & SFB53 $^{1}$ & $1.8-2.0$ & $55-61$ & 9414509 \\
\hline SFB37 & 0.7 & 21 & 9414458 & SFB54 $^{1}$ & $1.8-2.0$ & $55-61$ & 9414509 \\
\hline SFB38 & 0.8 & 24 & 9414458 & SFB55 & 1.6 & 49 & 9414509 \\
\hline SFB39 & 0.9 & 27 & 9414458 & SFB56 & 1.8 & 55 & 9414509 \\
\hline SFB40 & 1.0 & 30 & 9414523 & SFB57 & 2.0 & 61 & 9414509 \\
\hline SFB41 & 1.1 & 34 & 9414523 & SFB58 & 1.6 & 49 & 9414509 \\
\hline SFB42 & 1.1 & 34 & 9414523 & SFB59 & 1.8 & 55 & 9414509 \\
\hline SFB43 & 1.2 & 37 & 9414509 & & & & \\
\hline
\end{tabular}

${ }^{1}$ Vertical datum corrections for zones 51-54 are approximations. As a result of the limited amount of tide data capturing the full range of the tide in this region, precise conversions could not be determined. However, it is estimated that the actual conversion would fall within the range specified here. 


\section{Converting between the MLLW and NAVD88 Datums}

The authors realize that there has been confusion regarding the difference between datums and data referenced to datums and in which direction the adjustment should be applied to convert data referenced to MLLW to NAVD88 (or vice versa). An examination of tide stations reveals that everywhere in South San Francisco Bay, the geodetic datum of NAVD88 is slightly higher than the local tidal datum of MLLW. This is a direct comparison of the two datums. However, when comparing data referenced to these datums, the opposite is true, and for the same measurement, data referenced to NAVD88 will fall below those referenced to MLLW. This is illustrated by an example using the Alameda tide station (9414750), where NAVD88 is $0.07 \mathrm{~m}$ above MLLW (Fig. 7a). Data referenced to MLLW (a smaller value) falls above data referenced to the NAVD88 datum (a larger value) (Fig. 7b). In order to convert data referenced to MLLW to the NAVD88 datum, $0.07 \mathrm{~m}$ must be subtracted from the value. To convert data referenced to NAVD88 to the MLLW datum, $0.07 \mathrm{~m}$ must be added to the value.

(a)

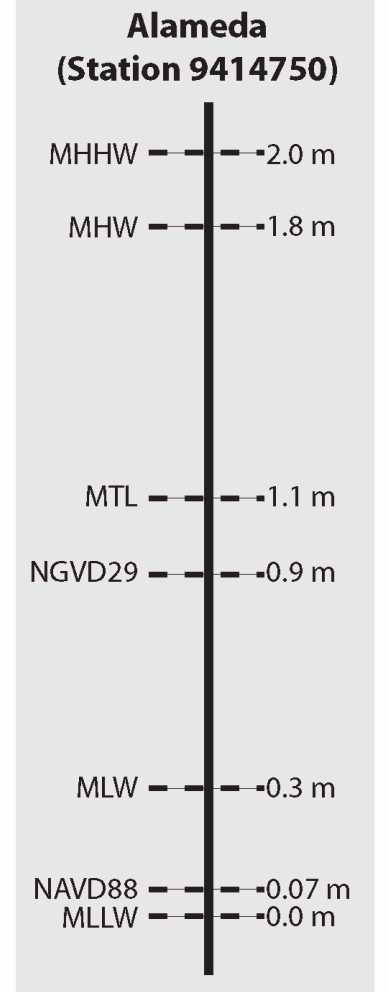

(b)

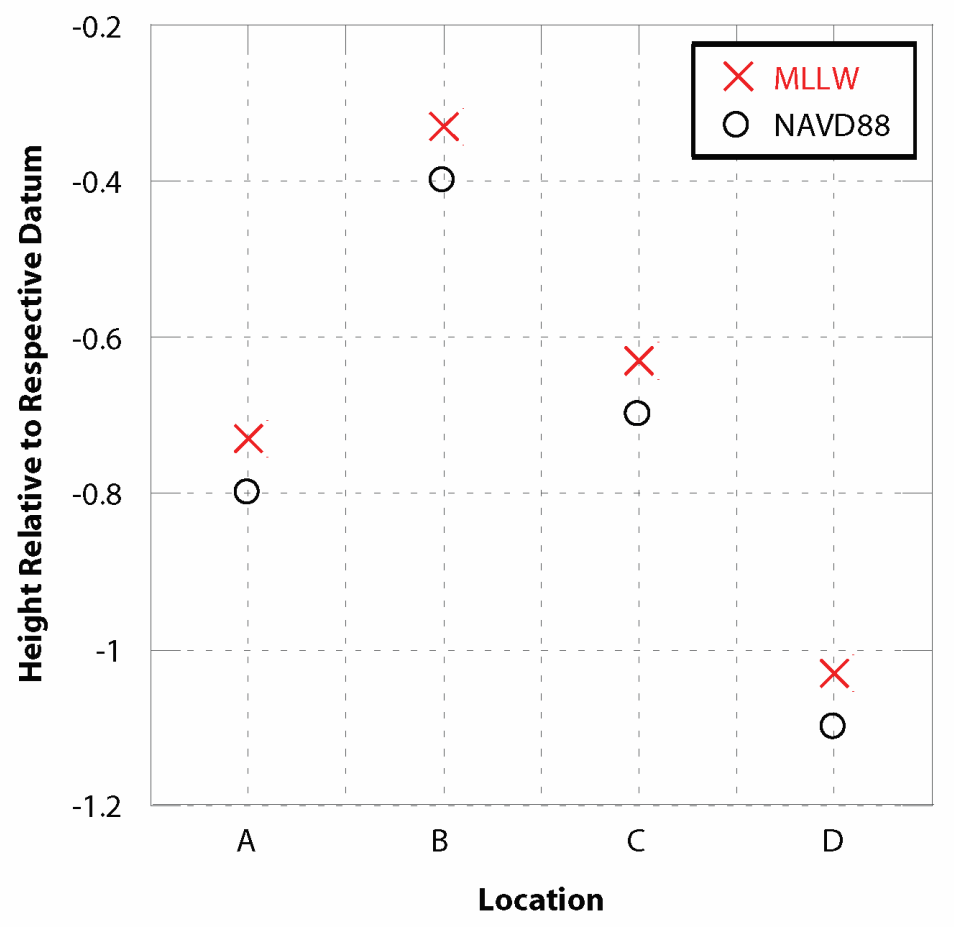

Figure 7. (a) Datum elevation information for tide station 9414750 (Alameda) obtained from the NOS tidal bench mark data sheet (http://tidesandcurrents.noaa.gov/). (b) Hypothetical sounding data near Alameda with soundings referenced to their respective datums. Note that soundings in this region referenced to MLLW are $0.07 \mathrm{~m}$ higher than soundings referenced to NAVD88, which is the inverse of the relationship of the reference datums (depicted in figure a). To convert soundings referenced to MLLW to NAVD88, subtract $0.07 \mathrm{~m}$; to convert soundings referenced to NAVD88 to MLLW, add $0.07 \mathrm{~m}$. 
The effect of referencing data to two datums is illustrated at a cross section of intertidal flats in South Bay where there is both bathymetry data collected at high tide referenced to MLLW and topographic lidar data collected at an extreme low tide referenced to NAVD88 (Fig. 8a). Before converting to a common datum, the lidar data (referenced to NAVD88) falls below the bathymetry data (referenced to MLLW) (Fig. 8b). The profile is located in tidal zone SFB44, where NAVD88 is $0.4 \mathrm{~m}$ above MLLW. After applying a correction of $0.4 \mathrm{~m}$ (subtracting $0.4 \mathrm{~m}$ from MLLW data to bring it to NAVD88), the two profiles overlap within the error of the measurements and the expected degree of geomorphic change during the eight months between the surveys (Fig. 8c).

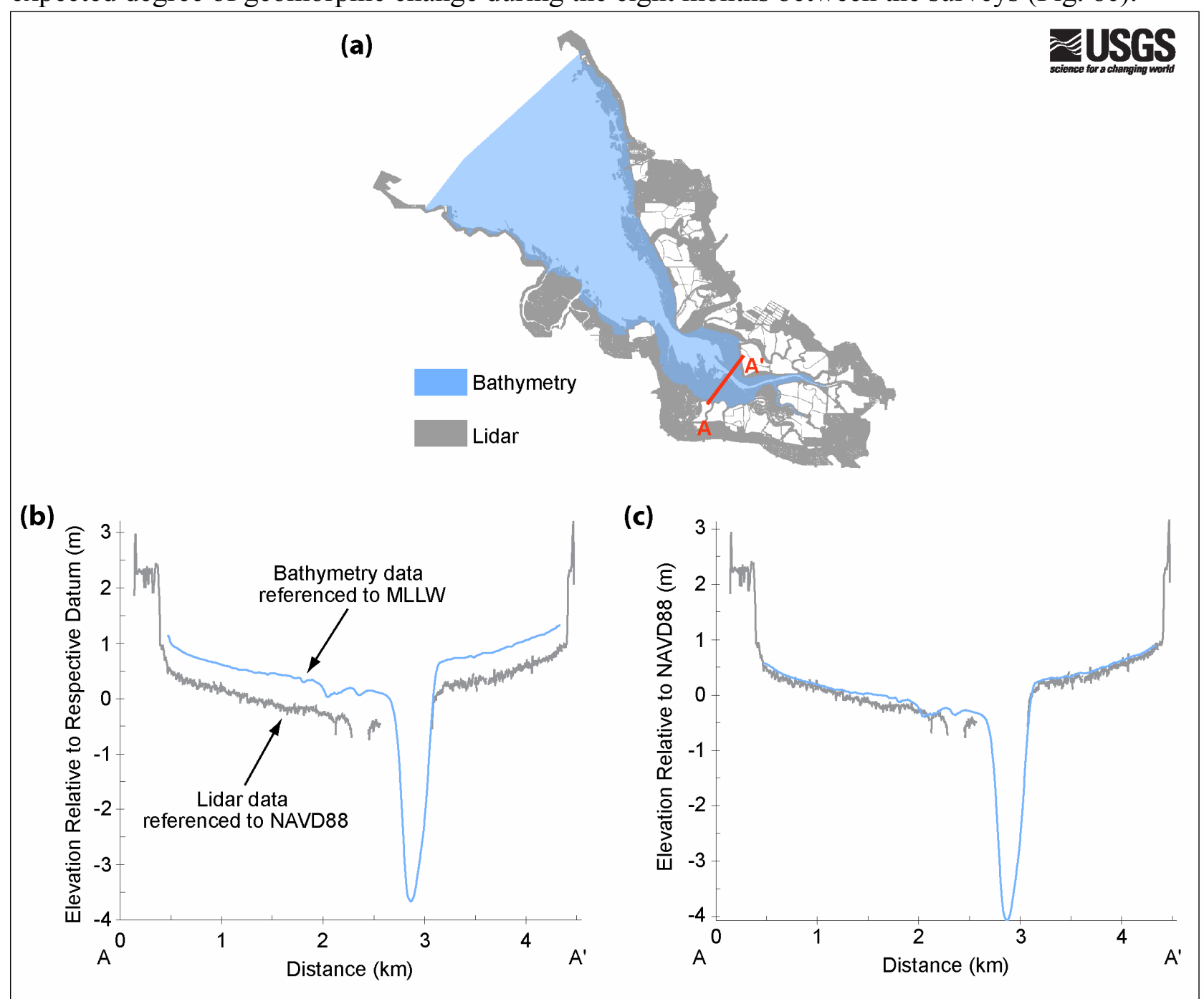

Figure 8. (a) Location of the cross section profile of a region of overlapping topographic data referenced to NAVD88 and bathymetric data referenced to MLLW. The profile is located in tidal zone SFB44, where NAVD88 is $0.4 \mathrm{~m}$ above MLLW. (b) Profile depicting the direction of the offset between data referenced to these two datums. (Note, the variability in the profile of the lidar data is due to the higher density of data points). (c) Cross section profile of bathymetry and lidar data after the bathymetry has been converted to NAVD88 by subtracting $0.4 \mathrm{~m}$. 
The overlap between the bathymetric and lidar surveys also serves as a secondary check on the accuracy of the MLLW to NAVD88 conversion. To compare the regions of overlap between the two surveys, the bathymetry was converted to NAVD 88 using the offsets provided by CO-OPS and differenced from the topographic lidar data. Figure 9 shows that the difference between the two surveys is in the range of $+/-10 \mathrm{~cm}$ for the majority of intertidal flats despite the fact that different surveying methodologies were applied and eight months passed between the two surveys.

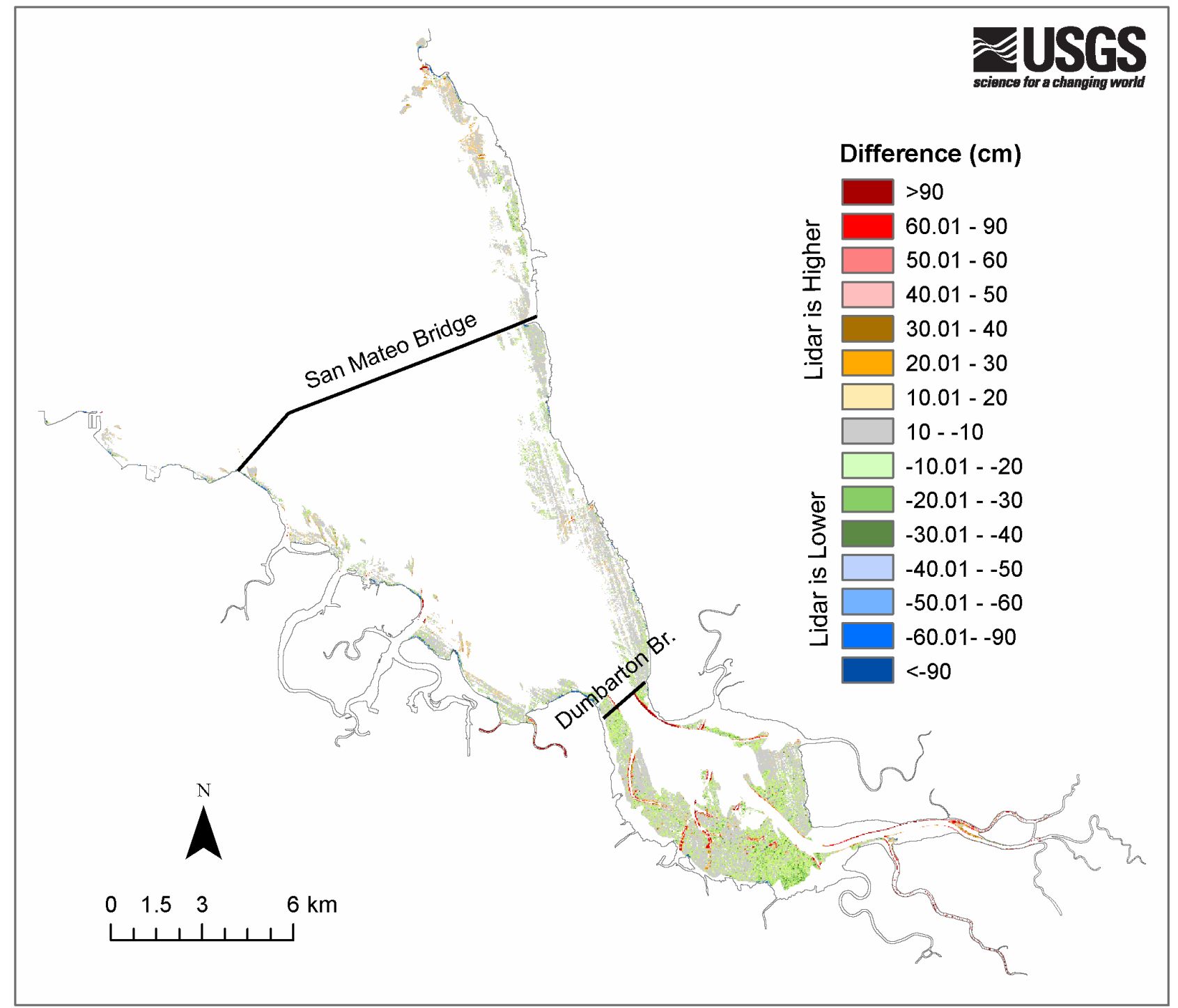

Figure 9. Difference $(\mathrm{cm})$ between bathymetric data (originally referenced to MLLW) and topographic lidar data (originally referenced to NAVD88) after the bathymetry data have been converted to NAVD88 using the offsets provided in Table 3. Positive differences indicate areas where the lidar data are higher than the bathymetry.

The difference between NAVD88 and MLLW varies spatially so it must not be assumed that the relationship between these two datums is consistent from location to location (Fig. 10). For example, at the San Francisco tide station (9414290), the MLLW datum is slightly higher than NAVD88, opposite the relation for South Bay. 


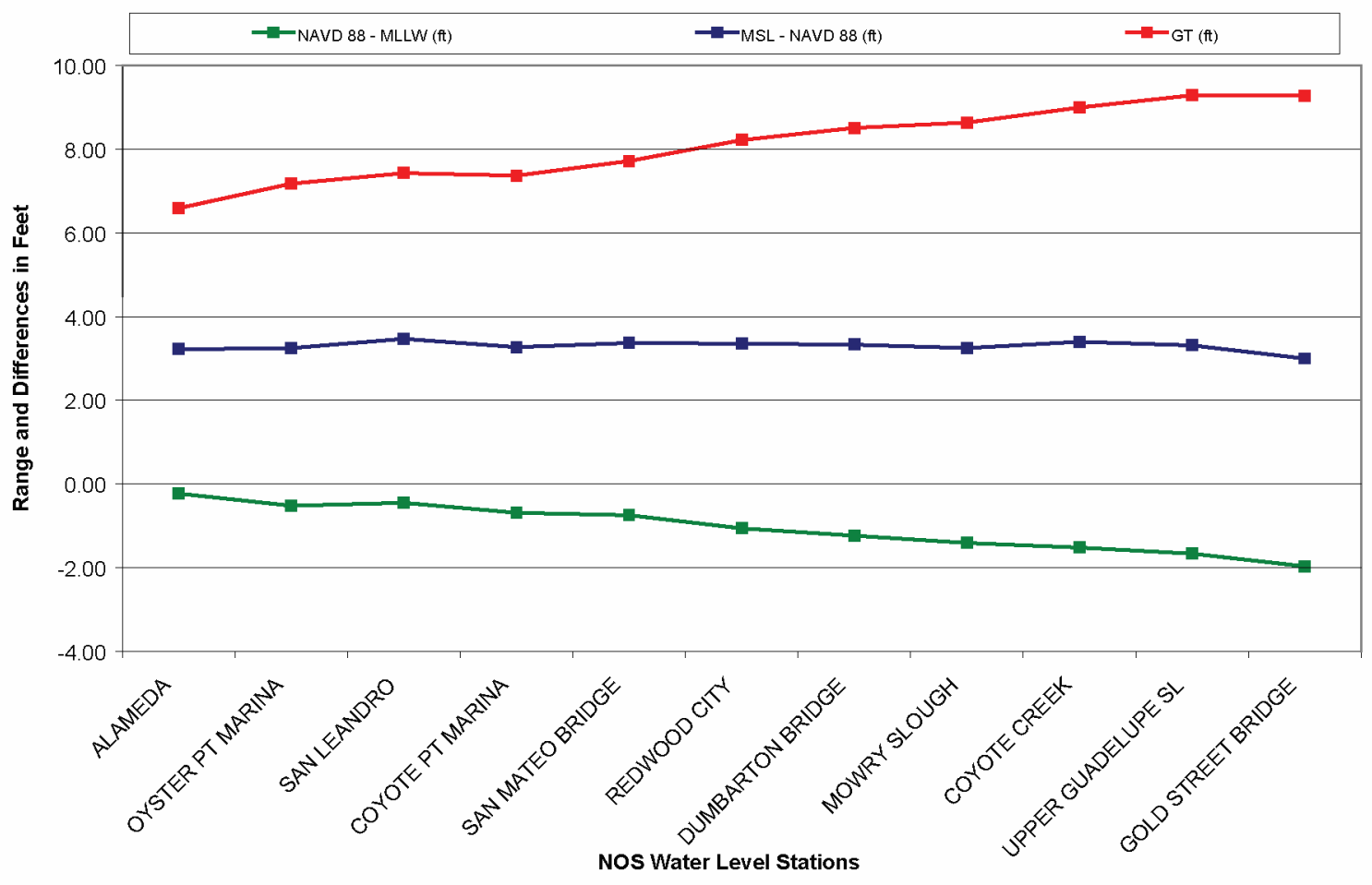

Figure 10. Comparison of tidal and geodetic datum differences in lower San Francisco Bay from Alameda (in the north) to Goldstreet Bridge (in the south). GT stands for great diurnal range (difference in height between mean higher high water and mean lower low water).

\section{Survey Quality}

Strict data collection procedures were followed to ensure that this survey met the standards of an Order 1 hydrographic survey (NOAA, 2006; USACE, 2002). The survey-grade depthfinder was calibrated using the barcheck procedures as often as four times daily (before and after each dayshift and nightshift) to adjust for varying acoustic velocities in the water column. These calibrations demonstrate that electronic depth measurements have a vertical accuracy of $+/-3 \mathrm{~cm}$ regardless of water depth. Horizontal positioning in coordinate system UTM NAD83 was obtained with an OmniSTAR GPS receiver with differential subscription service. Based upon calibrations performed at four locations around South Bay, the GPS has an absolute accuracy of $+/-2 \mathrm{~m}$. In addition to calibrating the absolute accuracy of the GPS before the beginning of the hydrographic survey, the navigation system was checked for precision (repeatability) twice daily at a single location in either San Leandro Marina or Redwood City Marina. The results from these daily inspections show less than $+/-1 \mathrm{~m}$ drift during the four months of surveying. The horizontal accuracy of soundings collected from a vessel moving at 5.5 knots is likely in the range of $+/-3 \mathrm{~m}$ (Appendix I).

Hydrographic surveys contain blatant, systematic, and random errors in both the horizontal positioning of the vessel $(\mathrm{x}, \mathrm{y})$ and the underwater bottom elevation $(\mathrm{z})$ measurements. Blatant errors (human blunders) are generally large errors attributed to inattentiveness or lack of skill on part of the observer and can usually be eliminated with adequate quality control procedures. 
Systematic errors are those that follow some physical law or rule by which they can be predicted and can generally be measured or modeled through calibration and removed from the sounding data (e.g., tide corrections or instrument calibrations) (Mills, 1998). Random errors are typically small, both above and below the true value, and result from the limitation of measuring devices and the inability to perfectly measure any quantity or to perfectly model any systematic error (Byrnes, 2002).

The accuracy of bay floor elevation measurements is affected by many random and systematic errors. Without a method for verifying each measured depth (as can be accomplished in land-based surveys) quality assessments of depth measurements must be obtained through statistical estimation. The quality of the survey can be assessed through the comparison of sounding values at the intersections of independent trackline crossings (Fig. 11). Hydrographic surveyors refer to the trackline crossing error as the precision or repeatability of the survey. This approximation encompasses various sources of potential error such as those introduced through vessel motions (heave, pitch, and roll), calibration of the depthfinder, horizontal positioning, tidal corrections, etc. If absolutely no error existed, the sounding values at the intersection of two tracklines would be identical, however due to random errors, the values typically vary slightly and provide a means of estimating the amount of error in a hydrographic survey.

Trackline crossing differences were calculated at over 900 locations throughout the survey area. As a result of the geographic layout of the tracklines, intersections occurred in three different situations. The majority of intersections (more than 600) occurred along seven survey lines collected perpendicular to primary survey lines (northwest-southeast) for the purpose of quality assessment or control $(\mathrm{QC})$. These $\mathrm{QC}$ lines extend from the northern survey boundary to approximately the Dumbarton Bridge (Fig. 11). A second type of trackline intersection occurs along the boundaries between the tidal zones developed by CO-OPS. Soundings were collected by individual tide zone with the planned survey lines overlapping $100 \mathrm{~m}$ into the adjacent tide zones. Any trackline intersections within these overlap regions were analyzed. Lastly, trackline intersections occurred where the center line and across channel lines meet in the narrow creeks and sloughs. In upper Coyote Creek and the adjacent sloughs, soundings were collected in tracklines running across the channel (bank to bank) and a second survey line was run perpendicular to these lines, down the deepest part (thalweg) of the channel. Based upon the trackline crossing analysis, survey errors do not introduce a bias - the average of all the differences in sounding values at trackline crossings in both the bay and sloughs is $1 \mathrm{~cm}$ (Table 4). The standard deviation of differences in soundings values at trackline crossings is greater for the sloughs $(8-20 \mathrm{~cm}$, average $15 \mathrm{~cm})$ than for the bay $(3-8 \mathrm{~cm}$, average $6 \mathrm{~cm})$. 


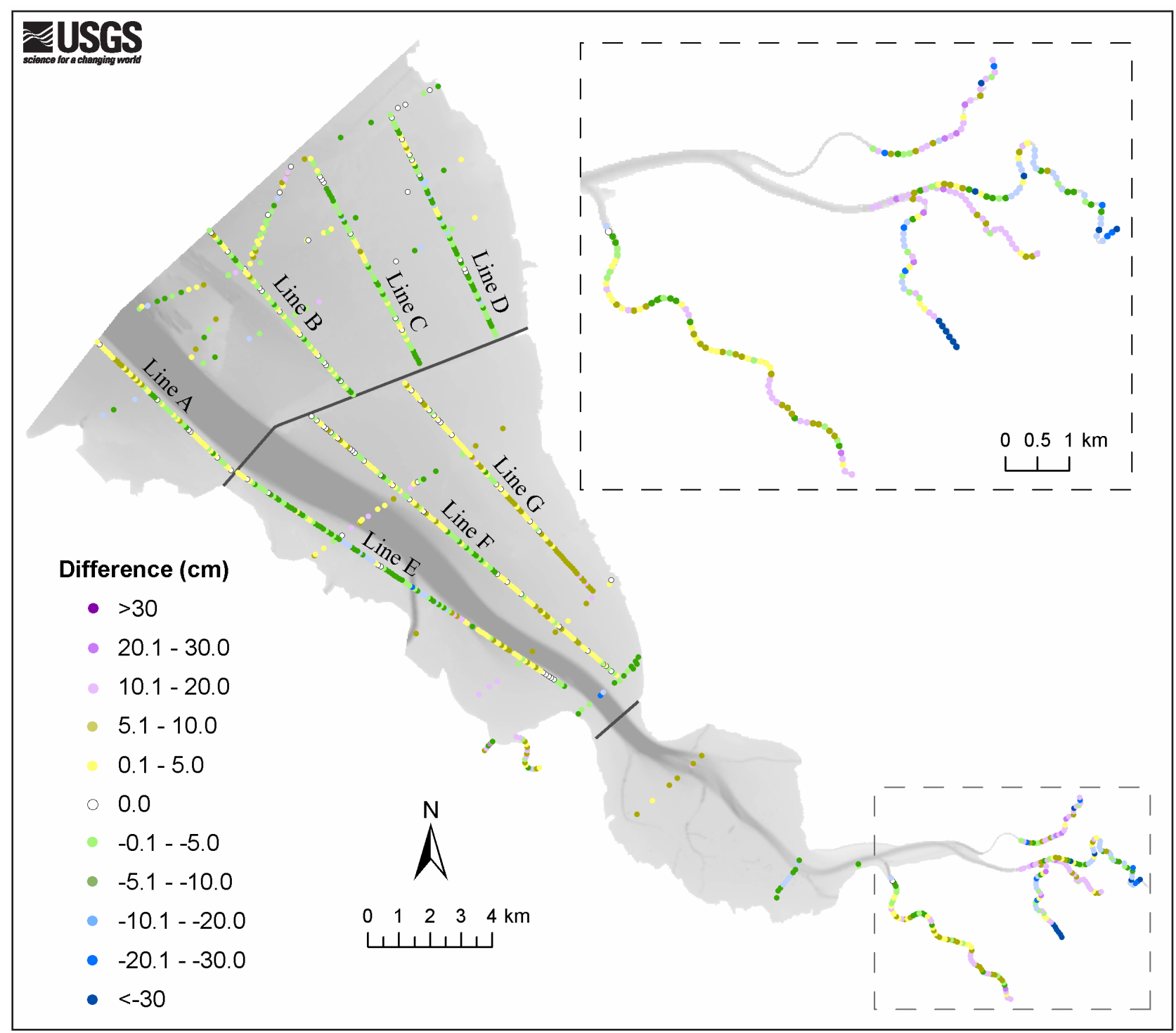

Figure 11. Differences in sounding values calculated at the intersection of independent tracklines. The differences provide an estimate of the quality of the survey. 
Table 4. Statistics of trackline crossing differences.

\section{Quality of Soundings in Bay}

\begin{tabular}{|c|c|c|c|c|c|}
\hline & Count & $\begin{array}{c}\text { Max Negative } \\
\text { Difference }(\mathrm{cm})^{1}\end{array}$ & $\begin{array}{c}\text { Max Positive } \\
\text { Difference }(\mathrm{cm})^{1}\end{array}$ & $\begin{array}{c}\text { Mean } \\
\text { Difference }(\mathrm{cm})^{1}\end{array}$ & $\begin{array}{c}\text { Standard } \\
\text { Deviation }(\mathrm{cm})\end{array}$ \\
\hline Line A & 62 & -9 & 9 & 1 & 4 \\
\hline Line B & 71 & -9 & 8 & -1 & 3 \\
\hline Line $C$ & 64 & -12 & 6 & -3 & 4 \\
\hline Line D & 74 & -15 & 7 & -4 & 4 \\
\hline Line E & 123 & -28 & 20 & -3 & 7 \\
\hline Line $\mathrm{F}$ & 127 & -9 & 9 & 1 & 4 \\
\hline Line $\mathrm{G}$ & 85 & -6 & 14 & 4 & 4 \\
\hline All QC Lines & 606 & -28 & 20 & -1 & 5 \\
\hline Zone Overlap ${ }^{2}$ & 155 & -22 & 17 & -1 & 8 \\
\hline All Bay Points & 761 & -28 & 20 & -1 & 6 \\
\hline
\end{tabular}

Quality of Soundings in Sloughs

\begin{tabular}{|c|c|c|c|c|c|}
\hline \multirow{7}{*}{$\begin{array}{c}\text { Ravenswood Sl. } \\
\text { Upper Coyote Cr. } \\
\text { Artesian Sl. } \\
\text { Mud Sl. } \\
\text { Alviso Sl. } \\
\text { All Creeks/Sloughs }\end{array}$} & Count & $\begin{array}{c}\text { Max Negative } \\
\text { Difference }(\mathrm{cm})^{3}\end{array}$ & $\begin{array}{c}\text { Max Positive } \\
\text { Difference }(\mathrm{cm})^{3}\end{array}$ & $\begin{array}{c}\text { Mean } \\
\text { Difference }(\mathrm{cm})^{3}\end{array}$ & $\begin{array}{c}\text { Standard } \\
\text { Deviation }(\mathrm{cm})\end{array}$ \\
\hline & 24 & -15 & 22 & 5 & 9 \\
\hline & 84 & -49 & 32 & -1 & 16 \\
\hline & 36 & -52 & 24 & -8 & 20 \\
\hline & 28 & -55 & 26 & 4 & 17 \\
\hline & 70 & -15 & 21 & 4 & 8 \\
\hline & 242 & -55 & 32 & 1 & 15 \\
\hline
\end{tabular}

${ }^{1}$ Differences for the QC lines were calculated by subtracting soundings from the bathymetry lines (running southwestnortheast) from those of the QC lines; therefore, a negative value means that soundings on the QC line are deeper than those on bathymetry lines.

${ }^{2}$ Differences calculated at regions of zone overlap were either subtracted from north to south or south to north, therefore, the sign (positive or negative) of the differences is not meaningful.

${ }^{3}$ Differences in sloughs were calculated by subtracting soundings from the bathymetry cross-channel lines from those of the thalweg, therefore a negative value means that the trackline running down the center of the channel is deeper than the across channel profile.

The high quality of the hydrographic survey is also supported by the observation that the differences between soundings calculated at trackline intersections do not increase with increasing depth, as would be the case if calibration of the depthfinder was inaccurate (Fig. 12). In addition, there was only a small correlation between the increase in trackline crossing difference and increases in slope. Only a limited number of trackline crossing intersections were analyzed along the steepest slope of the main channel, where horizontal positioning error results in a larger vertical difference than along the gentle slopes found in the rest of the bay. More trackline intersections along the margins of the main channel would have enabled a more robust analysis of sounding error in regions with slopes greater than 0.3 degrees. 
(a)

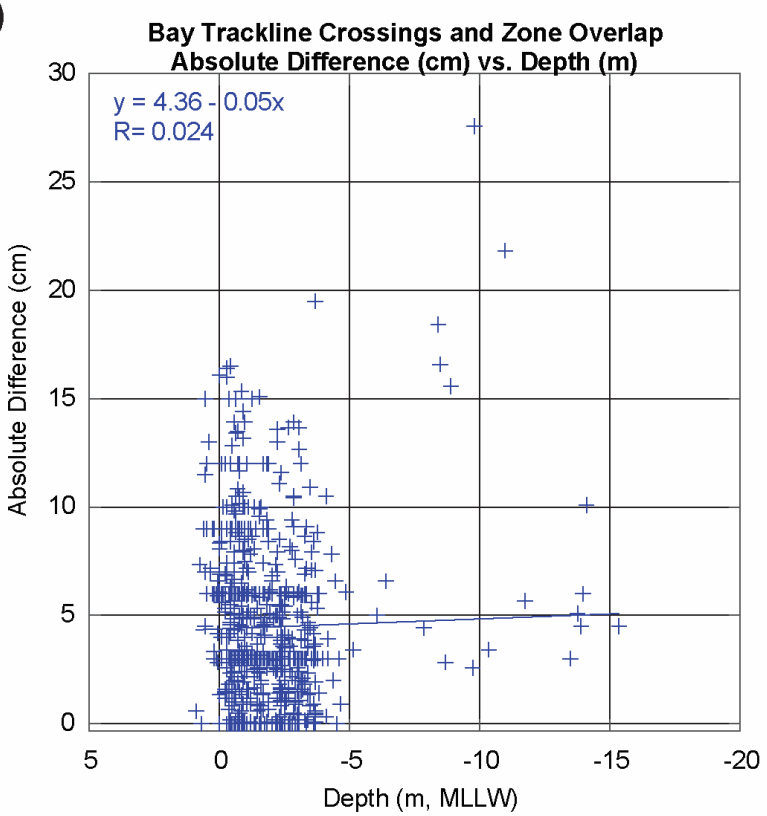

(b)

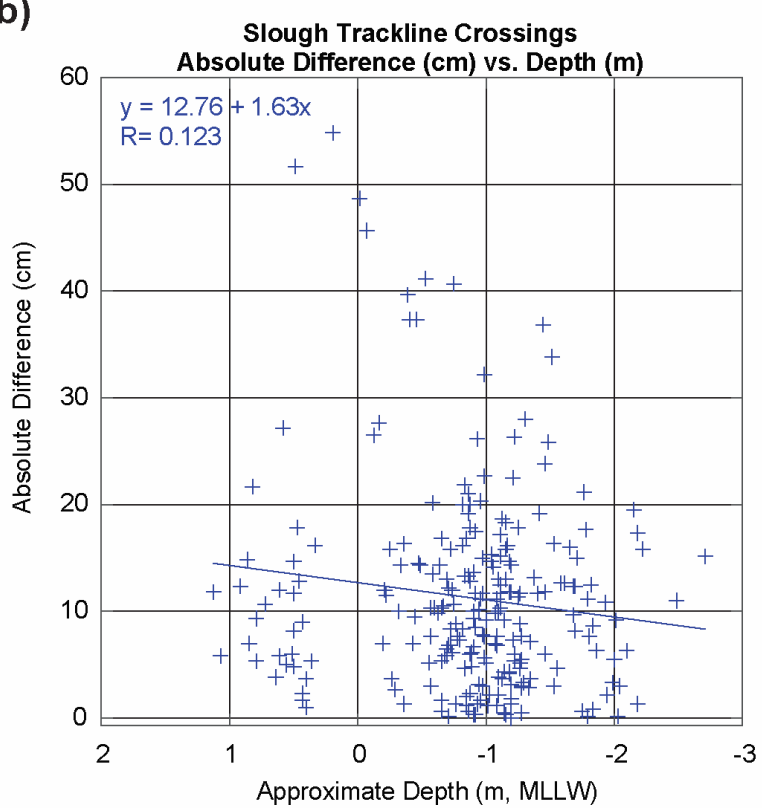

(c)

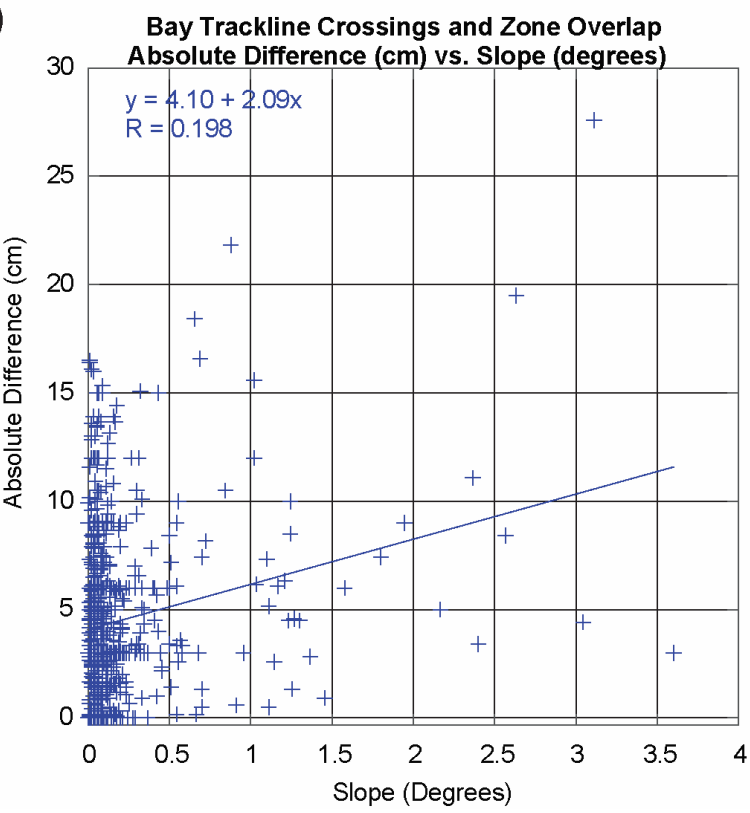

Figure 12. Relationship between the absolute value of the differences in soundings at independent trackline intersections with depth and slope. (a) Difference in soundings at trackline intersections vs. depth for soundings in the bay (b) Difference in soundings at trackline intersections vs. depth for soundings in the sloughs and creeks (c) Difference in soundings at trackline intersections vs. slope for soundings in the bay.

\section{Download Sounding Data}

The sounding data in this report have been thinned to one meter spacing along tracklines and are organized by individual tidal zones with 100-m overlap between adjacent zones (Fig. 13). With the exception of the far reaches of Coyote Creek, Mud Slough, and Alviso Slough (zones 5154 ) that are only referenced to NAVD88, all of the soundings are available relative to both MLLW 
and NAVD88. The sounding data are provided in comma delimited XYZ ( $\mathrm{x}$-coordinate, $\mathrm{y}-$ coordinate, depth) format at $h t t p: / / p u b s . u s g s . g o v / o f / 2007 / 1169$. The tidal zone boundaries are also available for download in the Environmental Sciences Research Institute's (ESRI) shapefile format. The data presented in this report were gridded using the methods of Foxgrover, et al., (2004) and rendered as color-shaded bathymetric relief (Fig. 14).

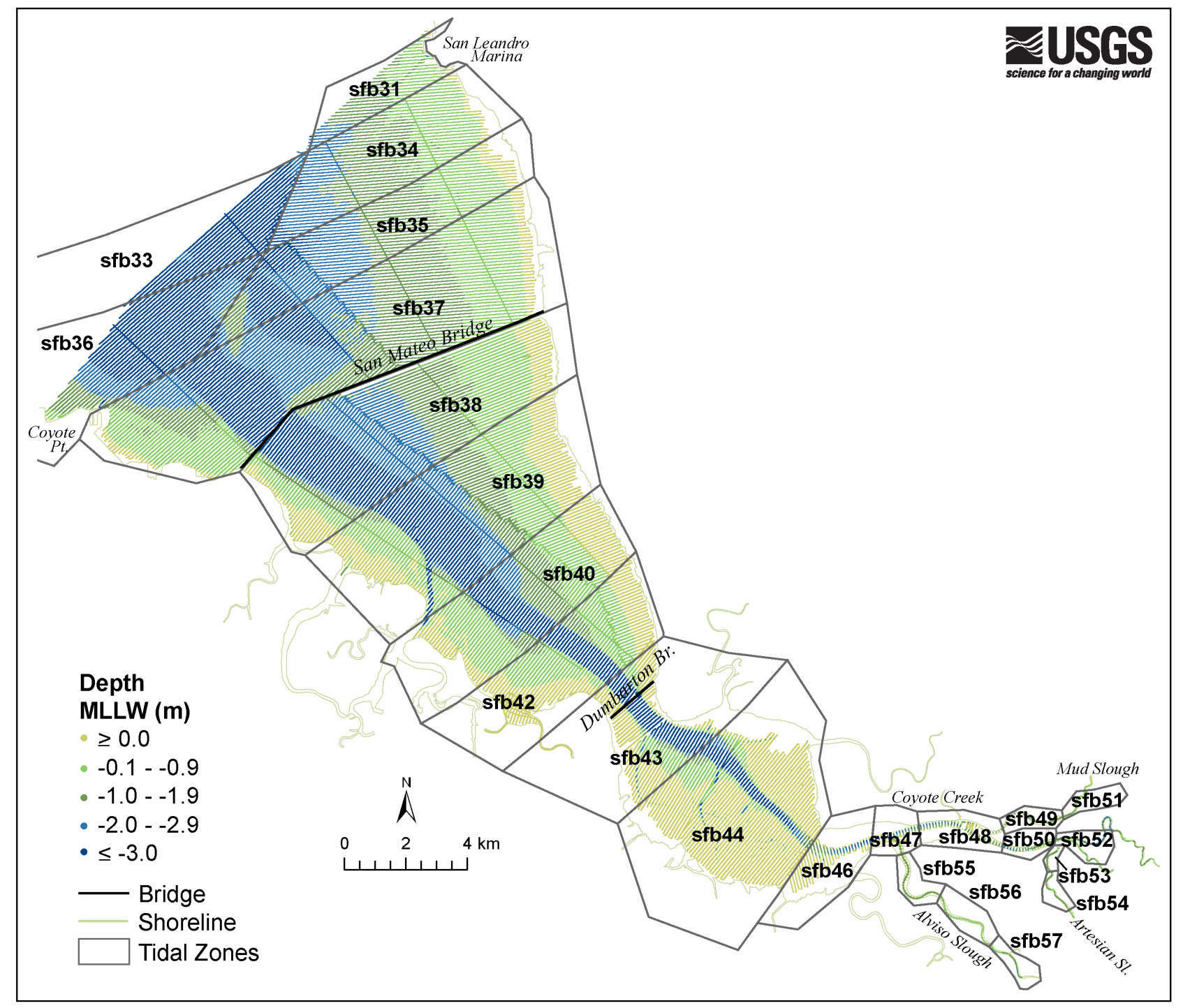

Figure 13. South Bay soundings available for download and partitioned based upon tidal zone boundaries. Zones not containing any soundings have been removed from the display. MLLW values have been approximated in far south sloughs (zones 51-54) shown above for display purposes only. 


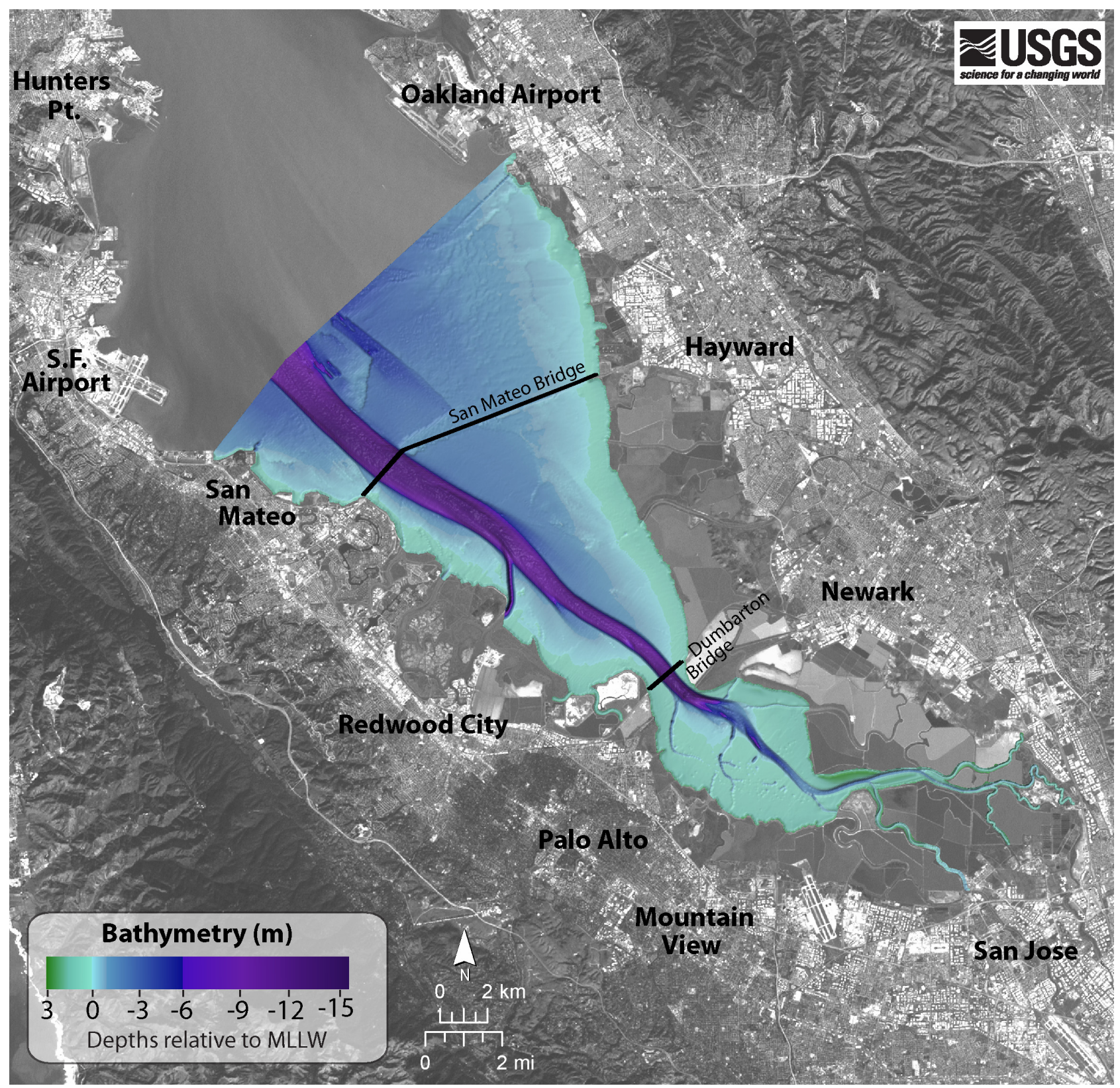

Figure 14. Shaded relief map of bathymetry gridded at $25 \mathrm{~m}$ resolution and color coded by depth (MLLW). Bathymetric grid generated using procedures similar to those described in Foxgrover, et al., (2004) where soundings as well as bathymetric contours are used to interpolate depths up to the shoreline. Black and white Landsat satellite imagery provided as backdrop. (MLLW values approximated in far south sloughs). 


\section{Acknowledgements}

The California Coastal Conservancy, U.S. Geological Survey Priority Ecosystems Science program, and the U.S. Geological Survey Coastal and Marine Geology program supported this research. The NOAA Center for Operational Oceanographic Products and Services played a key role in the hydrographic survey by assisting in the selection of tide gauge type, loaning accurate acoustic tide gauges, determining optimum locations for tide gauges, aiding in installation of tide gauges, and in developing tidal zoning to reduce soundings to the National Tidal Datum Epoch (NTDE) 1983-2001 MLLW at Alameda. Sea Surveyors, Inc. took great care to ensure that the 2005 bathymetric survey was as accurate as possible. This report was improved by reviews from Florence Wong and Patrick Barnard.

\section{References Cited}

Byrnes, M.R., Baker, J.L., and Li, Feng 2002, Quantifying potential measurement errors associated with bathymetric change analysis, ERDC/CHL CHETN-IV-50, U.S. Army Engineer Research and Development Center, Vicksburg, MS. [http://cirp.wes.army.mil/cirp/cetns/chetn-iv50.pdf].

Foxgrover, A.C., Higgins, S.A., Ingraca, M.K., Jaffe, B.E., and Smith, R.E., 2004, Deposition, erosion, and bathymetric change in South San Francisco Bay: 1858-1983: U.S. Geological Survey Open-File Report 2004-1192, 25 p. [URL: http://pubs.usgs.gov/of/2004/1192]

Foxgrover, A.C. and Jaffe, B.E., 2005, South San Francisco Bay 2004 topographic lidar survey: Data overview and preliminary quality assessment, U.S. Geological Survey Open-File Report OFR-2005-1284, 57 p. [URL: http://pubs.usgs.gov/of/2005/1284/]

Fregoso, T., Jaffe, B., Rathwell, G., Collins, W., Rhynas, K., Sullivan, S., Tomlin, V., Thompson, J., and Parchaso, P., 2005, Mapping South San Francisco Bay's Seabed Diversity for use in Restoration Planning (abs.) [URL: http://www.southbayrestoration.org/Events-symposium.html] International Hydrographic Organization, 1998, IHO Standards for Hydrographic

Surveys, International Hydrographic Organization, Special Publication No 44, 4th Edition, 23pp.

Jaffe. B.E. and Foxgrover, A.C., 2006a, A History of Intertidal Flat Area in South San Francisco Bay, California: 1858 to 2005, U.S. Geological Survey Open-File Report 2006-1262, 31 p. [URL: http://pubs.usgs.gov/of/2006/1262]

Jaffe, B.E. and Foxgrover, A.C., 2006b, Sediment Deposition and Erosion in South San Francisco Bay, California from 1956 to 2005; U.S. Geological Survey Open-File Report 2006-1287, 24.p. [URL: http://pubs.usgs.gov/of/2006/1287]

Mills, G.B., 1998, International Hydrographic Survey Standards, International Hydrographic Review LXXV (2), 7 p.

Nation Oceanic and Atmospheric Administration, 2003, Computational Techniques for Tidal Datums Handbook, NOAA Special Publication NOS CO-OPS 2, 113 p.

National Oceanic and Atmospheric Administration, 2006, NOS Hydrographic Surveys Specifications and Deliverables, 123 p. [URL:

http://chartmaker.ncd.noaa.gov/hsd/specs/specs.htm]

Poland, J.F., and Ireland, R.L. 1988, Land Subsidence in the Santa Clara Valley, California, as of 1982, U.S. Geological Survey Professional Paper 497-F, 61 p.

San Francisco Bay Joint Venture, 2001, Restoring the Estuary: An Implementation Strategy for the San Francisco Bay Joint Venture. [URL: http://www.sfbayjv.org/estuarybook.html] 
Swanson, R.L., 1974, Variability of Tidal Datums and Accuracy in Determining Datums from Short Series of Observations, NOAA Technical Report NOS 64, 41p.

U.S. Army Corps of Engineers Headquarters, 2002, Hydrographic Surveying Draft Engineer Manual EM 1110-2-1003, U. S. Army Corps of Engineers, Washington, DC, 506 p. [URL: www.usace.army.mil/publications/eng-manuals/em1110-2-1003/toc.htm.htm]

\section{Contact Information}

Bruce Jaffe, Project Chief

Email: bjaffe@usgs.gov

For details on the South Bay Salt Pond Restoration Project visit:

http://www.southbayrestoration.org 
Appendices 
Appendix I 


\section{HYDROGRAPHIC SURVEY OF SOUTH SAN FRANCISCO BAY}

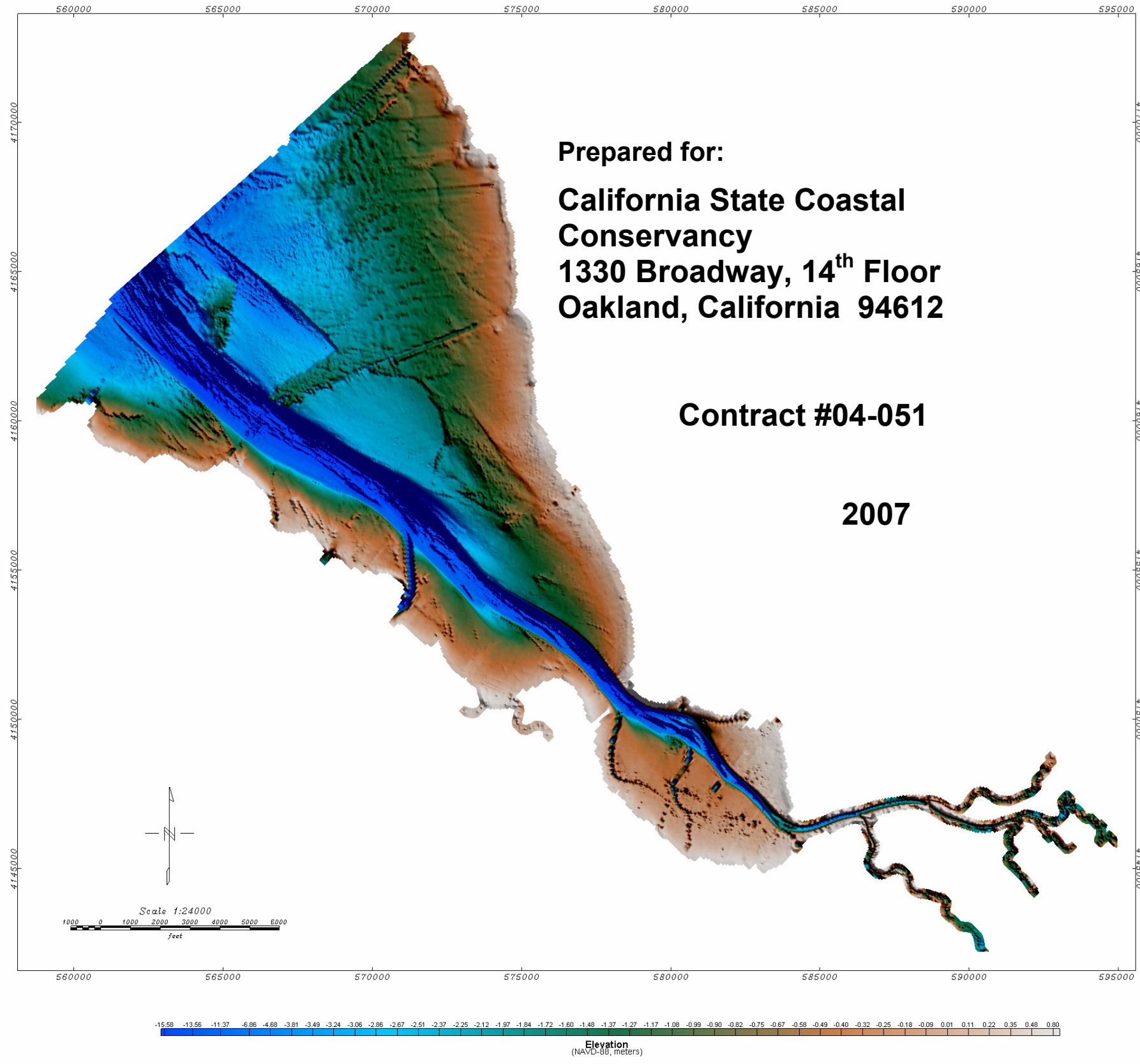

Prepared by: Sea Surveyor, Inc. 960 Grant Street, Suite C

Benicia, California 94510 


\section{TABLE OF CONTENTS}

1. INTRODUCTION 3

2. DESCRIPTION OF WORK 5

3. FIELD SURVEY METHODS 8

3.1 Field Survey Methodology 8

3.2 Survey Equipment 9

3.2.1 Survey Vessels 9

3.2.2 Survey-Grade Depthfinder 12

3.2.3 Seabed Classification System 13

3.2.4 Differential GPS Navigation 15

3.2.5 Tide Measurements 15

$\begin{array}{ll}3.3 \text { Tidal Benchmarks } & 18\end{array}$

3.4 Survey Schedule 24

3.5 Survey Personnel 26

4. ANALYTICAL METHODS 27

4.1 Vertical Datum Conversions 27

4.2 Tide Data Analyses 28

4.2.1 Tides in South San Francisco Bay 28

4.2.2 Tides in Sloughs and Creeks 28

4.3 Plotting and Checking of Tide-Corrected Soundings 32

4.4 Delivery of Final Soundings and Other Products 33

4.5 Analytical Personnel 33

5. QUALITY CONTROL RESULTS 35

5.1 QC Results for Differential GPS Navigation 35

5.2 QC Results for Depth Measurements 37

5.3 QC Results for Tide Measurements in Sloughs and Creeks 37

5.4 Final QC Results 38

6. BIBLIOGRAPHY 40

7. APPENDIX: List of Boundary Coordinates for Tide Zones (NOAA, 2006) 41

8. APPENIDX: Acoustic Seabed Classification Survey; South San Francisco Bay (Quester-Tangent Corporation, 2005) 


\section{Hydrographic Survey of South San Francisco Bay}

\section{INTRODUCTION}

The California State Coastal Conservancy funded an Order 1 hydrographic survey of South San Francisco Bay in support of the South Bay Salt Pond Restoration (SBSPR) Project. The SBSPR Project is the largest tidal wetland restoration project on the U.S. West Coast. The soundings from the hydrographic survey will be merged with the results from an aerial topographic Light Detection and Ranging (LIDAR) survey from May 2004 (Foxgrover and Jaffe, 2005) to create a terrain model of South San Francisco Bay. An accurate terrain model is essential for developing a sediment budget useful for evaluating different strategies for Salt Pond restoration. The U.S. Geological Survey (USGS) was responsible for overseeing the collection of hydrographic and LIDAR data sets, evaluating their accuracies, and for research purposes developing a terrainmodel and sediment budget for South Bay.

The hydrographic survey, conducted in January-April 2005, is the sixth survey of South Bay. The National Ocean Service (NOS; formerly the United States Coast \& Geodetic Survey) surveyed South San Francisco Bay five times, at approximate 30-year intervals, in 1858, 1898, 1931, 1956, and 1983. The USGS has already performed preliminary analyses on these historic surveys (Foxgrover, et al., 2004), and will incorporate the 2005 survey data to determine changes that have occurred within South San Francisco Bay from 1983 to 2005.

South Bay is the southern-most portion of San Francisco Bay and includes numerous sloughs and creeks. The tidally submerged lands of South San Francisco Bay cover portions of Alameda, Santa Clara, and San Mateo Counties. South San Francisco Bay has been defined as the area south of Hunter's Point (Foxgrover, et. al., 2004); however, the San Francisco Estuary Institute (SFEI) defines the northern boundary of South San Francisco Bay as being Coyote Point on the western shore and San Leandro Marina on the eastern shore (Goals Project, 1999). The California State Coastal Conservancy decided that surveying South San Francisco Bay as far north as Hunter's Point would be too costly and not necessary to accomplish the goals of the SBSPR Project. Instead, the survey of South San Francisco Bay extends as far north as the SFEI boundary line (Figure 1), defined by the following coordinates:

\begin{tabular}{|c|c|c|}
\hline UTM Zone 1 & ( & Latitude/Longitude (NAD-83) \\
\hline $\mathrm{N} 4.1602$ & & $\bar{N} 37^{\circ} 35.2406^{\prime} \quad$ W 122。20.2279' \\
\hline $4 \mathrm{~m}$ & E 561 & W 122。 $18.0524^{\prime}$ \\
\hline $4,173,122 \mathrm{~m}$ & E $571,415 \mathrm{~m}$ & W 122。11.3916' \\
\hline
\end{tabular}

The survey area extends south of the SFEI Boundary into Coyote Creek and includes four (4) sloughs (Alviso, Artesian, Mud, and Ravenswood) at the south end of San Francisco Bay. 


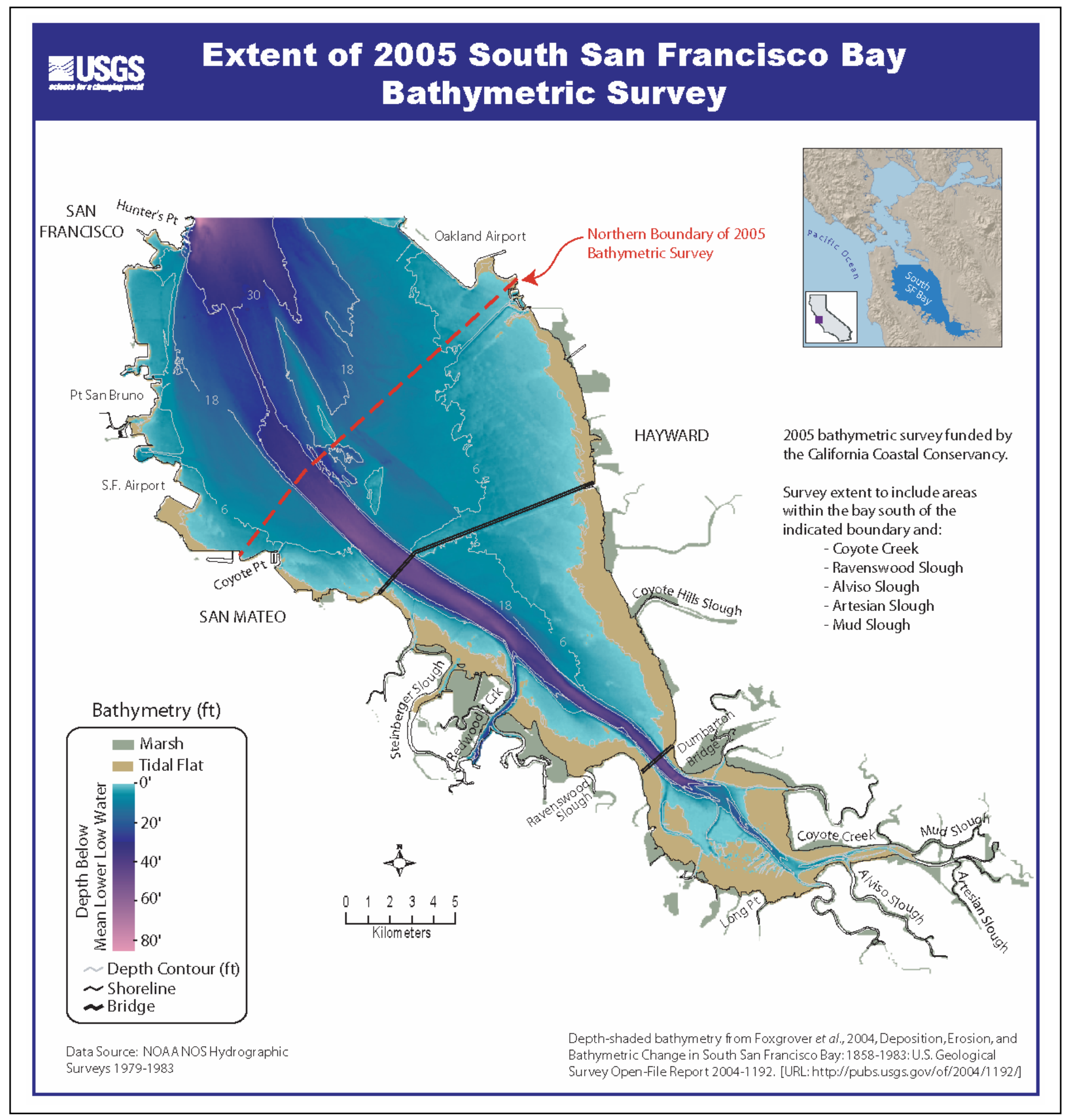

Figure 1: Extent of South San Francisco Bay Hydrographic Survey (modified from Foxgrover, et al, 2004). 


\section{DESCRIPTION OF WORK}

The hydrographic survey was funded by the State of California, conducted by a local Contractor, and relied on the expertise, resources, and good will of many Federal Agencies, including USGS, the National Oceanic and Atmospheric Administration (NOAA), and the National Geodetic Survey (NGS).

Sea Surveyor, Inc. of Benicia, California conducted the Order 1 hydrographic survey of South San Francisco Bay under Contract \#04-051 issued by the California State Coastal Conservancy on 12 October 2004. The Coastal Conservancy accepted the work performed by Sea Surveyor, Inc. on 17 November 2005 (Figure 2).

USGS prepared the scope-of-work for the hydrographic survey contract and provided technical oversight during the survey. USGS also furnished SUTRON data loggers to record the tide data, and provided a locked shed on the Dumbarton fishing pier that safely housed a tide gauge, recorder, and satellite dish. All data was delivered to the USGS Pacific Science Center in Santa Cruz, California.

The National Oceanic and Atmospheric Administration (NOAA) provided valuable expertise and resources for measuring tides used to correct the soundings, including:

- Tides were monitored at San Leandro Marina, San Mateo Bridge, Dumbarton Bridge, and Coyote Creek using NOAA-provided air-acoustic tide gauges.

- Tide data was transmitted at 6-minute intervals directly to NOAA via the GOES satellite.

- NOAA monitored uploaded tide data continuously (24-hours/day, 7-days/week) to ensure tide gauges performed correctly.

- NOAA processed the raw tide data, computed the Mean Lower Low Water (MLLW) vertical datum, and posted the 6-minute tide data on the CO-OPS website.

- NOAA defined the tides zones used to reduce the soundings.

- NOAA provided the conversions between the MLLW vertical datum and the North American Vertical Datum of 1988 (NAVD-88), based upon leveling conducted by the Contractor using methods specified by NGS.

The hydrographic survey was conducted during Winter 2005, the best season for collecting soundings in South San Francisco Bay. From October to March, South San Francisco Bay enjoys many periods of windless, flat-calm conditions that are ideal for collecting accurate soundings. Collecting accurate soundings is more difficult during Spring and Summer when strong, gusty winds and high waves prevail throughout South San Francisco Bay.

To make the soundings comparable to historical data, water depths were measured and corrected for tide using the same methods as used during the more recent of the historical surveys of South San Francisco Bay. Soundings were collected using a single-beam, survey-grade depthfinder having the same frequency and beam-width as used during the more recent of the historical surveys. Soundings were corrected to the MLLW vertical datum using tide data measured at the same location and reduced by the same organization (NOAA) as historical surveys. 


\section{(a. \\ Coastal \\ Conservancy}

November 17, 2005

Steve Sullivan

Sea Surveyor, Inc.

960 Grant Street, Suite C

Benicia, CA 94510

RE: $\quad$ South San Francisco Bay Bathymetry Survey, Contract \#04-051

Dear Mr. Sullivan:

This letter serves as acceptance of the work performed by Sea Surveyor, Inc. under contract \#04-051.

Sea Surveyor performed exceptional work on the bathymetry survey of South San Francisco Bay. Thanks for all of your hard work on this historic survey, your close coordination with USGS and NOAA, and for your commitment to keeping me informed of your progress. It has been a pleasure to work with you and I am very pleased with the results of the contract. The survey is already benefiting our analysis of restoration alternatives for the 15,100 acres of South Bay Salt Ponds and is destined to benefit innumerable studies of the San Francisco Bay and play a key role in our understanding of sedimentation and erosion in the Bay.

I hope we have an opportunity to work together again.

Sincerely,

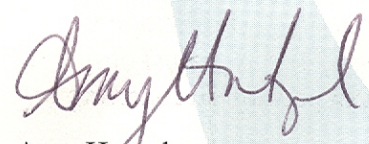

Amy Hutzel

Project Manager

1330 Broadway, 11 th Floor

Oakland, California 94612-2530

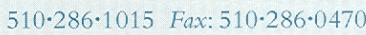

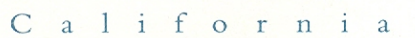

$S \quad t$ a $t$ e

C 0 a

C o n

Figure 2: Formal Letter Accepting Contractor's Work under Contract \#04-051. 
To increase the accuracy of the soundings, modern advances in computers, navigation, and geophysics were incorporated into the survey. High-speed computers and the Global Positioning System (GPS) replaced the sextant or LORAN-C navigation systems used for historical surveys, and the survey vessel collected soundings along straight lines instead of the arcs and radials used in some previous surveys. Recent advances in marine geophysics were also incorporated into the survey with the use of a seabed classification system that records and analyzes the acoustic properties of South Bay sediments, providing a baseline for future South Bay surveys. A heave compensator was added to remove sounding inaccuracies caused by waves.

Soundings were collected during periods of high tide in order to optimize "bank-to-bank" coverage of South Bay tidal flats, and provide maximum overlap with the aerial topographic LIDAR data collected months earlier during periods of low tide. Surveys were conducted both day and night to maximize survey efficiency and take advantage of the higher tides and calmer conditions that occur at night.

The hydrographic survey mapped 250 square kilometers (97 square miles) of tidally submerged lands in South San Francisco Bay. Soundings were collected in South Bay along a total of 2,600 $\mathrm{km}$ (1,618 miles) of trackline spaced at nominal 100m intervals. In addition to the South Bay survey, over $35 \mathrm{~km}$ (approximately 22 miles) of selected sloughs and creeks were surveyed along cross-sections spaced at nominal 100m intervals.

Soundings from the hydrographic survey are in meters referenced to two separate vertical datum, including MLLW and NAVD-88. USGS will compare soundings referenced to MLLW to historical NOS surveys of South San Francisco Bay, and merge soundings referenced to NAVD88 with the May 2004 LIDAR topographic data to create a terrain model of existing land surface elevation and bay bathymetry.

After passing all quality control checks, the final high-frequency $(200 \mathrm{kHz})$ soundings were thinned to $1 \mathrm{~m}$ intervals, grouped into zones, and delivered to the USGS Pacific Science Center in $\mathrm{x}, \mathrm{y}, \mathrm{z}$ format on $\mathrm{CD}$ disks referenced to Zone 10 North of the Universal Transverse Mercator (UTM) 1983 grid. Final soundings are referenced vertically to both NAVD-88 and MLLW, where possible. Other data delivered to USGS include:

- Tide data collected at 6-minute intervals by multiple pressure-sensing gauges in the sloughs and creeks of South San Francisco Bay.

- Raw (un-edited, un-corrected for tide) soundings spaced at nominal $0.15 \mathrm{~m}$ intervals,

- Digital depthfinder records, including barcheck calibrations, in .pcx format.

Quester Tangent, the manufacturer of the seabed classification system, processed the lowfrequency $(50 \mathrm{kHz})$ soundings and developed a map of acoustic diversity for South San Francisco Bay showing the seabed segmented into acoustically similar units. The low-frequency $(50 \mathrm{kHz})$ soundings were delivered to USGS in time-tagged, draft-corrected $\mathrm{x}, \mathrm{y}, \mathrm{z}$ format without correcting for tide.

The purpose of this Quality Control (QC) Report is to document the survey equipment, personnel, calibrations, analytical techniques, and QC procedures used for conducting the Order 1 hydrographic survey of South San Francisco Bay. The following sections describe the methodology, results, and QC procedures used for the survey. 


\section{FIELD SURVEY METHODS}

The hydrographic survey of South San Francisco Bay was conducted using Order 1 standards, methods and accuracies outlined in the U.S. Army Corps of Engineers' HYDROGRAPHIC SURVEYING MANUAL (USACE, 2002) and NOAA's HYDROGRAPHIC SURVEYS SPECIFICATIONS AND DELIVERABLES (NOS, 2003a). Tidal height was monitored, and soundings corrected for tide, using NOAA procedures and standards documented in the following publications:

- User's Guide for the Installation of Benchmarks and Leveling Requirements for Water Level Stations (NOS, 1987).

- Specifications and Deliverables for Installation, Operation, and Removal of Water Level Stations (NOS, 2003b).

- Summary of Procedures and Results from South San Francisco Bay Vertical Datum Determination and Conversion Study (NOAA, 2006).

The following sections describe the field survey methods, survey equipment, and personnel used to conduct the Order 1 hydrographic survey of South San Francisco Bay.

\subsection{Field Survey Methodology}

The survey was conducted using two 2-person field survey crews; one crew collected soundings during daylight periods of high tide, while the second crew used the same vessel and survey equipment to collect soundings during the high tides at night. Both survey crews practiced a strict regime of calibrating the survey-grade depthfinder twice per shift. At the beginning and end of each shift, the speed-of-sound calibration of the depthfinder was checked using the barcheck procedure and the transducer draft was manually-measured through the sonar well. Any discrepancies between the before-and-after or day-and-night calibrations were immediately investigated and resolved.

Soundings were collected across South San Francisco Bay along tracklines spaced at nominal $100 \mathrm{~m}$ intervals and oriented in a southwest-northeast direction (perpendicular to the general bathymetric contour of the seafloor). Survey tracklines were divided into tide zones defined by NOAA (2006), with 100m overlap into adjacent zones. Dividing the tracklines into tide zones simplified processing the soundings and provided a QC check in the overlap area around tide zone boundaries. Unless obstructions were encountered, soundings near the shoreline extend to elevation $+0.3 \mathrm{~m}$ MLLW or higher. When practical, soundings were collected around obstructions to complete sounding lines. Overlap between survey areas and cross-lines (tielines) are provided for quality-control assessment of the soundings.

Soundings were collected during all stages of the tide, provided that sufficient water depth was available for safe navigation. Areas shallower than-1m MLLW were surveyed during periods of extreme high tides when the water surface elevation is $+1.75 \mathrm{~m}$ MLLW or higher. Areas deeper than -3m MLLW were surveyed during all stages of the tide (high and low), but always during periods of "neap" tides when the water surface elevation changes less than $1.25 \mathrm{~m}$ 
between high and low tides. Survey lines terminated early because of shallow water during low or moderate tides were re-surveyed during extreme high tides in order to collect soundings as far upland as possible. For QC purposes, survey lines terminated early at low tide are re-surveyed at high tide with a minimum $100 \mathrm{~m}$ overlap.

During the hydrographic survey, a written log is prepared on a standardized form for each dayshift and nightshift. The log documents the personnel, vessel, equipment, layout, and weather/sea conditions. The time that each survey line begins and ends is entered in the log, and space is provided for notes to be added to describe unusual occurrences. The speed-of-sound adjustment, transducer draft, and depth of deepest barcheck are also included in the log. The digital depthfinder record is annotated to indicate the location of each sounding line, the date and time (hour/minute) each sounding line is taken, and explanation for any line terminated early.

\subsection{Survey Equipment}

The Order 1 hydrographic survey of South San Francisco Bay used the following equipment:

- One of three hydrographic survey vessels of $9 \mathrm{~m}, 8 \mathrm{~m}$, or $4 \mathrm{~m}$ length.

- One INNERSPACE Model 455 survey-grade depthfinder with 3-degree transducer.

- One TSS DMS-05 motion sensor.

- One QUESTER TANGENT Model QTC-V seabed classification system with $50 \mathrm{kHz}$ transducer, SUZUKI depthfinder, and laptop computer.

- One OMNISTAR GPS receiver with differential subscription service and antennas.

- Three $C L$ internal-recording, pressure-sensing tide gauges with external barometric sensors.

- Four NOAA tide gauges, including AQUATRAK Model 4100 air-acoustic water level sensors, SUTRON 8210 data loggers, and GOES satellite antennas.

- One DELL navigation computer with flat screen monitor and navigation software package for collecting and processing soundings.

- One Honda $1 \mathrm{~kW}$ generator or 110 -volt inverter.

- Six 12-volt deep-cycle batteries and one battery charger.

- One survey-grade construction level, tripod, and stadia rod.

- One barcheck with $17 \mathrm{~m}\left(55^{\prime}\right)$ stainless steel cable marked at $1.5 \mathrm{~m}\left(5^{\prime}\right)$ depths.

- Three leadlines (weighted survey tape incremented at 0.1 ' intervals).

- One Chevrolet Suburban vehicle for towing vessel and trailer.

- One of three boat trailers for $9 \mathrm{~m}, 8 \mathrm{~m}$ or $4 \mathrm{~m}$ survey vessels.

The following sections provide a detailed description of the vessels, depthfinders, navigation system, and tide gauges used for conducting the Order 1 hydrographic survey.

\subsubsection{Survey Vessels}

The Order 1 hydrographic survey of South San Francisco Bay was conducted using calibrated hydrographic survey vessels. These survey vessels employ a integrated system of sensors to measure and record the depth of water below the vessel at a rate of 20-times each second, 
three-dimensional motion of the vessel, and location of the vessel. Soundings are collected by a hull-mounted transducer located in the exact center of the vessel. A motion sensor, located directly above the transducer, records the roll/pitch/heave of the vessel and transmits changes in vessel displacement to the depthfinder as a correction to the soundings. The GPS antenna is located on the roof of the vessel directly over the transducer. Test course calibrations and squat/settlement curves are posted in each survey vessel and are incorporated in the survey computations software program, per Corps of Engineers specifications for Order 1 hydrographic surveys (USACE, 2002).

The survey vessels are calibrated to collect soundings while moving in a straight line and constant velocity. Sounding accuracy decreases when the vessel squat changes during turns and speed changes. To maximize accuracy of the sounding data, the vessels did not make abrupt turns nor alter speed until a survey line was completed, including QC overlap areas at the boundary of the tide zones. Sounding accuracy decreases when the vessel abruptly changes course and speed, which is unavoidable when collecting cross-sectional soundings in narrow sloughs and creeks.

Several times monthly, one of the survey vessels collecting soundings in South San Francisco Bay would undergo extensive calibration checks in the Port of Oakland by independent surveyors from the U.S. Army Corps of Engineers and Great Lakes Dredge \& Dock. To pass these calibration checks, soundings collected along five (5) pre-selected survey lines across the Oakland ship channel had to match those collected by two independent survey vessels within $\pm 1 \mathrm{~m}$ horizontal and \pm 0.1 ' vertical.

The Contractor used three (3) vessels to survey South San Francisco Bay, including the 9m Minotaur, the $8 \mathrm{~m}$ Betty Jo, and a $4 \mathrm{~m}$ flat-bottom skiff. Each vessel has distinct advantages that are useful for surveying in various environments in South San Francisco Bay. The larger and faster Minotaur was used to survey the majority of South San Francisco Bay, while the heavier and more rugged Betty Jo surveyed the hazardous, shallow areas between the Dumbarton Bridge and Coyote Creek. The flat-bottom skiff collected soundings in the sloughs and creeks.

A description of each vessel used during the South San Francisco Bay survey is provided in the following sections.

Minotaur: The 9m (29') Minotaur is a lightweight aluminum vessel with a shallow $0.6 \mathrm{~m}$ (2') draft that collected soundings and seabed classification data in all areas north of the Dumbarton Bridge. The Minotaur was based in San Leandro Marina during the survey. A 200hp, 4-stroke outboard motor powers the Minotaur to cruising speeds of 30-knots. The Minotaur was selected as the primary survey vessel for the hydrographic survey because its fast cruising speed minimized transit time to the various survey areas in South San Francisco Bay, and its efficient 4-stroke engine minimized fuel costs. The radar and spotlights on the roof of the Minotaur

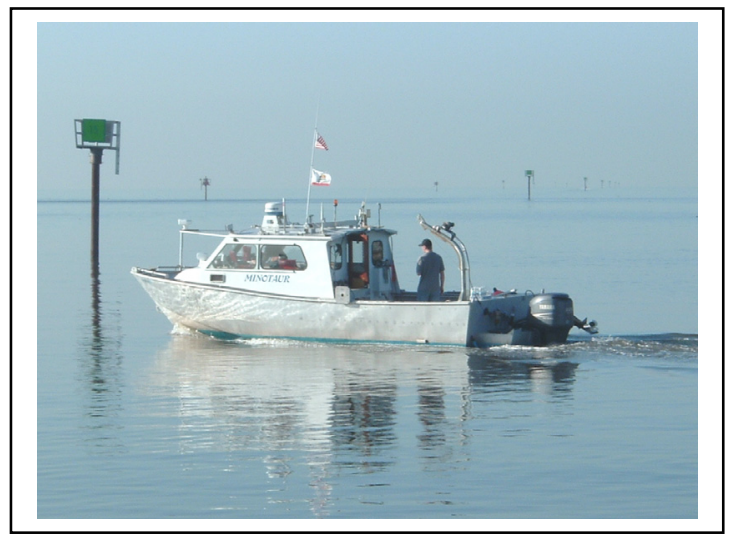

Figure 3: 9m Survey Vessel "Minotaur" 
allowed surveyors to avoid obstacles at night. The enclosed cabin, diesel-powered heater, cookstove, sink, and toilet made the Minotaur comfortable for the crew while they surveyed through the cold winter days and nights of January-February 2005.

While collecting soundings, the Minotaur maintained an over-the-ground velocity of 5.5 knots, \pm 0.25 knots. A $200 \mathrm{kHz}, 3$-degree transducer, mounted in a sonar well through the middle of the vessel, collects 20 soundings/second. The sonar well allows the survey crew to directly measure the depth (draft) of the hull-mounted transducer, and calibrate the depthfinder for acoustic velocity using the barcheck procedure. The antenna for the differential GPS navigation is on the vessel's roof directly over the transducer in the sonar well. The $50 \mathrm{kHz}$ transducer for the seabed classification system is attached to an over-the-side mount on the vessel's starboard side. Test course calibration and squat/settlement curves for the Minotaur are posted in the survey vessel and are incorporated in the survey computations software program, per Corps of Engineers specifications for Order 1 hydrographic surveys (USACE, 2002).

Since the lightweight (2-ton) aluminum Minotaur is susceptible to vertical displacement (heave) by waves, a TSS DMS-05 motion sensor was installed next to the sonar well to measure and correct the soundings for heave. The motion sensor data was input directly into the survey-grade depthfinder so that the raw soundings are corrected for vessel heave.

Betty Jo: The Betty Jo is a $8 \mathrm{~m}$ (25') Farallon Whaleback powered by a Chrysler-Marine 318 gas engine with single shaft-driven propeller. The Betty Jo surveyed the hazardous shallow-water area between the Dumbarton Bridge and Coyote Creek. The thick fiberglass hull of the Betty Jo protected the crew and survey equipment against frequent collisions with shallow-water obstructions. The Betty Jo is a heavy (5-ton) vessel with $1.1 \mathrm{~m}$ (3.5') draft, which minimizes its vertical displacement (heave) by waves. A motion sensor is typically unnecessary when collecting soundings with the Betty Jo, especially in calm conditions.

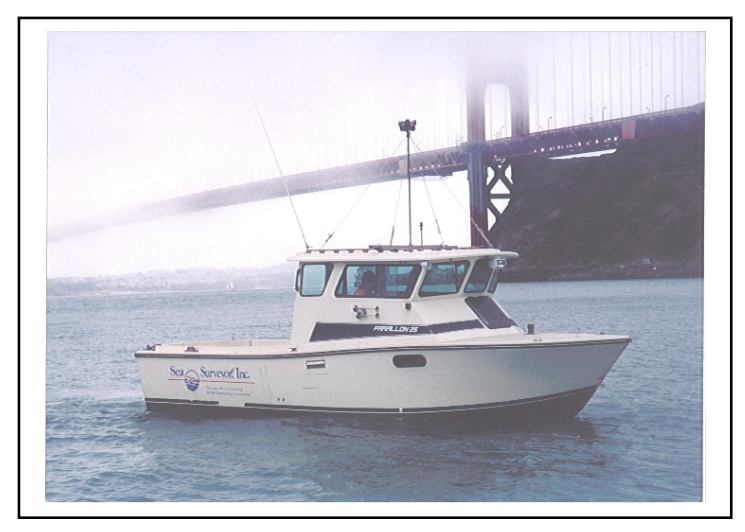

Figure 4: 8m Survey Vessel "Betty Jo"

The Betty Jo maintains an over-the-ground velocity of 5.5 knots $( \pm 0.25$ knots $)$ while collecting soundings at a rate of 20 depth measurements per second. The $200 \mathrm{kHz}$ transducer for the survey-grade depthfinder is installed in a sonar well through the center of the vessel. The sonar well allows the draft of the transducer to be directly measured during barcheck calibrations. The antenna for the differential GPS navigation is on the vessel's roof directly over the transducer in the sonar well. The $50 \mathrm{kHz}$ transducer for the seabed classification system is attached to an overthe-side mount on the vessel's port side. Test course calibration and squat/settlement curves for the Betty Jo are posted in the survey vessel and are incorporated in the survey computations software program, per Corps of Engineers specifications (USACE, 2002).

The Betty Jo was based in Redwood City Marina during the survey, but was cross-calibrated to 2 other Order 1 survey vessels in the Port of Oakland several times each month. During these cross-calibrations, the Betty Jo would collect soundings along five (5) pre-selected survey lines across the Oakland ship channel. Independent inspectors provided by the U.S. Army Corps of 
Engineers and Great Lakes Dredge \& Dock would observe the soundings being collected, then compare the soundings against those collected immediately afterwards by the survey vessels Wildcat and Diamond Reef. The independent inspectors found little difference between the soundings collected by any of the survey vessels, and all boat-to-boat calibrations matched within $\pm 1 \mathrm{~m}$ horizontal and \pm 0.1 ' vertical.

Flat-bottom Skiff: A 4m (14') aluminum skiff surveyed the shallow creeks and sloughs in South San Francisco Bay. The $4 \mathrm{~m}$ skiff is powered by an $18 \mathrm{hp} \mathrm{NISSAN} \mathrm{outboard} \mathrm{motor}$ controlled by a steering console. Weatherproof compartments hold the survey-grade depthfinder, GPS receiver, and navigation computer. A $1 \mathrm{~kW}$ generator provides electrical power. To reach the sloughs/creeks to be surveyed, the skiff was either launched at the unpaved boat launch ramp at the head of Artesian Slough or towed by the 25' Betty Jo from Redwood City Marina to the railroad bridge over Coyote Creek. The skiff did not utilize a $50 \mathrm{kHz}$ over-the-side transducer because the sloughs and creeks are too shallow to collect seabed classification data. Test course calibration and squat/settlement curves for the skiff are incorporated in the survey computations software program, per Corps of Engineers specifications (USACE, 2002).

Prior to conducting the hydrographic survey of each slough, a reconnaissance survey is conducted to locate the slough centerline and determine the upland extent of the survey. Reconnaissance soundings are

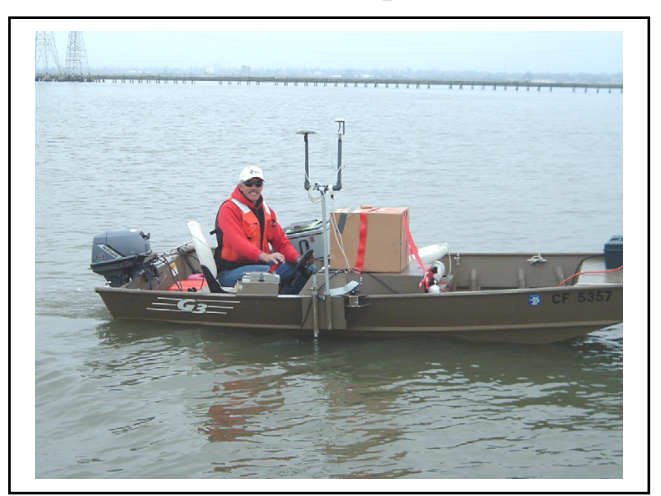

Figure 5: 4m Flat-Bottom Skiff shown during slough recon surveys. for planning purposes only, and are not included in the final data set. After completing the reconnaissance survey of each slough, the horizontal coordinates for the slough centerline is plotted on a digital map and segmented at $100 \mathrm{~m}$ intervals. Survey line coordinates are then programmed into the navigation computer so that cross-sectional profiles of the slough can be surveyed at $100 \mathrm{~m}$ intervals.

During the reconnaissance surveys, the survey-grade depthfinder's narrow-beam $200 \mathrm{kHz}$ transducer is attached to the side of the vessel; however, during the final cross-sectional survey of the sloughs, the survey-grade depthfinder's transducer is connected to the transom of the vessel. Attaching the transducer to the transom provides better accuracy and repeatability than does a side-mounted transducer. The GPS antenna is mounted directly over the transducer, regardless if it is side-mounted or transom-mounted.

\subsubsection{Survey-Grade Depthfinder}

Soundings are collected using an INNERSPACE Model 455 survey-grade depthfinder with digital and graphic output. Soundings are measured in feet to the nearest 0.1 -foot, but reported in meters $(\mathrm{m})$ to the nearest $0.01 \mathrm{~m}$. The depthfinder collects 20 soundings/second, typically spaced at nominal $0.15 \mathrm{~m}$ intervals along trackline.

The survey-grade depthfinder has a frequency of $208 \mathrm{kHz}$, with a 3.5 -degree cone measured at $6 \mathrm{db}$ point. The transducer for the depthfinder is mounted in a sonar well through the exact center of the vessel, per Corps of Engineers specifications for Order 1 hydrographic surveys (USACE, 2002). A center-mounted transducer is more accurate than a side-mounted transducer because 
it experiences less heave, pitch and roll. Mounting the transducer in an accessible sonar well simplifies calibrating the depthfinder and allows the depth of the transducer to be precisely measured to compensate for changes in vessel draft.

To ensure accurate soundings, the survey-grade depthfinder is calibrated twice during each survey period, and up to 4-times daily. The depthfinder must be calibrated for the acoustic velocity of the water column, which is a function of seawater density and directly related to conductivity, temperature, and depth. The strong tidal influence in South San Francisco Bay causes the acoustic velocity to vary not only vertically, but also horizontally and with time. During the hydrographic survey, the depthfinder is calibrated immediately before and after collecting soundings, and whenever the survey area changes. The calibrations are recorded so they can be reviewed for quality control.

The depthfinder is calibrated before and after each daily survey using the barcheck procedure (Figure 6). The pre-survey barcheck calibrates the depthfinder for acoustic velocity, while the post-survey barcheck demonstrates that the survey-grade depthfinder never varied more than $\pm 0.1^{\prime}$ at any of the $1.5 \mathrm{~m}\left(5^{\prime}\right)$ calibration checks. The barcheck procedure consists of using a stainless steel cable marked at $1.5 \mathrm{~m}$ intervals to lower a $0.5 \mathrm{~m}$ (18”) diameter steel plate through the sonar well. The steel plate serves as an acoustic target that is lowered to exact depths for calibrating the depthfinder. The depthfinder's speed-of-sound control is adjusted so that the acoustic target appears on the digital display precisely at its known depth. After the depthfinder is calibrated for the maximum practical depth, the barcheck is raised at $1.5 \mathrm{~m}$ intervals so that any variations in the calibration can be recorded.

A TSS DMS-05 motion sensor is used to correct the soundings for vertical displacement of the vessel by waves. The motion sensor measures the roll, pitch, and heave of the survey vessel and transmits the data 10-times each second to the INNERSPACE depthfinder. The depthfinder uses the motion sensor data to correct the soundings for wave-induced displacements of the vessel. The motion sensor was installed only in the lightweight, aluminum vessel Minotaur during the hydrographic survey north of the Dumbarton Bridge; the motion sensor was not needed south of the Dumbarton Bridge because the survey was conducted during flat calm conditions when soundings collected by the heavy, fiberglass Betty Jo showed no sign of heave-induced errors.

\subsubsection{Seabed Classification System}

An acoustic seabed classification system manufactured by QUESTER TANGENT CORPORATION of Sidney, B.C., Canada recorded the bottom sediment acoustic characteristics during the hydrographic survey. A low-frequency $50 \mathrm{kHz}$ depthfinder monitored the acoustic characteristics of the seafloor across South San Francisco Bay, excluding the shallow sloughs and creeks. The acoustic signal is generated by a SUZUKI 2025 depthfinder using a $50 \mathrm{kHz}$ transducer with 24-degree beam width on an over-the-side mount on the survey vessel. A QTC VIEW sounder interface module records the return signal. The depthfinder was operated at 0-to$40 \mathrm{~m}$ range with a pulse duration of $0.3 \mathrm{~ms}$.

The acoustic seabed classification system digitally acquires each raw echo at a rate of three soundings per second and records the waveform for later analyses. GPS navigation data is simultaneously logged as comma-delimited ASCII records which in this case was a NMEA GPGGA string. Both the full waveform and envelope data were logged by the system. The sonar data is stored in a laptop computer using a QTC proprietary format 


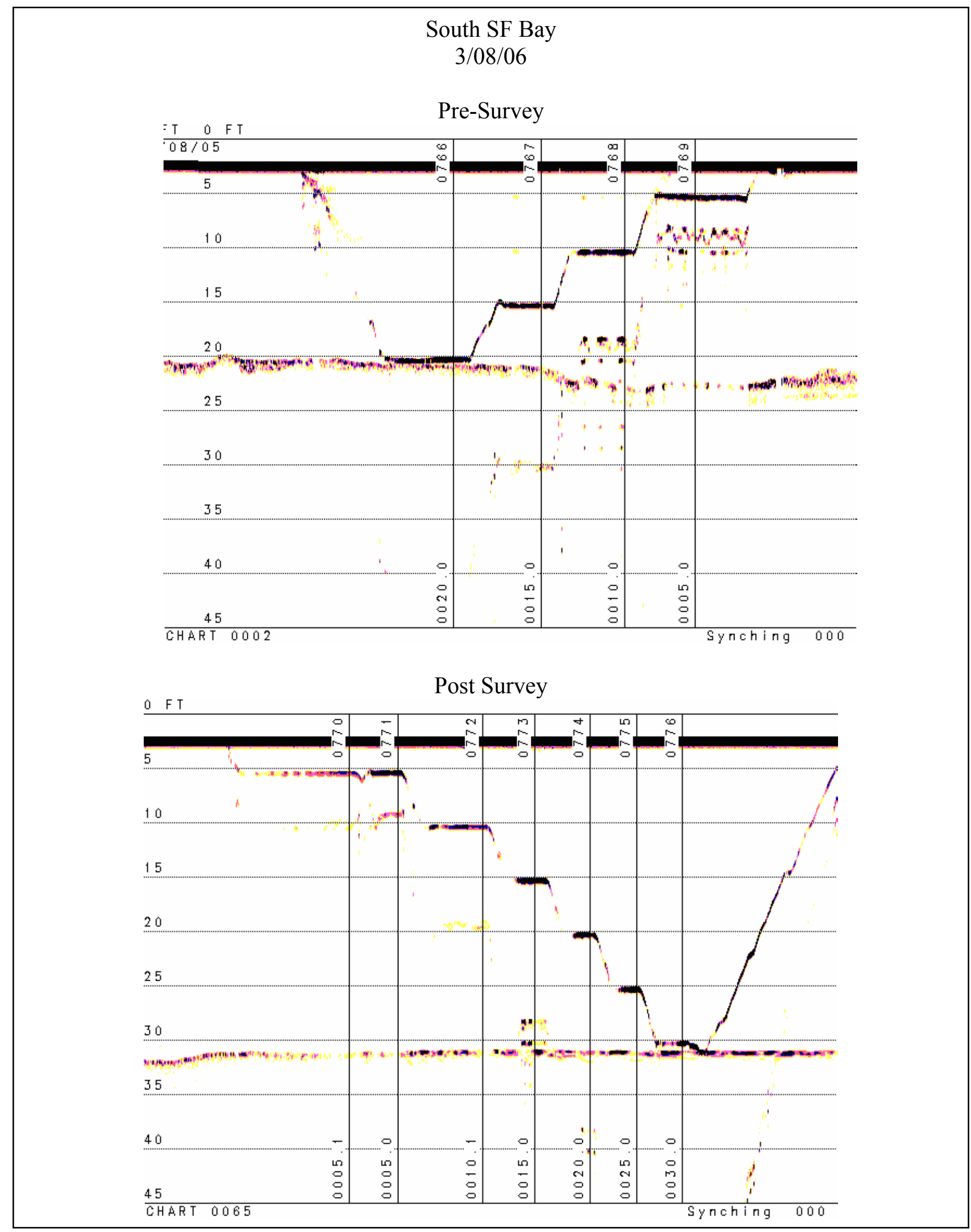

Figure 6: Typical barcheck calibration of the survey-grade depthfinder, showing daily preand post-survey barcheck calibrations at $1.5 \mathrm{~m}\left(5^{\prime}\right)$ depth intervals. 


\subsubsection{Differential GPS Navigation}

The soundings and all data are referenced to UTM Zone 10 North geographic coordinates, in meters, based on the Global Positioning System (GPS) with differential-corrections. Although differential GPS allows sub-meter level accuracies to be routinely obtained, horizontal accuracies achievable from a moving survey vessel are likely in the range of $\pm 3 \mathrm{~m}$.

The differential GPS navigation system includes a GPS receiver aboard the survey vessel, an onshore GPS base station that calculates the differential correction, and a satellite that transmits the differential correction to the survey vessel. For the South Bay survey, an OMNISTAR Model LR-8 GPS receiver with differential correction service was used to record the location of the survey vessel at 1-second intervals during the hydrographic survey. The GPS navigation antenna is mounted on the roof of the survey vessel directly above the 3-degree transducer, making correction offsets unnecessary.

Navigation and sounding data is recorded and displayed by a computer with trackline control software aboard the survey vessel. The navigation software displays the location of the survey vessel in relation to a pre-plotted line, and provides digital information useful for helming the vessel along the line. Prior to beginning the survey, pre-plots of the planned survey lines are prepared and input into the navigation computer. The navigation system uses CORPSCON, a coordinate conversion program developed by the U.S. Army Corps of Engineers, to convert between various coordinate systems and to convert NAD-27 to NAD-83.

\subsubsection{Tide Measurements}

Soundings are referenced to a common vertical datum by measuring and correcting for variations in tide height. During the hydrographic survey, water surface elevation was measured at seven locations in South San Francisco Bay, including:

- San Leandro Marina (NOAA Station 9414688)

- West San Mateo Bridge (NOAA Station 9414458)

- Dumbarton Bridge (NOAA Station 9414509)

- Entrance to Coyote Creek (NOAA Station 9414575)

- Railroad Bridge crossing Coyote Creek

- Top of Artesian Slough (at San Jose Wastewater Treatment Plant)

- Alviso Slough at Gold Street Bridge (NOAA Station 9414551)

Tides at San Leandro Marina, San Mateo Bridge, and Dumbarton Bridge were monitored using air-acoustic water level sensors referenced to the MLLW vertical datum. In the sloughs and creeks, tides were measured using pressure-sensing tide gauges referenced to NAVD-88. The following sections describe the methods and equipment used to measure tides for correcting soundings to a common vertical datum.

Air-Acoustic Tide Gauges: NOAA measures tides using an AQUATRAK Model 4100 airacoustic water level sensor controlled and monitored by a SUTRON data logger. NOAA typically uses the SUTRON Model 8200 data logger to control, record and transmit data from an air-acoustic water level sensor; however, NOAA had no Model 8200 data loggers available to loan the Contractor for the South San Francisco Bay survey. Instead, USGS provided the "next generation" of data loggers, the SUTRON Model 8210 . The Model 8210 is sufficiently different 
from the Model 8200 that the User's Guide (NOS, 1998) for installing and operating the acoustic gauge did not apply.

Since the tide gauges could not be made operational without an instruction manual, the Contractor shipped the AQUATRAK sensors and SUTRON Model 8210 data loggers to NOAA's Field Operations Division in Chesapeake, Virginia for programming and testing. The Contractor sent an electronics technician to Chesapeake, Virginia to receive training and transport the instruments back to South San Francisco Bay for installation.

While the air-acoustic tide gauges were being programmed and tested by NOAA in Chesapeake, Virginia, the Contractor installed 10cm-diameter PVC stilling wells at San Leandro Marina, San Mateo Bridge, Dumbarton Bridge, and the entrance to Coyote Creek (Figure 7). The PVC stilling wells protect the AQUATRAK air-acoustic sensor and provide a calm water surface for measuring elevation. The PVC stilling wells are $10 \mathrm{~m}$ long, extend $6 \mathrm{~m}$ below the water surface at low tide, and are mounted vertically on to existing structures (pier, tower, or navigation beacon).
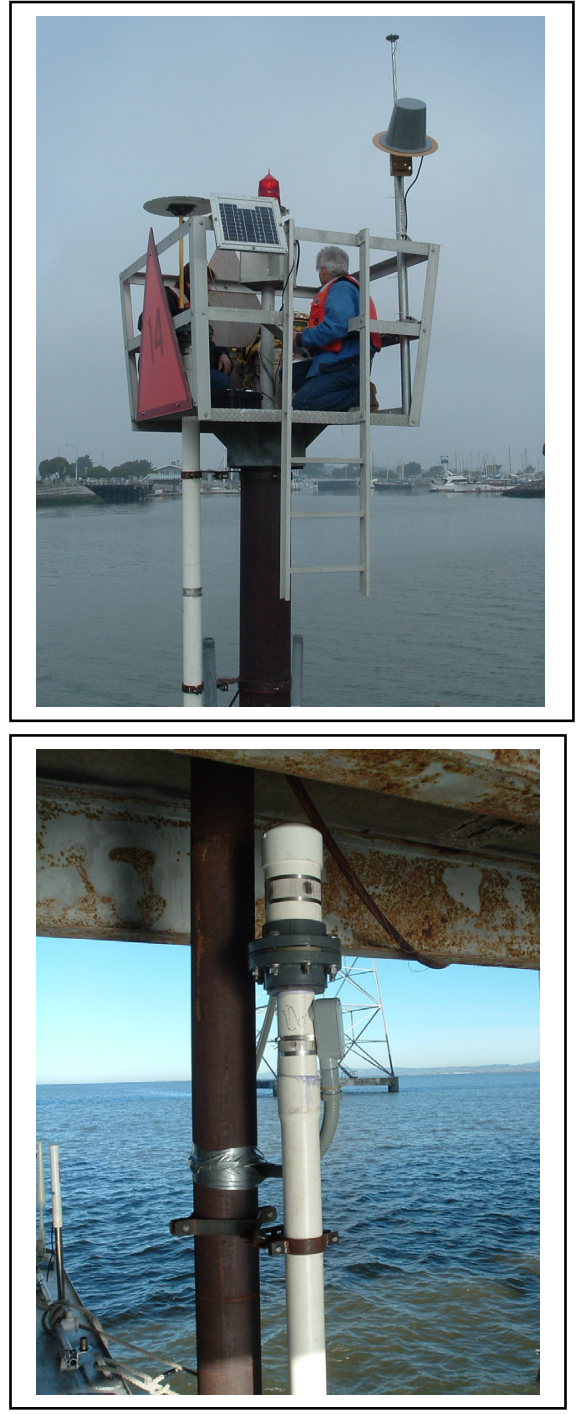
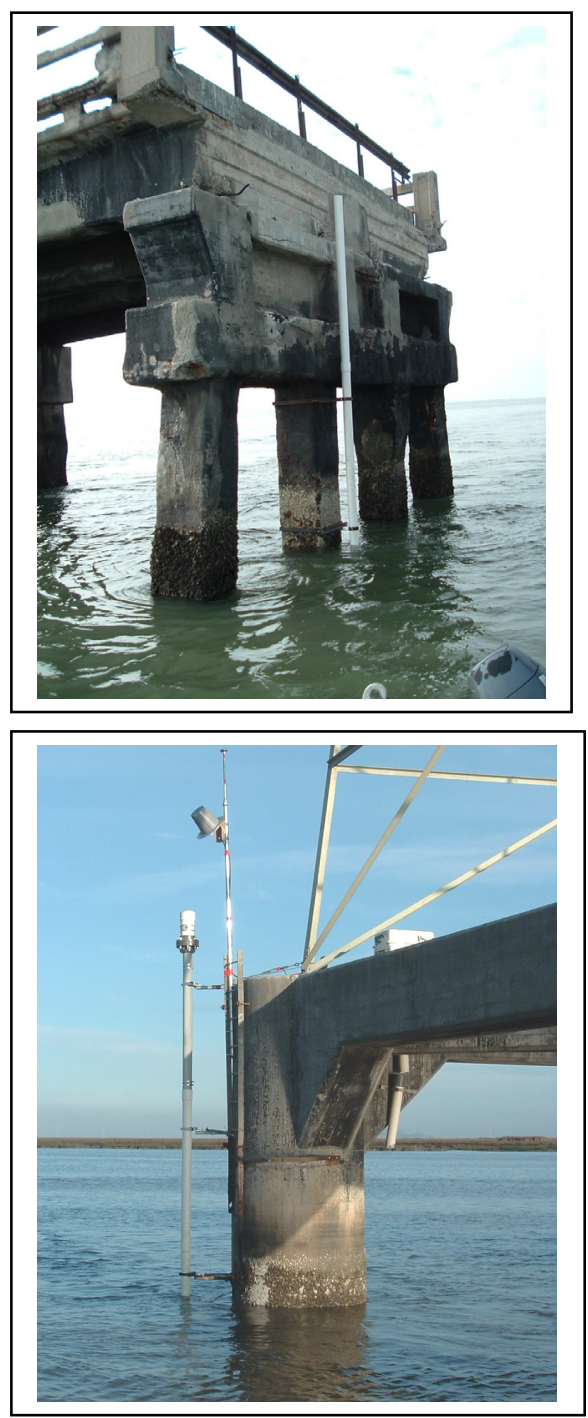

Figure 7: Stilling wells and airacoustic tide gauges installed at four (4) locations, including:

Beacon 14 in San Leandro Marina (upper left),

End of San Mateo Bridge Fishing Pier (upper right),

Under Dumbarton Bridge Fishing Pier (lower left), and

On the PG\&E electrical tower in Coyote Creek (lower right). 
The air-acoustic tide gauges at San Leandro Marina, San Mateo Bridge, and Dumbarton Bridge became operational between 31 December 2004 and 4 January 2005. The air-acoustic tide gauge installed on the electrical tower in Coyote Creek never became operational. The 3 operating tide gauges measured water surface elevation at six (6) minute intervals, with the period of the average centered at the six minute mark (i.e., :00,:06,:12, etc.). The water level data was transmitted directly to NOAA using GOES satellite antennas provided by the California Coastal Conservancy. After processing the tide data, NOAA made the tide data available on their COOPS website approximately 1 -week later.

Pressure Sensing Tide Gauges: Tides in Coyote Creek, Artesian Slough, and Alviso Slough were monitored using internal-recording, pressure-sensing tide gauges provided by the Contractor. Pressure is an indirect measure of water height above the sensor. A pressuresensing tide gauge (Figure 8) has two pressure sensors; one above-water that monitors changes in air pressure and one below-water that measures underwater pressure. Any fluctuations in the tide record caused by changes in barometric pressure are removed by subtracting the air pressure from the underwater pressure. The tide gauge filters out waves/wakes from the tide data by averaging 0.5 -second samples collected for 2-minutes centered on each 6-minute interval. The manufacturer (Coastal Leasing, Inc. of Cambridge, Massachusetts) calibrated the pressuresensing tide gauges in December 2004 immediately prior to the field survey.

Pressure-sensing tide gauges were installed at multiple locations in the sloughs and creeks of South San Francisco. Multiple tide gauges provide backup in the event of data loss from a single instrument, and provide valuable information on the long-period wave velocity as the tide ebbs and floods. The elevation of the tide gauges was determined prior to the survey, and checked again after the survey ended, by a California-registered land surveyor using nearby tidal benchmarks for reference. In addition, the accuracy of the tide readings was manually-checked multiple times on the days that soundings were collected using a weighted tape to measure the vertical distance between the water surface and nearby benchmark. After recovering the gauges, the tide data was downloaded, processed, and transmitted to NOAA and USGS for analyses.

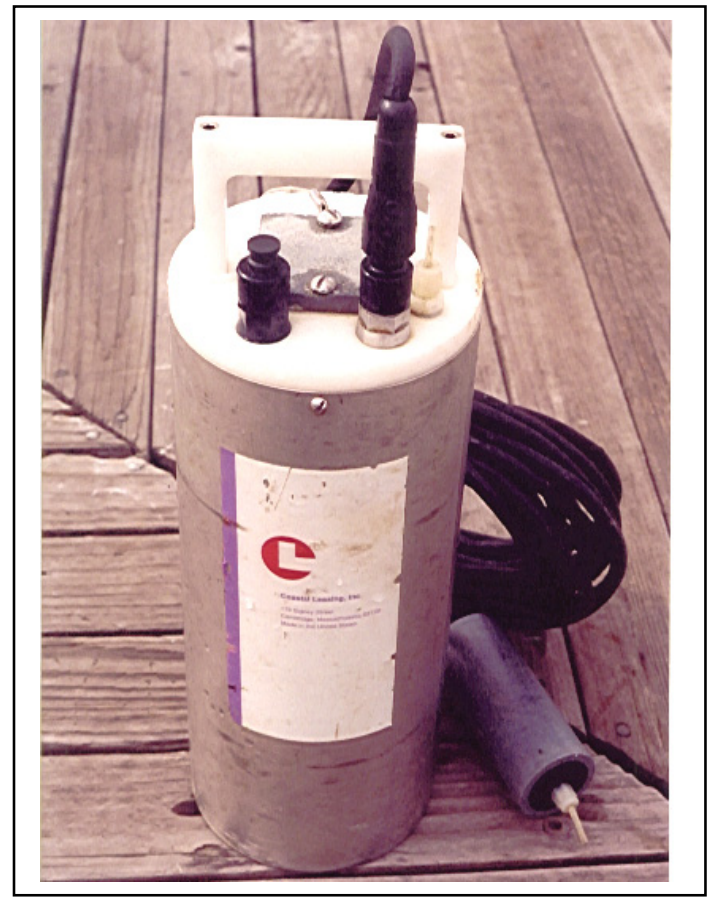

Figure 8: Pressure-Sensing Tide Gauge with external barometric sensor on $10 \mathrm{~m}$ cable. 


\subsection{Tidal Benchmarks}

During the hydrographic survey, tide data was collected at key locations in South San Francisco Bay to correct the soundings for changes in the water surface elevation. Tide data and corrected soundings are referenced to MLLW of the 1983-2001 tidal epoch. MLLW (calculated over a specific 19-year tidal epoch) is the same vertical datum used during 5 historic surveys of South San Francisco Bay conducted by NOS at approximate 30-year intervals in 1858, 1898, 1931, 1956, and 1983. The tide data collected in January-April 2005 is from the same location and reduced by the same organization (NOS) as historical surveys.

The MLLW tidal datum is useful for comparing present with historic soundings; however, soundings must be converted to the modern North American Vertical Datum of 1988 (NAVD88 ) in order to be compatible and merged with topographic data to create a terrain model. Although some of the South Bay tidal benchmarks have geodetic ties to the now superseded National Geodetic Vertical Datum of 1929 (NGVD-29), few are tied to the newly adopted NAVD-88 vertical datum and conversions are not available.

Fortunately, some of the historic tidal benchmarks set by NOS in South San Francisco Bay still exist in good, stable condition and have published MLLW elevations (http://tidesandcurrents. noaa.gov) for the modern (1983-2001) tidal epoch. Coincidently, an ongoing program by the National Geodetic Service (NGS) provides GPS-derived orthometric NAVD-88 elevations for Height Modernization control points in South San Francisco Bay on the NGS website at http://www.ngs.noaa.gov. Using the Height Modernization control points as reference, the NAVD-88 elevation of the historic tidal benchmarks in South San Francisco Bay can be determined using conventional land surveying techniques and/or modern GPS survey methods. Measuring the NAVD-88 elevation of the tidal benchmarks provides information from which conversions between MLLW and NAVD-88 can be derived.

A California-registered land surveyor used static GPS techniques and conventional differential leveling methods to measure the NAVD-88 elevation of the tidal benchmarks using the Height Modernization control points as reference. Determining the NAVD-88 elevation of South Bay tidal benchmarks allows datum conversions between MLLW and NAVD-88 to be developed for South San Francisco Bay.

Prior to conducting the survey, the historic tidal benchmarks that still exist were located. After a discussion with NGS, surveyors developed a plan for measuring the NAVD-88 elevation of tidal benchmarks using Height Modernization control points as reference. The survey plan included:

- Conventional survey techniques using optical leveling equipment when the tidal benchmark and Height Modernization control point are in close proximity. Differential leveling is conducted according to both NGS and NOS standards. Leveling methods meet NGS 2nd Order specifications and the optical leveling equipment, a Zeiss NI-2 automatic level with micrometer, meets NGS leveling standards. To calibrate the optical instrument to NOS standards, the survey crew performed collimation tests daily.

- When a tidal benchmark is far from the reference Height Modernization control point, the static GPS method is used. For static GPS surveys, highly-accurate Trimble 4000-SSI receivers are set simultaneously over the tidal benchmark and Height Modernization control point, and GPS data is collected at both locations for 2 sessions of 1-hour each separated by 3 -hours minimum. 
- If a tidal benchmark is located under a structure and far from a Height Modernization control point, the land surveyor uses static GPS to set an offset point near the tidal benchmark, and then establishes a tie to the tidal benchmark using differential leveling.

The NAVD-88 elevation of the existing NOS tidal benchmarks in South San Francisco Bay were surveyed both before (December 2004) and after (July 2005) the hydrographic survey. A description of the historic tidal benchmarks surveyed at each tide gauge location is provided below:

San Leandro Marina (NOS Station 9414688): Two historic tidal benchmarks set by NOS still exist at San Leandro Marina, including Tidal BM-4, 1974 (VM-8382) and 4688-B, 1976 (VM-8386). NOS designates TIDAL BM 4, 1974 as the primary benchmark and assigns it an elevation of 5.345m above MLLW. Tidal benchmark 4688-B, 1976 is both a secondary NOS tidal benchmark and an NGS Height Modernization control point (HT2327), with an elevation of $2.809 \mathrm{~m}$ above MLLW and $2.690 \mathrm{~m}$ above NAVD- 88.

San Mateo Bridge West Fishing Pier (NOS Station 9414458): Three historic tidal benchmarks set by NOS still exist, including Brass Disk \#1 (VM-8127), Brass Pin \#1 (VM-8128), and Brass Pin \#2 (VM-8129). NOS designates the primary benchmark as Brass Disk \#1 (VM-8127) and assigns it an elevation of 5.092m MLLW. NOTE: A Height Modernization control point labeled "Guano Reset, HT0580" is located in a well near the San Mateo Bridge West Fishing Pier, but it is different than historic tidal benchmarks called "Guano Island, 1851 (HT0579)", "Guano Island No. 61851 \& 1967 (HT0581)”, or “Guano Island No. 7, 1851 \& 1967 (HT2279)”.

Dumbarton East Fishing Pier (NOS Station 9414509): Four historic tidal benchmarks still exist, and two are listed in the NGS database with NAVD-88 elevations. NOS designates the primary benchmark as U553, 1956 (VM-8150) and assigns it an elevation of 7.290m MLLW. Secondary tidal benchmarks that still exist include V553, 1956 (VM8151), 4509K, 1996 (VM-13327), and 4509H, 1983 (VM-8154). Tidal benchmark 4509H, 1983 is Height Modernization control point DG6880.

Coyote Creek Transmission Towers (NOS Station 9414575): Five tidal benchmarks set by NOS on power transmission towers still exist and three are listed in the NGS database with approximate NAVD-88 elevations using VERTCON conversions. NOS designates the primary benchmark as TIDAL BM 1, 1975 (VM-8354) and assigns it elevation 5.518m MLLW. Secondary tidal benchmarks, their VM number, and PID number (if any) include:

\begin{tabular}{|c|c|c|}
\hline Tidal BM & NOS VM No. & NGS PID No \\
\hline$\overline{\text { Lag Bolt } 2}$ & $\overline{\text { VM-8356 }}$ & None \\
\hline D-555, 1956 & VM-8357 & HT1412 \\
\hline E-555, 1956 & VM-8358 & HT1413 \\
\hline H-555, 1956 & VM-8360 & HT1409 \\
\hline
\end{tabular}

Port of Redwood City (NOS Station 9414523): NOS maintains a continuously operating air-acoustic tide gauge at the Port of Redwood City, and designates the primary bench mark as Wharf 4, 1985 (VM-13856) located nearby. NOS assigns tidal benchmark Wharf 4, 1985 an elevation of 4.639m MLLW. 
Oyster Point Marina (NOS Station 9414392): One benchmark, Tidal BM 12, 1975 (VM8109 ), set by NOS during historical surveys of South San Francisco Bay still exists at Oyster Point Marina. NOS assigns Tidal BM 12, 1975 an elevation of 19.286m MLLW.

Alviso/Gold Street Bridge (NOS Station 9414551): One benchmark, Tidal BM 9, 1974 (VM-8347), set by NOS during historical surveys of South San Francisco Bay still exists on Gold Street Bridge in Alviso. NOS assigns Tidal BM 9, 1974 an elevation of $6.859 \mathrm{~m}$ MLLW.

Table 1 presents the results from the tidal benchmark survey. NOS used the survey results to define the MLLW-to-NAVD88 datum conversions for all areas of South San Francisco Bay, except Artesian Slough, Upper Mud Slough and Upper Coyote Creek.

\begin{tabular}{|c|c|c|}
\hline & SITE & Oyster Point Marina \\
\hline $\begin{array}{l}\text { INFORMATION OBTAINED } \\
\text { FROM NOS WEBSITE AT } \\
\text { http://tidesandcurrents. } \\
\text { noaa.gov }\end{array}$ & $\begin{array}{l}\text { Tidal Benchmark } \\
\text { NOAA Number } \\
\text { VM Number } \\
\text { MLLW Elevation }\end{array}$ & $\begin{array}{l}\text { Tidal BM 12, } 1975 \\
9414392 \\
8109 \\
63.27 \mathrm{ft}(19.286 \mathrm{~m})\end{array}$ \\
\hline $\begin{array}{l}\text { RESULTS FROM } 2005 \\
\text { LAND SURVEY BY } \\
\text { TUCKER \& ASSOCIATES } \\
\text { PLS \#4460 }\end{array}$ & $\begin{array}{l}\text { NAVD- } 88 \text { Elevation } \\
\text { Latitude WGS- } 84 \\
\text { Longitude WGS-84 } \\
\text { Methods } \\
\text { Month/Year of Survey } \\
\text { Elevations }\end{array}$ & $\begin{array}{l}62.82 \mathrm{ft}(19.147 \mathrm{~m}) \\
37^{\star} 39^{\prime} 44^{\prime \prime} \mathrm{N} \\
122^{\star} 23^{\prime} 13^{\prime \prime} \mathrm{W} \\
\text { Differential leveling from } \\
\text { nearby offset point set by } \\
2 \text { sessions of Static GPS } \\
\text { of 1-hour each separated } \\
\text { by 3-hours minimum. } \\
\text { July 2005. } \\
\text { Session 1: } 57.849^{\prime} \\
(17.632 \mathrm{~m}) \\
\text { Session 1: } 57.771^{\prime} \\
(17.609 \mathrm{~m})\end{array}$ \\
\hline $\begin{array}{l}\text { HEIGHT MODERNIZATION } \\
\text { CONTROL POINT USED } \\
\text { AS REFERENCE (from NGS } \\
\text { http://www.ngs.noaa.com) }\end{array}$ & $\begin{array}{l}\text { Height Mod. Control Pt. } \\
\text { PID Number } \\
\text { Elevation (NAVD-88) } \\
\text { Epoch }\end{array}$ & $\begin{array}{l}\text { Guano Island Reset } \\
\text { HT0580 } \\
11.38 \mathrm{ft}(3.468 \mathrm{~m}) \\
2002.75\end{array}$ \\
\hline $\begin{array}{l}\text { TIDE DATA } \\
\text { COLLECTED AT } \\
\text { SITE }\end{array}$ & $\begin{array}{l}\text { Tide Gauge Type } \\
\text { Data Duration } \\
\text { Vertical Datum } \\
\text { Data File Name(s) }\end{array}$ & $\begin{array}{l}\text { None } \\
\text { None } \\
\text { None } \\
\text { None }\end{array}$ \\
\hline
\end{tabular}

Table 1: Results from Survey of Tidal Benchmarks and Height Modernization Control Points. 
SITE Alviso - Gold Street Bridge Coyote Creek Tower \#1

Coyote Creek Tower \#2

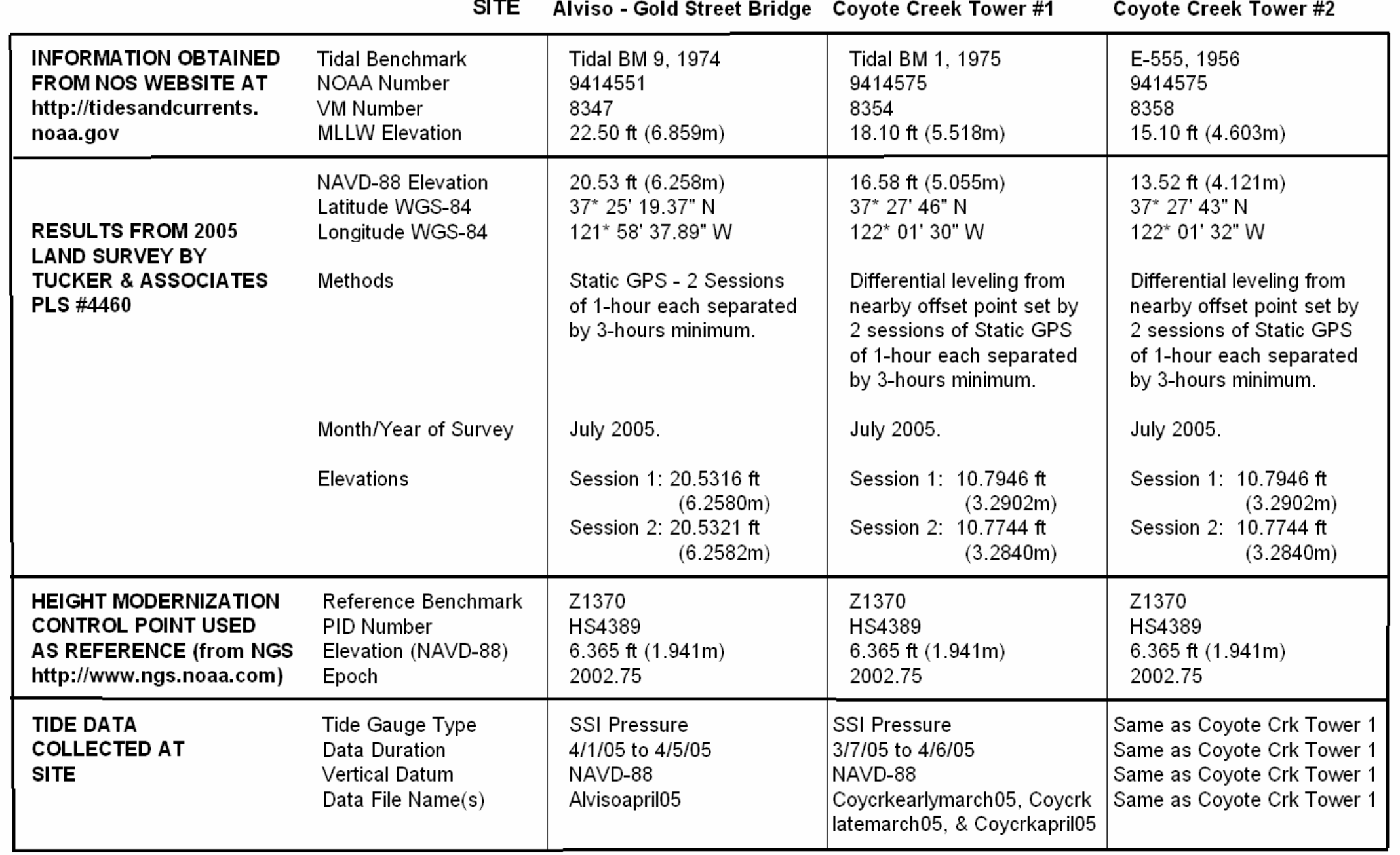

TABLE 1 (continued): Results from Survey of Tidal Benchmarks and Height Modernization Control Points. 


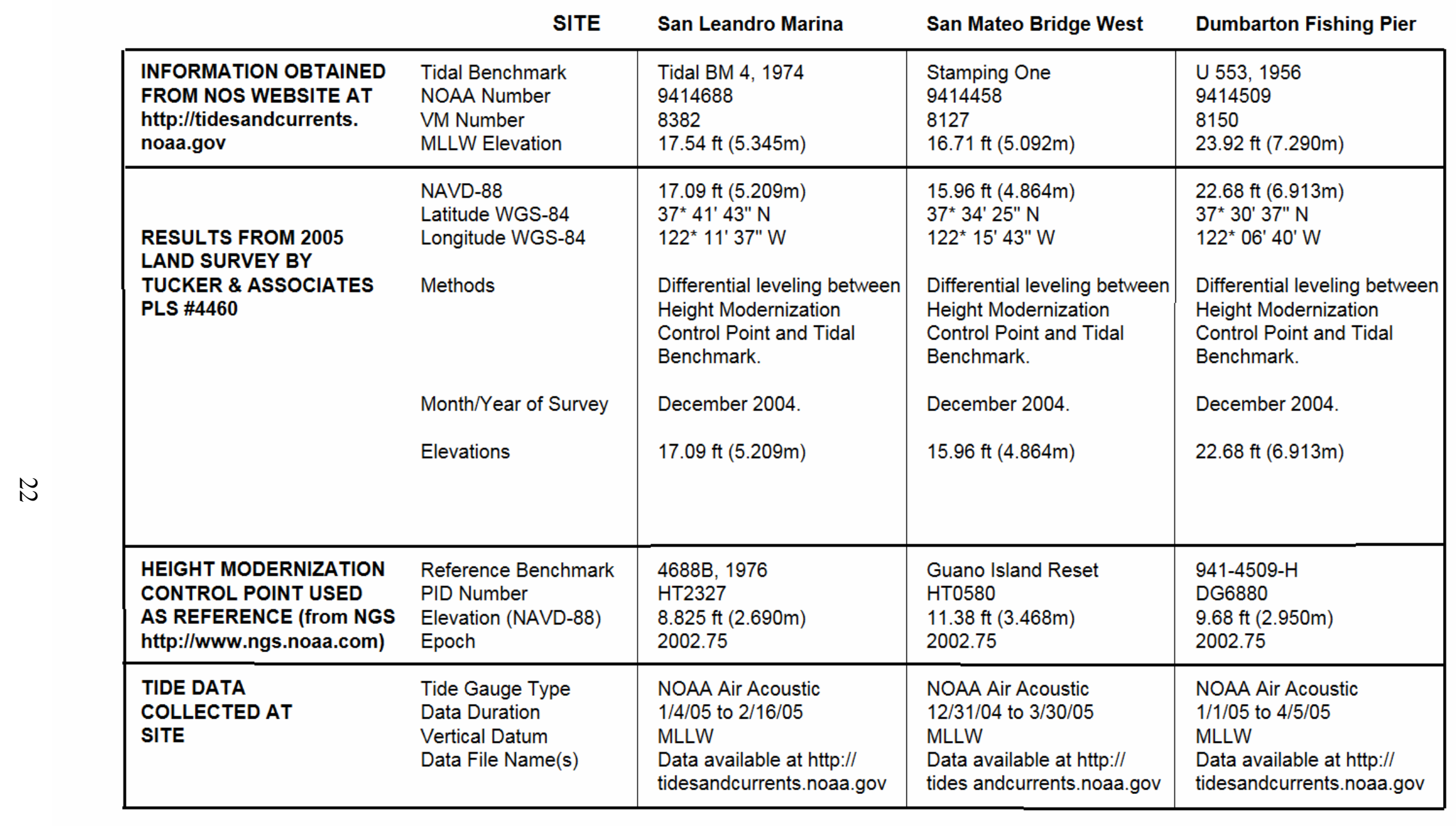

TABLE 1 (continued): Results from Survey of Tidal Benchmarks and Height Modernization Control Points. 


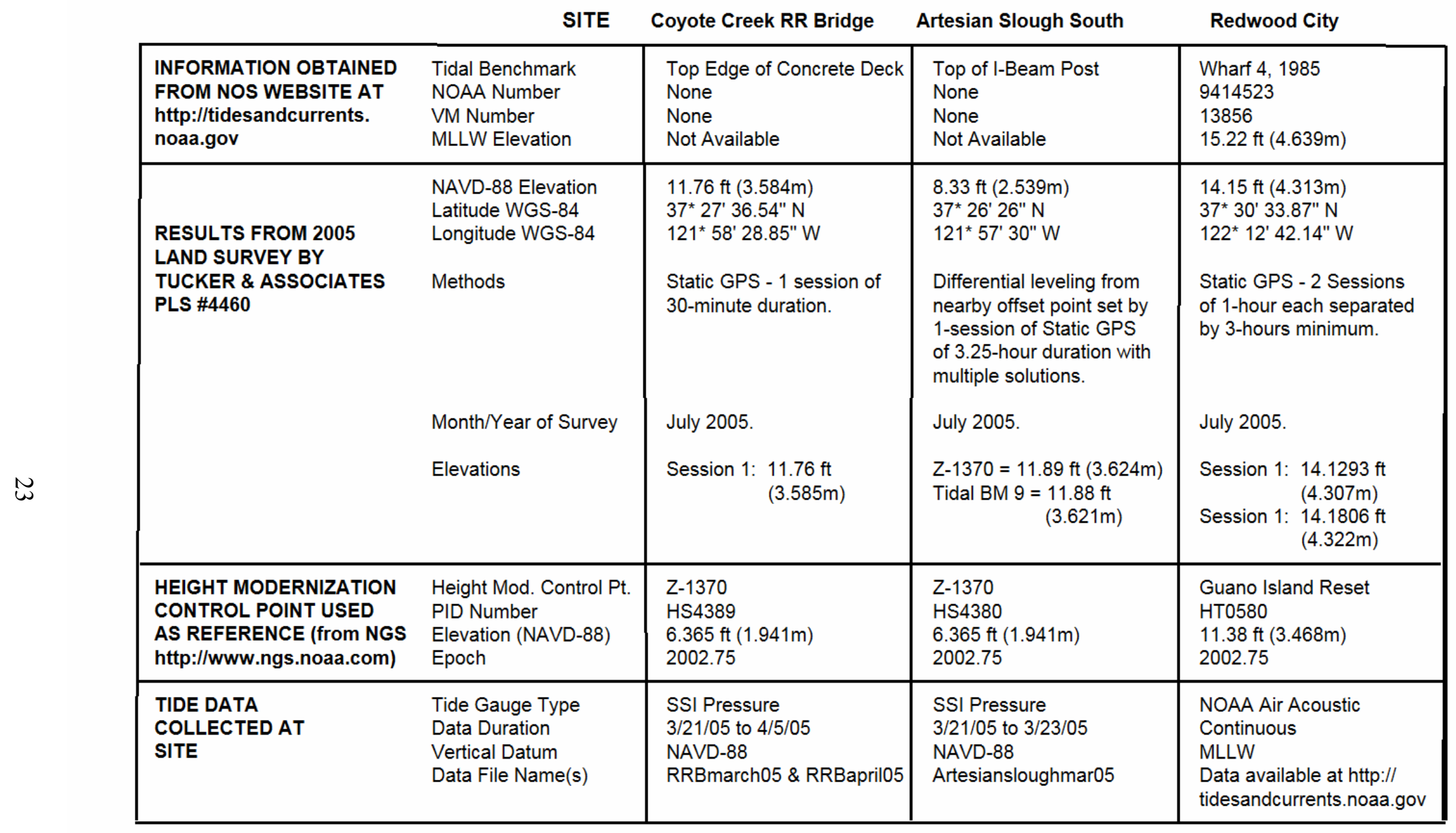

TABLE 1 (continued): Results from Survey of Tidal Benchmarks and Height Modernization Control Points. 


\subsection{Survey Schedule}

The hydrographic survey began on 10 January 2005 and finished on 5 April 2005. Table 2 provides a summary of the survey activities, including dates, zones, calibration results and data collected. The survey collected soundings and seabed classification data day and night, during optimal tide and weather conditions. Barcheck calibration of the survey-grade depthfinder occurred twice during each survey period (day and night) to the deepest depth available in the area. The seabed classification system collected data throughout South San Francisco Bay, but not in the shallow sloughs and creeks.

TABLE 2: Summary of survey dates, calibrations, and data collected in South San Francisco Bay

\begin{tabular}{|c|c|c|c|c|c|c|}
\hline Date & Shift & Tide Zone & $\begin{array}{c}\text { Speed } \\
\text { of } \\
\text { Sound } \\
\end{array}$ & $\begin{array}{c}\text { Max. Depth of } \\
\text { Pre- \& Post- } \\
\text { Barchecks } \\
\end{array}$ & Soundings & $\begin{array}{l}\text { Seabed } \\
\text { Classif- } \\
\text { ication }\end{array}$ \\
\hline $1 / 10 / 05$ & Day & SFB34 & 4850 & $10^{\prime} \& 10^{\prime}$ & $\mathrm{X}$ & $\mathrm{X}$ \\
\hline $1 / 12 / 05$ & Day & SFB34 & 4830 & $10^{\prime} \& 10^{\prime}$ & $\mathrm{X}$ & $X$ \\
\hline $1 / 13 / 05$ & Day & SFB34 & 4840 & $10^{\prime} \& 10^{\prime}$ & $X$ & $X$ \\
\hline $1 / 14 / 05$ & Day & SFB34, SFB37 & 4840 & $10^{\prime} \& 10^{\prime}$ & $\mathrm{X}$ & $\mathrm{X}$ \\
\hline $1 / 15 / 05$ & Day & SFB34, SFB35 & 4840 & $10^{\prime} \& 10^{\prime}$ & $\mathrm{X}$ & $\mathrm{X}$ \\
\hline $1 / 15 / 05$ & Night & SFB34, SFB35 & 4840 & $10^{\prime} \& 10^{\prime}$ & $\mathrm{X}$ & $\mathrm{X}$ \\
\hline $1 / 16 / 05$ & Day & SFB37 & 4840 & $10^{\prime} \& 10^{\prime}$ & $\mathrm{X}$ & $\mathrm{X}$ \\
\hline $1 / 16 / 05$ & Night & SFB35 & 4840 & 10'\& 40' & $X$ & $X$ \\
\hline $1 / 17 / 05$ & Day & SFB37 & 4840 & $10^{\prime} \& 35^{\prime}$ & $\mathrm{X}$ & $\mathrm{X}$ \\
\hline $1 / 17 / 05$ & Night & SFB35, SFB33 & 4840 & $15^{\prime} \& 30^{\prime}$ & $X$ & $X$ \\
\hline $1 / 18 / 05$ & Day & SFB37, SFB38 & 4840 & 10'\& 10' & $\mathrm{X}$ & $\mathrm{X}$ \\
\hline $1 / 18 / 05$ & Night & SFB36 & 4840 & $25^{\prime} \& 25^{\prime}$ & $\mathrm{X}$ & $\mathrm{X}$ \\
\hline $1 / 19 / 05$ & Day & SFB31, SFB37 & 4840 & $15^{\prime} \& 15^{\prime}$ & $X$ & $X$ \\
\hline $1 / 19 / 05$ & Night & SFB33 & 4840 & $25^{\prime} \& 40^{\prime}$ & $X$ & $\mathrm{X}$ \\
\hline $1 / 20 / 05$ & Day & SFB31, SFB37 & 4840 & $40^{\prime} \& 40^{\prime}$ & $X$ & $X$ \\
\hline $1 / 20 / 05$ & Night & SFB36 & 4840 & $45^{\prime} \& 35^{\prime}$ & $\mathrm{X}$ & $\mathrm{X}$ \\
\hline $1 / 21 / 05$ & Day & SFB37, SFB38 & 4840 & $40^{\prime} \& 40^{\prime}$ & $\mathrm{X}$ & $\mathrm{X}$ \\
\hline $1 / 21 / 05$ & Night & SFB36, SFB38 & 4840 & $20^{\prime} \& 50^{\prime}$ & $\mathrm{X}$ & $\mathrm{X}$ \\
\hline $1 / 22 / 05$ & Day & SFB37 & 4840 & $10^{\prime} \& 10^{\prime}$ & $\mathrm{X}$ & $\mathrm{X}$ \\
\hline $1 / 23 / 05$ & Day & SFB37, SFB38 & 4840 & $10^{\prime} \& 10^{\prime}$ & $\mathrm{X}$ & $\mathrm{X}$ \\
\hline $1 / 24 / 05$ & Day & SFB38 & 4840 & $35^{\prime} \& 45^{\prime}$ & $\mathrm{X}$ & $X$ \\
\hline
\end{tabular}




\begin{tabular}{|c|c|c|c|c|c|c|}
\hline $1 / 25 / 05$ & Day & SFB38 & 4840 & $45^{\prime} \& 45^{\prime}$ & $\mathrm{X}$ & $X$ \\
\hline $1 / 26 / 05$ & Day & SFB38, SFB39 & 4840 & $45^{\prime} \& 45^{\prime}$ & $\mathrm{X}$ & $\mathrm{X}$ \\
\hline $1 / 27 / 05$ & Day & SFB38, 39, 40 & 4840 & $45^{\prime} \& 45^{\prime}$ & $\mathrm{X}$ & $X$ \\
\hline $1 / 28 / 05$ & Day & SFB38, SFB39 & 4840 & $45^{\prime} \& 45^{\prime}$ & $\mathrm{X}$ & $X$ \\
\hline $2 / 02 / 05$ & Night & QC Survey Lines & 4860 & $35^{\prime} \& 35^{\prime}$ & $\mathrm{X}$ & X \\
\hline $2 / 03 / 05$ & Night & SFB34, 37,38,39 & 4860 & $10^{\prime}, 30^{\prime}, \& 45^{\prime}$ & $\mathrm{X}$ & $\mathrm{X}$ \\
\hline $2 / 04 / 05$ & Night & SFB39 & 4860 & $40^{\prime} \& 40^{\prime}$ & $\mathrm{X}$ & $\mathrm{X}$ \\
\hline $2 / 05 / 05$ & Night & SFB39 & 4860 & $25^{\prime} \& 25^{\prime}$ & $\mathrm{X}$ & $X$ \\
\hline $2 / 07 / 05$ & Day & SFB40, SFB42 & 4860 & $40^{\prime} \& 40^{\prime}$ & $\mathrm{X}$ & $X$ \\
\hline $2 / 08 / 05$ & Day & SFB39, SFB40 & 4860 & $40^{\prime} \& 40^{\prime}$ & $\mathrm{X}$ & $\mathrm{X}$ \\
\hline $2 / 09 / 05$ & Day & SFB40 & 4850 & $40^{\prime} \& 40^{\prime}$ & $\mathrm{X}$ & $\mathrm{X}$ \\
\hline $2 / 10 / 05$ & Day & SFB42 & 4860 & $35^{\prime} \& 35^{\prime}$ & $\mathrm{X}$ & X \\
\hline $2 / 11 / 05$ & Day & SFB42 & 4860 & $40^{\prime} \& 40^{\prime}$ & $\mathrm{X}$ & $\mathrm{X}$ \\
\hline $2 / 19 / 05$ & Day & SFB42, SFB43 & 4860 & $35^{\prime} \& 10^{\prime}$ & $\mathrm{X}$ & $\mathrm{X}$ \\
\hline $2 / 23 / 05$ & Day & SFB43 & 4860 & $40^{\prime} \& 40^{\prime}$ & $\mathrm{X}$ & $X$ \\
\hline $2 / 24 / 05$ & Day & SFB43, SFB & 4860 & $45^{\prime} \& 45^{\prime}$ & $\mathrm{X}$ & $\mathrm{X}$ \\
\hline $2 / 25 / 05$ & Day & SFB44 & 4860 & $15^{\prime} \& 15^{\prime}$ & $\mathrm{X}$ & $X$ \\
\hline $2 / 26 / 05$ & Day & SFB44 & 4860 & $20^{\prime} \& 15^{\prime}$ & $\mathrm{X}$ & $X$ \\
\hline $2 / 28 / 05$ & Day & $\mathrm{QC}$ lines & 4880 & $50^{\prime} \& 40^{\prime}$ & $\mathrm{X}$ & $\mathrm{X}$ \\
\hline $3 / 07 / 05$ & Day & SFB43 & 4880 & $50^{\prime} \& 45^{\prime}$ & $\mathrm{X}$ & X \\
\hline $3 / 08 / 05$ & Day & SFB44, SFB46 & 4880 & $20^{\prime} \& 30^{\prime}$ & $\mathrm{X}$ & $X$ \\
\hline $3 / 09 / 05$ & Day & SFB46, SFB47 & 4870 & $15^{\prime} \& 30^{\prime}$ & $\mathrm{X}$ & $\mathrm{X}$ \\
\hline $3 / 10 / 05$ & Day & SFB44 & 4870 & $15^{\prime} \& 15^{\prime}$ & $X$ & $X$ \\
\hline $3 / 11 / 05$ & Day & Coyote Creek & 4800 & $15^{\prime} \& 15^{\prime}$ & $\mathrm{X}$ & \\
\hline $3 / 12 / 05$ & Day & $\begin{array}{l}\text { Ravenswood } \\
\text { Slough (recon) }\end{array}$ & 4800 & $10^{\prime} \& 10^{\prime}$ & $\mathrm{X}$ & \\
\hline $3 / 22 / 05$ & Day & $\begin{array}{l}\text { Coyote Creek \& } \\
\text { Artesian Slough }\end{array}$ & 4770 & $10^{\prime} \& 10^{\prime}$ & $\mathrm{X}$ & \\
\hline $3 / 24 / 05$ & Day & Coyote Creek & 4700 & $10^{\prime} \& 10^{\prime}$ & X & \\
\hline $3 / 25 / 05$ & Day & Mud Slough & 4700 & $10^{\prime} \& 10^{\prime}$ & $\mathrm{X}$ & \\
\hline $3 / 26 / 05$ & Day & $\begin{array}{l}\text { Ravenswood } \\
\text { Slough }\end{array}$ & 4700 & $5^{\prime} \& 10^{\prime}$ & $\mathrm{X}$ & \\
\hline $4 / 05 / 05$ & Day & Alviso Slough & 4720 & $10^{\prime} \& 10^{\prime}$ & $\mathrm{X}$ & \\
\hline
\end{tabular}

TABLE 2: Summary of survey dates, calibrations, and data collected in South San Francisco Bay 


\subsection{Survey Personnel}

The Field Survey Leader for the hydrographic survey is Mr. Steve Sullivan. Mr. Sullivan is Vice-President of Sea Surveyor, Inc. and he is responsible for overall sounding accuracy. Mr. Sullivan helmed the survey vessel at night, and inspected the depth and navigation data collected during the day to ensure pre- and post-survey calibrations are within tolerance.

Two teams comprised of two members each conducted the hydrographic survey. One team surveyed during the day, while the second team used the same boat and survey equipment to survey at night. Survey crewmembers included:

Steve Sullivan

Scott Cross

James Ramber

Shawn Emard
Field Survey Leader \& Vessel Operator (night shift)

Vessel Operator (day shift)

Navigator/Sonar Operator (night shift)

Navigator/Sonar Operator (day shift) 25-years experience

15-years experience

40-years experience

7 -years experience

Mr. Karl Rhynas of Quester-Tangent Corporation installed and tested the $50 \mathrm{kHz}$ seabed classification system aboard the survey vessel. Mr. Tom Hamel and Mr. Matt Tanner of Sea Surveyor, Inc. installed and maintained the air acoustic and pressure-sensing tide gauges. Mr. Tom Tucker, California-registered land surveyor No. 4460, used optical and GPS techniques per NOAA specifications to determine the elevation of the air acoustic and pressure-sensing tide gauges. Mr. Tucker also used GPS techniques and first-order Height Modernization benchmarks to determine the NAVD-88 elevation of NOS tidal benchmarks.

Mr. Manoj Samant managed NOAA's involvement in the South San Francisco Bay hydrographic survey. Mr. Samant coordinated the activities of the Contractor in numerous tasks to ensure results meet NOAA standards for water level measurements. Mr. Samant provided the Contractor with the location of historic tidal benchmarks and proper methods for surveying using optical and GPS methods. Mr. Samant advised the land surveyor on how to determine the elevation of the air-acoustic tide gauges, and he coordinated the loan of NOAA's air-acoustic sensors. Mr. Samant also coordinated NOAA's analytical efforts to define the MLLW vertical datum and NAVD-88 conversions for South San Francisco Bay.

Mr. Tom Mero, Chief of the CO-OPS Requirements and Development Division, reviewed the scope of work prepared by USGS for the hydrographic survey and provided specific instructions regarding the proper location of the tide monitoring stations and need to use tidal zonation for correcting the soundings. Mr. Clyde Kakazu of NOAA's Pacific Operation Branch in Seattle, Washington made a site visit with the Contractor to tide gauge locations in South San Francisco Bay and provided valuable insight into installation methods, problems, and solutions. Mr. Phil Labraro of NOAA's Field Operations Division in Chesapeake, Virginia programmed the air acoustic tide gauges and provided technical advice on proper installation and use of the instruments. NOAA's Mr. Tom Landon, and others, prepared, tested and shipped the tide gauges to the Contractor. 


\section{ANALYTICAL METHODS}

After completing each day of the field hydrographic survey, the Contractor copied the sounding and navigation data on to a compact disk (CD) and transferred the data to their office in Benicia, California for review and processing. In the office, raw soundings are edited to remove extraneous depth and navigation spikes and tide corrections are applied to reduce the soundings to a common vertical datum. Initially, soundings in South San Francisco Bay were referenced to MLLW, while soundings in the sloughs and creeks were referenced to NAVD-88. The South Bay soundings were then converted to the NAVD-88 vertical datum, and the slough/creek soundings converted to MLLW (where available), using NOAA-provided conversions.

The following sections describe the vertical datum conversions, tide data, and tide zonation scheme used for the South San Francisco Bay hydrographic survey.

\subsection{Vertical Datum Conversions}

A California-registered land surveyor used fast-static GPS techniques referenced to first order Height Modernization benchmarks to determine the NAVD-88 elevation of NOAA tidal benchmarks throughout South San Francisco Bay. After evaluating the NAVD-88 elevation of South Bay tidal benchmarks, NOAA (2006) developed the datum conversions between MLLW and NAVD-88 for tide zones in South San Francisco Bay (Table 3).

Using the NOAA-provided datum conversions, South Bay soundings referenced to MLLW can be converted to NAVD-88 and the slough/creek soundings referenced to NAVD-88 can be converted to MLLW. NAVD-to-MLLW conversions are approximated for Tide Zones 51-54, which includes Artesian Slough, the upstream-most portion of Mud Slough, and the upstreammost portion of Coyote Creek. Located at the edge of tidal influence, these areas have insufficient water at low tide for gauges to operate, making defining the MLLW datum difficult.

Table 3: Vertical Datum Conversions by Tide Zone for South San Francisco Bay (NOAA, 2006).

\begin{tabular}{|c|c|c|c|c|c|}
\hline $\begin{array}{l}\text { Tidal } \\
\text { Zone }\end{array}$ & $\begin{array}{l}\text { NAVD- } 88 \\
\text { above MLLW }\end{array}$ & $\begin{array}{l}\text { Control } \\
\text { Station } \\
\end{array}$ & $\begin{array}{l}\text { Tidal } \\
\text { Zone }\end{array}$ & $\begin{array}{l}\text { NAVD- } 88 \\
\text { above MLLW }\end{array}$ & $\begin{array}{l}\text { Control } \\
\text { Station }\end{array}$ \\
\hline SFB28 & $\overline{0.4^{\prime}(12 \mathrm{~cm})}$ & $\overline{9414688}$ & $\overline{\text { SFB44 }}$ & $\overline{1.3^{\prime}(40 \mathrm{~cm})}$ & $\overline{9414509}$ \\
\hline SFB29 & $0.5^{\prime}(15 \mathrm{~cm})$ & 9414688 & SFB45 & $1.4^{\prime}(43 \mathrm{~cm})$ & 9414509 \\
\hline SFB30 & $0.5^{\prime}(15 \mathrm{~cm})$ & 9414688 & SFB46 & $1.4^{\prime}(43 \mathrm{~cm})$ & 9414509 \\
\hline SFB31 & $0.5^{\prime}(15 \mathrm{~cm})$ & 9414688 & SFB47 & $1.5^{\prime}(46 \mathrm{~cm})$ & 9414509 \\
\hline SFB32 & $0.5^{\prime}(15 \mathrm{~cm})$ & 9414688 & SFB48 & $1.6^{\prime}(49 \mathrm{~cm})$ & 9414509 \\
\hline SFB33 & $0.6^{\prime}(18 \mathrm{~cm})$ & 9414688 & SFB49 & $1.7^{\prime}(52 \mathrm{~cm})$ & 9414509 \\
\hline SFB34 & $0.6^{\prime}(18 \mathrm{~cm})$ & 9414688 & SFB50 & $1.7^{\prime}(52 \mathrm{~cm})$ & 9414509 \\
\hline SFB35 & $0.6^{\prime}(18 \mathrm{~cm})$ & 9414688 & SFB51 & $1.8^{\prime}-2.0^{\prime}(55-61 \mathrm{~cm})$ & 9414509 \\
\hline SFB36 & $0.6^{\prime}(18 \mathrm{~cm})$ & 9414688 & SFB52 & $1.8^{\prime}-2.0^{\prime}(55-61 \mathrm{~cm})$ & 9414509 \\
\hline SFB37 & $0.7^{\prime}(21 \mathrm{~cm})$ & 9414458 & SFB53 & $1.8^{\prime}-2.0^{\prime}(55-61 \mathrm{~cm})$ & 9414509 \\
\hline SFB38 & $0.8^{\prime}(24 \mathrm{~cm})$ & 9414458 & SFB54 & $1.8^{\prime}-2.0^{\prime}(55-61 \mathrm{~cm})$ & 9414509 \\
\hline SFB39 & $0.9^{\prime}(27 \mathrm{~cm})$ & 9414458 & SFB55 & $1.6^{\prime}(49 \mathrm{~cm})$ & 9414509 \\
\hline SFB40 & $1.0^{\prime}(30 \mathrm{~cm})$ & 9414523 & SFB56 & $1.8^{\prime}(55 \mathrm{~cm})$ & 9414509 \\
\hline SFB41 & $1.1^{\prime}(34 \mathrm{~cm})$ & 9414523 & SFB57 & $2.0^{\prime}(61 \mathrm{~cm})$ & 9414509 \\
\hline SFB42 & $1.1^{\prime}(34 \mathrm{~cm})$ & 9414523 & SFB58 & $1.6^{\prime}(49 \mathrm{~cm})$ & 9414509 \\
\hline SFB43 & $1.2^{\prime}(37 \mathrm{~cm})$ & 9414509 & SFB59 & $1.8^{\prime}(55 \mathrm{~cm})$ & 9414509 \\
\hline
\end{tabular}




\subsection{Tide Data Analyses}

Air-acoustic tide gauges measured water surface elevation at 6-minute intervals at San Leandro Marina, San Mateo Bridge, and Dumbarton Bridge and transmitted the data directly to NOAA via the GOES satellite. The air-acoustic tide data is referenced to MLLW. Tides in the sloughs and creeks were also measured at 6-minute intervals, but referenced to the NAVD-88 vertical datum. The following sections describe the analytical techniques used to correct the soundings for tide in South San Francisco Bay and the sloughs/creeks.

\subsubsection{Tides in South San Francisco Bay}

The tide data for San Leandro Marina, San Mateo Bridge, and Dumbarton Bridge is available in sequential or tabulated form, or can be viewed as a plot, on NOAA's CO-OPS website (http://tidesandcurrents.noaa.gov).

To retrieve the water level data from the CO-OPS website, select HISTORIC TIDE DATA from the PRODUCT menu and set SIX MINUTE WL for the time interval and MLLW as the datum. The tide data is available in either feet or meters, with time available in either Greenwich Mean or local standard. The tide stations and their duration of measurement include:

\begin{tabular}{|c|c|c|c|}
\hline LOCATION & STATION NO. & BEGIN TIME/DATE & END TIME/DATE \\
\hline San Leandro Marina & 99414688 & $11: 00 \mathrm{hrs}$ on $1 / 04 / 05$ & $\overline{13: 54 \mathrm{hrs} \text { on } 2 / 16 / 05}$ \\
\hline vest side & 9414458 & $16: 00 \mathrm{hrs}$ on $12 / 31 / 04$ & $23: 54 \mathrm{hrs}$ on $3 / 30 / 05$ \\
\hline Dumbarton Bridge, east side & 9414509 & 00:00 hrs on $1 / 01 / 05$ & $13: 54 \mathrm{hrs}$ on $4 / 05 / 05$ \\
\hline
\end{tabular}

NOAA processed the tide data, computed the tidal datum, and defined the tide zones (NOAA, 2006) using engineering and oceanographic practices specified in the NOS Hydrographic Survey Manual (NOS, 2003a). NOAA computed the MLLW datum for South San Francisco Bay after reviewing a minimum of 30 continuous days of tide data from San Leandro Marina, San Mateo Bridge, and Dumbarton Bridge. NOAA used tide data from their permanent gauges in Alameda (Station 9414750) and Redwood City (Station 9414523) as datum control.

After processing and reviewing the tide data, NOAA divided South San Francisco Bay into discrete "tide zones" (Figure 9). The height of tide in each zone is calculated by applying a timeand range-multiplier (Table 4) to actual tides measured at the controlling gauge. Boundary coordinates for the tide zones are listed as an Appendix in Section 7 of this report.

\subsubsection{Tides in Sloughs and Creeks}

Tides in the sloughs and creeks of South San Francisco Bay were monitored at multiple locations simultaneously during the hydrographic survey using pressure-sensing tide gauges referenced to NAVD-88.

After the internal-recorded data is downloaded from the tide gauge in the field, the barometric pressure data is subtracted from the underwater pressure data. Pressure data is then converted to water surface elevation using equations provided by the manufacturer based on sensor calibration immediately prior to beginning the hydrographic survey. The accuracy of the electronic tide data is checked against multiple manual tide measurements collected for quality control purposes during the field survey. Tides are manually measured using a weighed tape to determine the vertical distance between the water surface and a nearby benchmark. 
Table 4: Time- and Range-Correctors and Controlling Tide Stations for Tide Zones in South San Francisco Bay (*modified from NOAA, 2006).

\begin{tabular}{|c|c|c|c|}
\hline & Time (min) & Range & Tide \\
\hline Zone & Corrector & Corrector & Station \\
\hline$\overline{\text { SBF2 } 8}$ & -24 & $\overline{x 0.93}$ & $\overline{9414688}$ \\
\hline SBF29 & -18 & $\mathrm{x} 0.95$ & 9414688 \\
\hline SFB30 & -12 & $\mathrm{x} 0.95$ & 9414688 \\
\hline SBF31 & -6 & $\mathrm{x} 0.97$ & 9414688 \\
\hline SBF31A & 0 & $\mathrm{x} 1.00$ & 9414688 \\
\hline SBF32 & -18 & $\mathrm{x} 0.97$ & 9414688 \\
\hline SFB33 & -18 & x0.99 & 9414688 \\
\hline SFB34 & -6 & x0.99 & 9414688 \\
\hline SBF35 & -6 & $\mathrm{x} 1.01$ & 9414688 \\
\hline SBF36 & -12 & $\mathrm{x} 1.01$ & 9414688 \\
\hline SFB37 & 0 & $\mathrm{x} 0.98$ & 9414458 \\
\hline SFB38 & +6 & $\mathrm{x} 1.01$ & 9414458 \\
\hline SFB39 & +12 & $\mathrm{x} 1.03$ & 9414458 \\
\hline SFB40 & -6 & x0.94 & 9414509 \\
\hline SBF41 & -6 & $\mathrm{x} 0.95$ & 9414509 \\
\hline SFB42 & 0 & $\mathrm{x} 0.97$ & 9414509 \\
\hline SFB43 & +6 & $\mathrm{x} 1.00$ & 9414509 \\
\hline SFB44 & $+7 *$ & $\mathrm{x} 1.03$ & 9414509 \\
\hline SFB46 & $+8^{*}$ & $\mathrm{x} 1.06$ & 9414509 \\
\hline
\end{tabular}

Figure 9: Tide Zones and Controlling Tide Stations (NOAA, 2006).

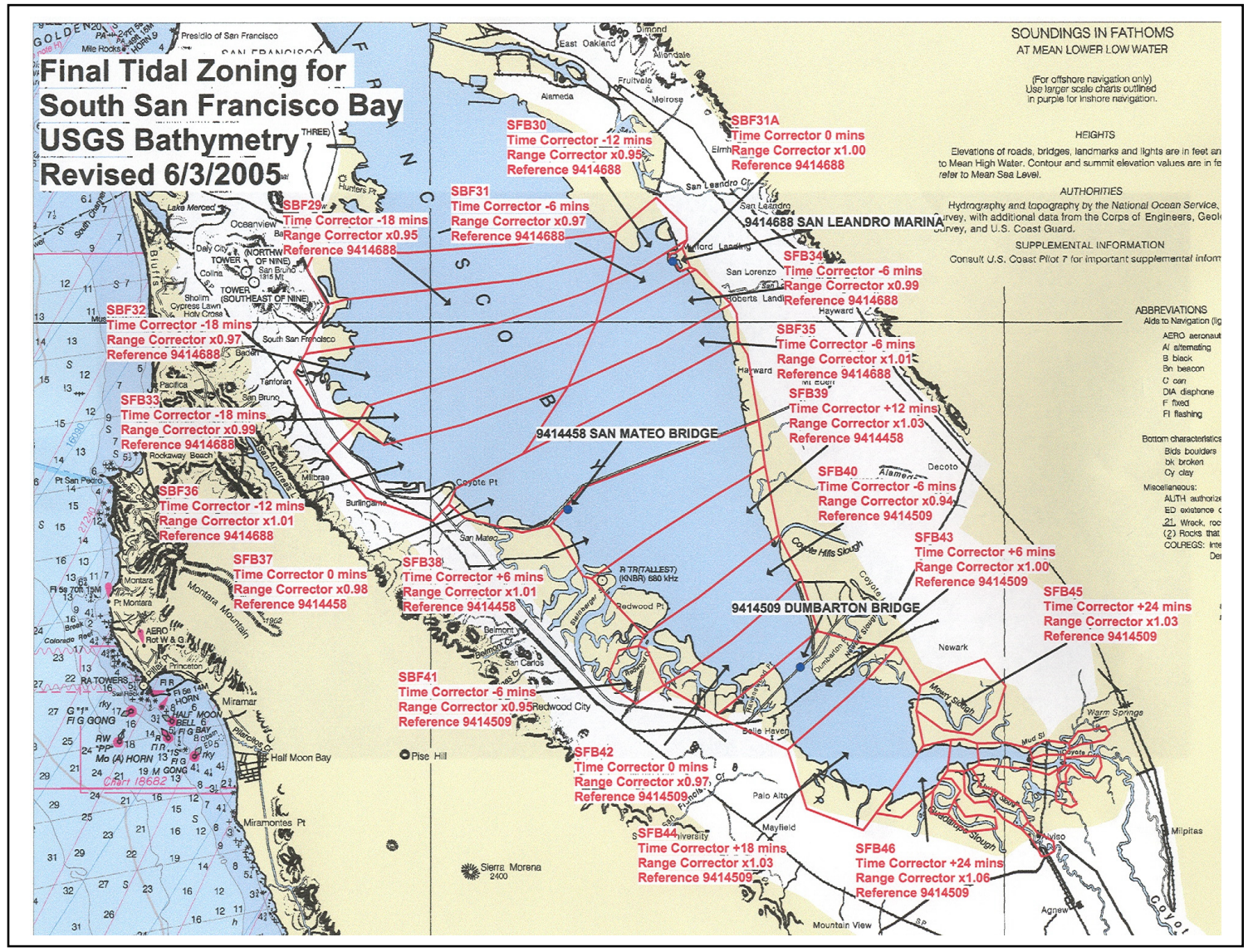


Water level measurements were collected at four locations shown in Figure 10, including PG\&E tower at Coyote Creek (NOAA Station 9414575), Gold Street Bridge in Alviso Slough (NOAA Station 9414551), south end of Artesian Slough (at unpaved boat ramp downstream of discharges at wastewater treatment plant), and Railroad Bridge in Coyote Creek. Tide data duration is presented below:

\begin{tabular}{|c|c|c|c|}
\hline LOCATION & $\underline{\text { STATION }}$ & $\underline{B E G I N / E N D ~ D A T E}$ & FILE NAME (.tid) \\
\hline \multirow[t]{3}{*}{ PG\&E Tower in Coyote Creek } & 9414575 & $3 / 7 / 05$ to $3 / 19 / 05$ & Coycrkearlymarch05 \\
\hline & & $3 / 20 / 05$ to $3 / 31 / 05$ & Coycrklatemarch05 \\
\hline & & $4 / 1 / 05$ to $4 / 6 / 05$ & Coycrkapril05 \\
\hline \multirow[t]{2}{*}{ Railroad Bridge over Coyote Creek } & -- & $3 / 21 / 05$ to $3 / 31 / 05$ & Rrbmarch05 \\
\hline & & $4 / 1 / 05$ to $4 / 5 / 05$ & Rrbapril05 \\
\hline Artesian Slough boat ramp (dirt) & -- & $3 / 21 / 05$ to $3 / 23 / 05$ & Artesiansloughmar05 \\
\hline Gold Street Bridge & 9414551 & $4 / 1 / 05$ to $4 / 5 / 05$ & Alvisoapril05 \\
\hline
\end{tabular}

To determine the tide corrector to apply to cross-sectional soundings in South Bay sloughs and creeks, the tide measured by gauges upstream and downstream of the cross-section is interpolated based upon the location of the cross-section in relation to the location of the tide gauges. If an upstream gauge is not available, the tide measured by the downstream gauge is modified based upon the wave velocity and exaggeration observed in other South Bay sloughs and creeks. The following paragraphs provide a zone-by-zone description of the analytical methods used to make tide corrections for referencing the soundings collected in the sloughs and creeks to the NAVD-88 vertical datum. Boundary coordinates are provided in Section 7.

Zone SFB43: Area centered on Dumbarton Bridge. Soundings referenced to MLLW using NOAA Tide Station 9414509 (Dumbarton) with time corrector of +6 minutes and range corrector of $x 1.00$, then converted to NAVD- 88 by subtracting $0.37 \mathrm{~m}$.

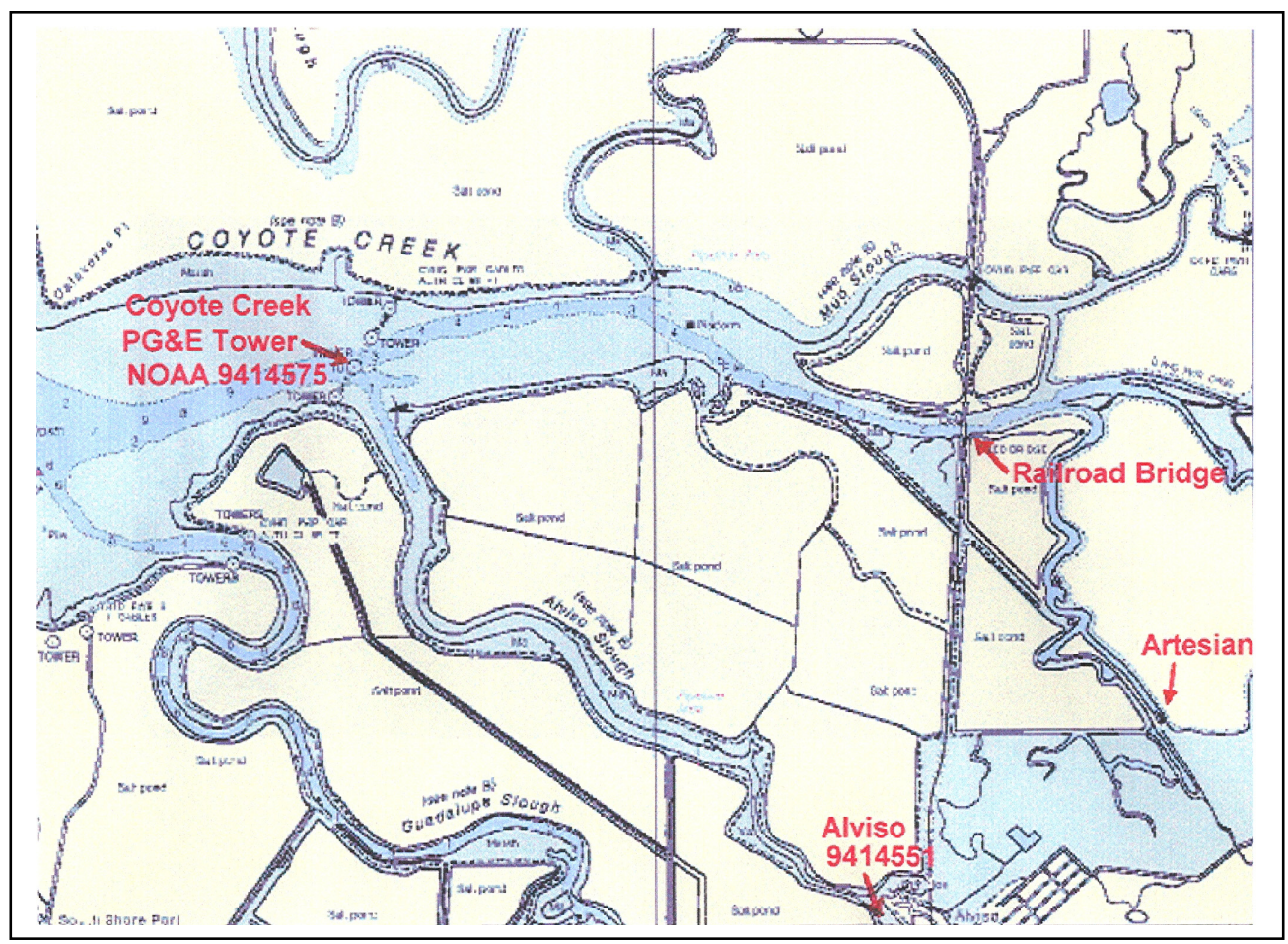

Figure 10: Location of pressure-sensing tide gauges in South Bay sloughs and creeks. 
Zone SFB44: Boundary coordinates provided in Section 7. Soundings referenced to MLLW using NOAA Tide Station 9414509 (Dumbarton) with a time corrector of +7 minutes and a range corrector of $\mathrm{x} 1.03$, then converted to NAVD- 88 by subtracting $0.4 \mathrm{~m}$.

Zone SFB46: Boundary coordinates provided in Section 7. Soundings referenced to MLLW using NOAA Tide Station Dumbarton with a time corrector of +8 minutes and a range corrector of $\mathrm{x} 1.06$, then converted to NAVD- 88 by subtracting $0.43 \mathrm{~m}$.

Zone SFB47: Boundary coordinates provided in Section 7. March 9 and April 5 soundings referenced to NAVD88 using a pressure gauge at Coyote Creek Tower, then converted to MLLW by adding $0.46 \mathrm{~m}$.

Zone SFB48: Coyote Creek from east of Electrical Towers to mouth of Mud Slough. March 11 soundings referenced to NAVD88 using a pressure gauge at Coyote Creek Tower with a time corrector of +3 minutes and a range corrector of $x 1.01$, then converted to MLLW by adding $0.49 \mathrm{~m}$. March 25 soundings referenced to NAVD88 using an upstream pressure gauge at the Railroad Bridge and a downstream pressure gauge at Coyote Creek Tower, then converted to MLLW by adding $0.49 \mathrm{~m}$.

Zone SFB49: Mouth of Mud Slough. March 25 soundings referenced to NAVD88 using an upstream pressure gauge at the Railroad Bridge and a downstream pressure gauge at Coyote Creek Tower, then converted to MLLW by adding $0.52 \mathrm{~m}$.

Zone SFB50: Coyote Creek, centered on Railroad Bridge. March 11 soundings referenced to NAVD88 using a pressure gauge at Coyote Creek Tower with a time corrector of +6 minutes and a range corrector of $x 1.02$, then converted to MLLW by adding $0.52 \mathrm{~m}$. March 22 soundings in Coyote Creek referenced to NAVD88 using a pressure gauge at the Railroad Bridge, then converted to MLLW by adding $0.52 \mathrm{~m}$. March 22 soundings in Artesian Slough referenced to NAVD88 using a pressure gauge at the Railroad Bridge, then converted to MLLW by adding $0.52 \mathrm{~m}$. March 24 soundings in Coyote Creek referenced to NAVD88 using a pressure gauge at the Railroad Bridge, then converted to MLLW by adding $0.52 \mathrm{~m}$.

Zone SFB51: Upstream portion of Mud Slough. March 25 soundings in Mud Slough referenced to NAVD88 using a pressure gauge at the Railroad Bridge. Conversion from NAVD88 to MLLW is estimated at $0.55 \mathrm{~m}-0.61 \mathrm{~m}$ and has not been applied to the soundings.

Zone SFB52: Upstream portion of Coyote Creek. March 24 soundings in Coyote Creek referenced to NAVD88 using a pressure gauge at the Railroad Bridge. Conversion from NAVD88 to MLLW is estimated at $0.55 \mathrm{~m}-0.61 \mathrm{~m}$ and has not been applied to the soundings.

Zone SFB53: Downstream portion of Artesian Slough. March 22 soundings in Artesian Slough referenced to NAVD88 using an upstream pressure gauge in Artesian Slough and a downstream pressure gauge at the Railroad Bridge. Conversion from NAVD88 to MLLW is estimated at $0.55 \mathrm{~m}-0.61 \mathrm{~m}$ and has not been applied to the soundings. 
Zone SFB54: Upstream portion of Artesian Slough. March 22 soundings in Artesian Slough referenced to NAVD88 using an upstream pressure gauge in Artesian Slough and a downstream pressure gauge at the Railroad Bridge. Conversion from NAVD88 to MLLW is estimated at $0.55 \mathrm{~m}-0.61 \mathrm{~m}$ and has not been applied to the soundings.

Zone SFB55: Downstream portion of Alviso Slough. April 5 soundings in Alviso Slough referenced to NAVD88 using an upstream pressure gauge in Alviso Slough and a downstream pressure gauge at the Coyote Creek Tower, then converted to MLLW by adding $0.49 \mathrm{~m}$.

Zone SFB56: Middle portion of Alviso Slough. April 5 soundings in Alviso Slough referenced to NAVD88 using an upstream pressure gauge in Alviso Slough and a downstream pressure gauge at the Coyote Creek Tower, then converted to MLLW by adding $0.55 \mathrm{~m}$.

Zone SFB57: Upstream Portion of Alviso Slough. April 5 soundings in Alviso Slough referenced to NAVD88 using an upstream pressure gauge in Alviso Slough and a downstream pressure gauge at the Coyote Creek Tower, then converted to MLLW by adding $0.61 \mathrm{~m}$.

The tide data collected in South San Francisco Bay sloughs and creeks is in feet, referenced to the NAVD-88 vertical datum and available in MICROSOFT EXCEL format. The tide data collected in the sloughs and creeks was also delivered in metadata format to the San Francisco District, Corps of Engineers for inclusion with their South Bay Shoreline Study.

\subsection{Plotting and Checking of Tide-Corrected Soundings}

The field survey was organized in a manner that simplified correcting the soundings for tide and provided a quality control check on sounding precision (repeatability). Planned survey lines were separated into individual tide zones, with the planned survey lines overlapping 100m into adjacent tide zones. Overlapping 100m into adjacent tide zones allow redundant soundings to be collected for $200 \mathrm{~m}$ along each survey line around the boundaries of the tide zones. The $200 \mathrm{~m}$ of overlapping soundings around the boundaries of the tide zones provide an effective tool for assessing the precision (repeatability) of soundings collected at different times, different tidal stages, and processed using different time- and range-correctors from controlling tide stations.

The soundings are edited and corrected for tide using the time- and range-corrector for the appropriate zone. After applying tide corrections, soundings are thinned in preparation for plotting. Soundings must be thinned because raw soundings, spaced at approximate $0.15 \mathrm{~m}$ intervals, are too dense to be legible when plotted. To fit the soundings from individual tide zones on E-size paper (24" $\mathrm{x} 36$ ") paper, soundings are thinned to a spacing of $5 \mathrm{~m}$ intervals and plotted at scale 1:2,400 (1"=200').

After plotting, the soundings are carefully examined, especially at the intersection of "tie line" soundings collected specifically for quality control purposes along tracklines oriented perpendicular to the primary survey lines. Soundings are manually contoured at 2' depth intervals to ensure all soundings within each tide zone receive equal examination.

After the soundings in each tide zone are plotted, contoured, examined, and proven to be internally consistent, the soundings from all tide zones are combined so that overlapping 
soundings around the tide zone boundaries can be examined. The soundings are considered correct when overlapping soundings from adjacent tide zones match within Order 1 standards. If overlapping soundings from adjacent tide zones do not match within tolerance, the soundings from both non-agreeing tide zones undergo a rigorous quality control check. If the soundings in non-agreeing tide zones pass their respective quality control checks, then the tide corrector is likely in error and requires adjustment. For example, NOAA reviewed and modified the timeand range-correctors and controlling tide station for Tide Zones 38-42 between the San Mateo and Dumbarton Bridges after the Contractor found that the overlapping soundings from these tide zones did not match. After NOAA lowered the influence of the Redwood City station and modified the time- and range correctors for Zones 38-42, the Contractor re-applied the revised tides to the raw soundings and the overlapping soundings for these zones matched within tolerance.

\subsection{Delivery of Final Soundings and Other Products}

A MICROSOFT EXCEL spreadsheet was developed for each tide zone in South San Francisco Bay listing the horizontal coordinates, MLLW elevation, and NAVD-88 elevation of each sounding. After passing all quality control checks, the final high-frequency $(200 \mathrm{kHz})$ soundings were delivered to the USGS Pacific Science Center in Santa Cruz, California. Final soundings were thinned to $1 \mathrm{~m}$ intervals and grouped by zone in $\mathrm{x}, \mathrm{y}, \mathrm{z}$ format on CD disks referenced to Zone 10 North of the Universal Transverse Mercator (UTM) 1983 grid. Final soundings are referenced vertically to both NAVD-88 and MLLW, where possible.

Other data delivered to USGS include:

- Tide data collected at 6-minute intervals by multiple pressure-sensing gauges in the sloughs and creeks of South San Francisco Bay.

- Raw (un-edited, un-corrected for tide) soundings spaced at nominal $0.15 \mathrm{~m}$ intervals,

- Digital depthfinder records, including all barcheck calibrations, in .pcx format.

Quester Tangent, the manufacturer of the seabed classification system, processed the lowfrequency $(50 \mathrm{kHz})$ data and developed a map of acoustic diversity for South San Francisco Bay showing the seabed segmented into acoustically similar units. The low-frequency $(50 \mathrm{kHz})$ soundings were delivered to USGS in time-tagged, draft-corrected x,y,z format without correcting for tide. Quester Tangent's report on the processing and results from the lowfrequency seabed classification survey of South San Francisco Bay is presented in Section 8.

\subsection{Analytical Personnel}

Dr. Bruce Jaffe of the USGS Pacific Science Center prepared the scope of work for the South San Francisco Bay hydrographic survey, established the goals for the project, and served as Federal sponsor to obtain NOAA's support.

After the raw soundings are collected, Ms. Shannon Emard of Sea Surveyor, Inc. used a graphics editor to review the depth and navigation data and remove any spikes or incorrect data. Ms. Emard then used Microsoft EXCEL software to correct the soundings for tide and convert from MLLW to NAVD-88 using methods prescribed by NOAA, 2006. Mr. Shawn Emard of Sea Surveyor, Inc. conducted a second edit of the soundings to ensure that the processed data was correct. He also checked that all tide corrections and datum conversions had been properly made. Mr. Steve Sullivan, Survey Manager, conducted a final check on the soundings and prepared this QC Report. 
Mr. Tom Mero, Chief of NOAA's Center for Operational Oceanographic Products and Services (CO-OPS) Requirements and Development Division, provided specific instructions regarding analytical techniques and the tide zonation scheme to be used for correcting the soundings. Mr. Craig Martin of NOAA analyzed the tide data, defined the boundaries and time- and rangecorrectors for the tide zones, and posted the tide data on the CO-OPS website. Dr. James Hubbard and Mr. Gerald Hovis of NOAA computed the vertical datum conversions for South San Francisco Bay. Ms. Marti Ikehara, State Geodetic Advisor for the National Geodetic Survey (NGS), provided technical guidance regarding establishing elevations using GPS techniques, vertical datums, and subsidence in South San Francisco Bay.

Ms. Glenda Rathwell and Mr. Karl Rhynas of Quester-Tangent Corporation analyzed the seabed classification data and prepared a map of acoustic diversity for South San Francisco Bay showing the seabed segmented into acoustically similar units. Their report on seabed classification of South San Francisco Bay sediments is presented as an Appendix in Section 8.

Ms. Anne Sturm of the San Francisco District, U.S. Army Corps of Engineers prepared a metadata file for the tide data collected in the South San Francisco Bay sloughs and creeks. The slough/creek tide data is included as part of the Corps' South San Francisco Bay Shoreline Project. Ms. Sturm also acquired funding from the Corps to prepare a metadata file to document the results of the tidal benchmark surveys used to establish the NAVD88-to-MLLW conversions.

Final high-frequency $(200 \mathrm{kHz})$ soundings and low frequency $(50 \mathrm{kHz})$ seabed classification data were delivered to Ms. Amy Foxgrover of USGS Pacific Science Center. After Ms. Foxgrover conducts an independent quality control assessment of the data, she will compare soundings referenced to MLLW to historical surveys of South San Francisco Bay, and merge soundings referenced to NAVD-88 with the May 2004 LIDAR topographic data to create a terrain model of existing land surface elevation and bay bathymetry 


\section{QUALITY CONTROL RESULTS}

Quality control procedures for the Order 1 hydrographic survey of South San Francisco Bay include the following checkpoints:

- Pre-survey calibration of navigation system at four (4) permanent horizontal control points surrounding the survey area (same 4 points used to reference LIDAR survey).

- Daily checks on the precision (repeatability) of the navigation system at a single point in San Leandro Marina or Redwood City Marina.

- Daily barcheck calibrations of the survey-grade depthfinder immediately before and after collecting soundings.

- Daily comparison between electronic depth measurements and depths measured manually using a weighted tape.

- Comparison of observed tides vs. predicted tides for the same location.

- Comparison of tides from adjacent gauges located upstream and downstream.

- Comparison of electronic water level measurements by pressure-sensing tide gauges vs. manual measurements of water surface elevation using a nearby benchmark as reference.

- Second and third checks of the edited soundings to ensure that all tide corrections and datum conversions are properly made.

- Comparison of soundings at the intersection of primary and perpendicular survey lines and in overlap areas around tide zone boundaries.

- Comparison of final soundings with historical NOAA surveys of the same area.

The following sections provide results from quality control checks and calibrations of the navigation system, survey-grade depthfinder, and tide gauges. The absolute precision (repeatability) of the soundings at the intersection of perpendicular tracklines and in overlapping survey areas around the tide zone boundaries is discussed.

\subsection{QC Results for Differential GPS Navigation}

The GPS receiver aboard the survey vessel automatically and continuously checks the quality of the geometric accuracy (called HDOP, or Horizontal Dilution of Precision) during the hydrographic survey. The GPS receiver is configured such that satellites less than ten degrees above the horizon are not used in the position computation. The navigation software automatically halts the survey if the HDOP exceeds 5.0, the Order 1 survey standard (USACE, 2002). The GPS receiver also monitors the rate of the pseudo-range correctors used in the position computation, and stops the survey collection software if the age of range corrections exceeds 3 seconds.

In December 2004, prior to beginning the hydrographic survey, the Contractor removed the differential GPS receiver from the survey vessel and calibrated it at the same four permanent horizontal control monuments around South San Francisco Bay used to reference the aerial LIDAR survey (Terrapoint, 2005). Based upon the GPS calibration at 4 locations around South San Francisco Bay, the navigation system used to collect the soundings has an absolute accuracy better than $\pm 2 \mathrm{~m}$. The results from the GPS calibrations are presented on the next page: 
Horizontal Control Point: HS2851

Omnistar Coordinate: N37 $26^{\prime} 10.050^{\prime \prime} \quad \mathrm{W} 121^{\circ} 54^{\prime} 24.900^{\prime \prime}$

UTM: E596,701.5m N4,143,815.7m

NGS Coordinate: N37 26'10.03474" W121 54' 24.89490"

UTM: E596,701.6m N4,143,815.2m

LIDAR Output Coordinate: N37 $26^{\prime} 10.03157^{\prime \prime} \quad$ W121 ${ }^{\circ} 54^{\prime} 24.89230$

UTM: E596,701.7m N4,143,815.1m

Difference between Omnistar and NGS Coordinate: $0.51 \mathrm{~m}$

Horizontal Control Point: AI7653

Omnistar Coordinate: N37 $7^{\circ} 43^{\prime} 11.034^{\prime \prime} \quad \mathrm{W} 122^{\circ} 07^{\prime} 09.240^{\prime \prime}$

UTM: E577,623.1m N4,175,084.4m

NGS Coordinate: N37 43'11.04190" W122 07’09.20691"

UTM: E577,623.9m N4,175,084.7m

LIDAR Output Coordinate: N37 43' 11.04196” W W122 07' 09.20686”

UTM: E577,623.9m N4,175,084.7m

Difference between Omnistar and NGS Coordinate: $0.85 \mathrm{~m}$

Horizontal Control Point: HT0565

Omnistar Coordinate: N37 $35^{\prime} 28.656^{\prime \prime} \quad$ W $122^{\circ} 19^{\prime} 09.984^{\prime \prime}$

UTM: E560,081.8m N4,160,687.4m

NGS Coordinate: N37 35'28.63257' W122 $17^{\circ}$ '09.91243"

UTM: E560,083.6m N4,160,686.7m

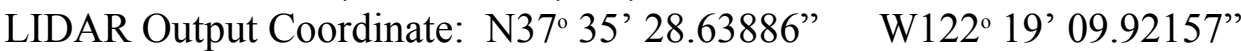

UTM: E560,083.3m N4,160,686.9m

Difference between Omnistar and NGS Coordinate: $1.93 \mathrm{~m}$

Horizontal Control Point: AH7470

Omnistar Coordinate: N37 $30^{\prime} 28.715^{\prime \prime} \quad \mathrm{W} 122^{\circ} 12^{\prime} 39.107^{\prime \prime}$

UTM: E569,745.0m N4,151,518.7m

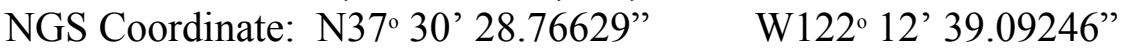

UTM: E569,745.4m N4,151,520.3m

LIDAR Output Coordinate: N37 $30^{\prime} 28.76286^{\prime \prime} \quad$ W122 $12^{\prime} 39.08903$

UTM: E569,745.5m N4,151,520.2m

Difference between Omnistar and NGS Coordinate: $1.65 \mathrm{~m}$

In addition to calibrating the absolute accuracy of the differential GPS navigation before beginning the hydrographic survey, the navigation system was checked for precision (repeatability) twice daily at a single location in either San Leandro Marina or Redwood City Marina. The results from the twice-daily check of GPS precision (repeatability) show less than $\pm 1 \mathrm{~m}$ drift during the 4-month hydrographic survey.

During collection of soundings along the eastern shoreline of South San Francisco Bay, an unknown microwave source (possibly radar from Oakland International Airport) occasionally disrupted the differential corrections being received aboard the survey vessel. When differential corrections were disrupted, the survey was immediately stopped and any soundings collected were discarded and re-surveyed when differential corrections were again received. The field survey crew found that placing metal shielding on the north side of the differential GPS antennae eliminated the microwave disruptions. 


\subsection{QC Results for Depth Measurements}

The soundings were reviewed and edited in the office using a software program that allows the depth and navigation data to be displayed, checked and corrected on the computer screen against the graphical records collected in the field. Soundings were edited three-times, and the results compared, to ensure that all spikes and questionable data are removed.

Results from the barcheck calibrations conducted before and after each dayshift and nightshift during the survey were carefully reviewed in the field and during data processing. The difference between the pre- and post-survey barcheck calibrations are never greater than $\pm 3 \mathrm{~cm}$ $\left( \pm 0.1^{\prime}\right)$ at any of the $1.5 \mathrm{~m}\left(5^{\prime}\right)$ depth intervals checked daily. Likewise, manual depth measurements collected twice daily at random locations in South San Francisco Bay matched electronic soundings within $\pm 3 \mathrm{~cm}\left( \pm 0.1^{\prime}\right)$, except between the Dumbarton Bridge and Coyote Creek. Between the Dumbarton Bridge and Coyote Creek, manual depth measurements are consistently deeper than electronic soundings because the 1-pound leadline used to manually measure water depths sinks into the soft, water-saturated sediments.

A review of the daily barcheck calibrations for the survey-grade depthfinder indicates that the speed-of-sound in South San Francisco Bay increased during the 3-month survey. During January 2005, barcheck calibrations measured the speed-of-sound at between 4830-4850 feet/second. The speed-of-sound increased to between 4850-4860 feet/second during February 2005, and again during March 2005 to between 4870-4880 feet/second. A lower speed-of-sound (between 4700-4720 feet/second) was measured in the sloughs and creeks of South San Francisco Bay during late March-early April 2005, probably a result of freshwater influence from winter runoff.

\subsection{QC Results for Tide Measurements in Sloughs and Creeks}

Water level data collected at multiple locations in the sloughs and creeks of South San Francisco Bay by pressure-sensing tide gauges was carefully reviewed and compared against:

- Manual measurements of water level surface collected during the hydrographic survey using nearby benchmarks as reference,

- Predicted tides in the sloughs and creeks, calculated by applying time- and rangemultipliers to tide data from the nearest controlling NOAA tide station, as specified by NOAA (2006), and

- Tide data collected by adjacent gauges located upstream or downstream.

Manual tide measurements matched electronic water level data collected by the pressure-sensing tide gauges within $\pm 1.5 \mathrm{~cm}\left( \pm 0.05^{\prime}\right)$ at the entrance to Coyote Creek and Artesian Slough, within $\pm 3 \mathrm{~cm}\left( \pm 0.1^{\prime}\right)$ in Alviso Slough, and within $\pm 6 \mathrm{~cm}( \pm 0.2$ ') at the Railroad Bridge. The manual tide measurements matched electronic tide data best at high tide. The greatest differences between manual water level measurements and electronic tide data occurs at low tide, immediately before the water level falls below the tide gauge, exposing the underwater pressure sensor to air. 
Comparing water surface elevations observed by the pressure-sensing tide gauges against predicted tides for the appropriate tide zones defined by NOAA (2006) indicates that high tide is about $8 \mathrm{~cm}\left(0.25^{\prime}\right)$ higher and up to 0.5 -hours earlier than NOAA predictions for South San Francisco Bay sloughs and creeks. This difference between the observed and predicted height and time of high tide in the sloughs and creeks may be caused by freshwater runoff from winter storms. Changing the controlling tide station to the air-acoustic tide gauge at Coyote Creek electrical tower (if it had been operational) might have increased the accuracy of the time- and range-multipliers in the sloughs and creeks.

\subsection{Final QC Results}

The hydrographic survey was conducted using standards, methods and accuracies outlined in the U.S. Army Corps of Engineers Hydrographic Manual (USACE, 2002). Soundings in South San Francisco Bay were corrected for tide and referenced to MLLW and NAVD-88 using methods described in NOAA (2006). Slough and creek soundings were referenced to NAVD-88 by applying tide corrections measured by pressure-sensing gauges, and converted to MLLW (where possible) using methods described in NOAA (2006).

Soundings were collected throughout South San Francisco Bay and five sloughs/creeks to an elevation of greater than +1 m NAVD-88. A quality control review of the density of soundings collected in South San Francisco Bay shows no gaps exist in the survey coverage, except for small areas containing shipwrecks, bridges, aqueducts, or other obstructions. Aquatic vegetation did not interfere with soundings anywhere in South San Francisco Bay, except along isolated shoreline areas in the creeks and sloughs.

The precision (repeatability) of the soundings is better than $\pm 8 \mathrm{~cm}\left( \pm 0.26^{\prime}\right)$. Daily barcheck calibrations of the survey-grade depthfinder demonstrate that electronic depth measurements are accurate to $\pm 3 \mathrm{~cm}( \pm 0.1$ '), regardless of water depth. Manual measurements of water depths using a weighted tape matched electronic depth measurements within $\pm 3 \mathrm{~cm}\left( \pm 0.1^{\prime}\right)$. The absolute precision of the soundings is assessed where perpendicular survey lines cross or in areas of overlapping soundings. In the $200 \mathrm{~m}$ overlap areas around tide zone boundaries and at the intersection between primary survey lines and perpendicular "tie-lines", soundings collected at different times and at different tide stages match within $\pm 8 \mathrm{~cm}\left( \pm 0.26^{\prime}\right)$ or better. Accuracy decreases to $\pm 15 \mathrm{~cm}\left( \pm 0.5^{\prime}\right)$ in the sloughs and creeks.

Based upon GPS calibrations and examination of sounding intersections, the horizontal accuracy of soundings collected from a vessel moving at 5.5 knots is likely in the range of $+3 \mathrm{~m}$.

Navigation inaccuracies of $\pm 3 \mathrm{~m}$ have little effect on sounding accuracies in the majority of South San Francisco Bay because the seafloor in the open Bay is relatively flat and featureless; however, a positioning error of $\pm 3 \mathrm{~m}$ in the narrow, steeply-sloping channels of sloughs and creeks has a significant effect on sounding precision (repeatability).

Soundings in the sloughs and creeks extend to the end of navigable waters. Soundings extend upstream past the point of tidal influence, where referencing elevations to tidal datums becomes suspect. Soundings collected along the centerline (or thalweg) of the creeks and sloughs match cross-sectional soundings within $\pm 15 \mathrm{~cm}\left( \pm 0.5^{\prime}\right)$. The lower precision (repeatability) of the 
slough/creek soundings compared to the open Bay soundings is caused by a number of factors, including:

- Soundings in the sloughs and creeks were collected using a $4 \mathrm{~m}$ flat-bottom skiff, which is not as stable a platform as the larger, heavier survey boats that collected soundings in the open Bay. The quick turns and speed changes necessary for the skiff to collect crosssectional soundings across the narrow channels of the creeks and sloughs affects the $\mathrm{draft} /$ squat calibrations, and lowers sounding precision.

- Navigation accuracy is a significant issue in the narrow, steeply-sloped channels of the sloughs and creeks.

- Difficulty in accurately measuring or predicting tides at intermediate locations in the sloughs and creeks, primarily because there is insufficient water depth to install highlyaccurate air-acoustic tide gauges.

Obtaining higher accuracy soundings in the sloughs and creeks may not be possible from a moving boat, and may require leadline/tagline methods between two fixed shore points whose vertical and horizontal positions are accurately known from static GPS surveys. Manual (leadline) depth measurements are often more accurate than electronic soundings in the soft, water-saturated sediments at the bottom of the sloughs and creeks.

The survey equipment, data collection methods, and analytical procedures used to conduct the hydrographic survey represents the Contractor's best effort to collect bank-to-bank soundings in South San Francisco Bay. After careful collection, processing, and review of the soundings, Sea Surveyor, Inc. is confident that all soundings meet Order 1 standards and accuracies, and the final data meets or exceeds the requirement for a Order 1 hydrographic survey. The only issue with the soundings may be that the survey line spacing $(100 \mathrm{~m})$ is further apart than advised for Order 1 surveys. Order 1 hydrographic surveys are typically conducted along survey lines spaced at nominal 15-30m intervals. The soundings collected in South San Francisco Bay may not detect small changes in seafloor elevation that occur between survey lines. 


\section{BIBLIOGRAPHY}

Foxgrover, A.C. and Jaffe, B.E. 2004. South San Francisco Bay 2004 Topographic Lidar Survey: Data Overview and Preliminary Quality Assessment. U.S. Geological Survey Open File Report OFR-2005-1284. 57 p. [URL: http://pubs.usgs.gov/of/2005/1284/]

Foxgrover, A.C., Higgins, S.A., Ingraca, M.K., Jaffe, B.E., and Smith, R.E. 2004. Deposition, Erosion, and Bathymetric Change in South San Francisco Bay: 1858-1983. U.S. Geological Survey Open-File Report OFR-2004-1192. 25 p. [URL: http://pubs.usgs.gov/of/2004/1192/]

Goals Project. 1999. Baylands Ecosystem Habitat Goals. A report of habitat recommendations prepared by the San Francisco Bay Area Wetlands Ecosystem Goals Project. U.S.

Environmental Protection Agency, San Francisco, Calif./S.F. Bay Regional Water Quality Control Board, Oakland, Calif.

National Ocean Service. 1987. User's Guide for the Installation of Benchmarks and Leveling Requirements for Water Level Stations. NOAA, Office of Oceanography and Marine Assessment. Rockville, MD 20852.

National Ocean Service. 1998. User's Guide for 8200 Acoustic Gauge (Installation and Operation). NOAA, Requirements and Engineering Branch, Oceanographic Products and Services Division. Silver Springs, MD 20910.

National Ocean Service. 2003a. Hydrographic Surveys - Specifications and Deliverables. NOAA, Requirements and Engineering Branch, Oceanographic Products and Services Division. Silver Springs, MD 20910.

National Ocean Service. 2003b. Specifications and Deliverables for Installation, Operation, and Removal of Water Level Stations. NOAA, Requirements and Engineering Branch, Oceanographic Products and Services Division. Silver Springs, MD 20910.

NOAA. 2006. Summary of Procedures and Results from South San Francisco Bay Vertical Datum Determination and Conversion Study. Supporting the 2005 USGS South San Francisco Bay Bathymetry Study and South Bay Salt Pond Restoration Project. Prepared by the Center for Operation Oceanographic Products and Services (CO-OPS). National Ocean Service, NOAA, Silver Spring, MD. In preparation.

Quester Tangent Corporation. 2005. Acoustic Seabed Classification Survey of South San Francisco Bay. Document No. SS-SC75-716C-00. Available from Quester Tangent at Marine Technology Centre, 201-9865 West Saanich Road, Sidney, B.C., Canada V8L 5Y8.

Terrapoint USA. 2005. Lidar Project Report for USGS South Bay Restoration Project. Contract \#2206-H. Available from Terrapoint at 25216 Grogans Park Drive, The Woodlands, TX 77380.

U.S. Army Corps of Engineers. 2002. Hydrographic Surveying Manual. EM 1110-2-1003. Department of the Army, CECW-EE / CECW-OD, Washington, D.C. 20314-1000. 


\title{
SECTION 7
}

\section{APPENDIX}

\section{BOUNDARY COORDINATES FOR TIDE ZONES}

\author{
Prepared by:
}

NOAA, 2006 


\begin{tabular}{|c|c|c|c|c|}
\hline \multirow{2}{*}{$\frac{\text { Zone }}{\text { SFB31 }}$} & \multirow{2}{*}{ N $\frac{\text { Latitude }}{37.666447}$} & \multirow{2}{*}{$\mathrm{W} \frac{\text { Longitude }}{122.237032}$} & \multicolumn{2}{|c|}{ UTM Zone 10 North } \\
\hline & & & E 567,858.1m & $\mathrm{N} 4,171,148.7 \mathrm{~m}$ \\
\hline & N 37.685036 & W 122.230391 & E $569,740.3 m$ & $\mathrm{~N} \mathrm{4,172,005.2m}$ \\
\hline & N 37.692614 & W 122.208964 & E 571,955.7m & N $4,173,383.2 m$ \\
\hline & N 37.704862 & W 122.183702 & E $571,708.5 m$ & $\mathrm{~N} 4,172,966.7 \mathrm{~m}$ \\
\hline & N 37.701128 & W 122.186547 & E $571,338.3 m$ & $\mathrm{~N} 4,172,700.1 \mathrm{~m}$ \\
\hline & N 37.698754 & W 122.190772 & E $571,075.4 \mathrm{~m}$ & $\mathrm{~N} 4,172,643.3 \mathrm{~m}$ \\
\hline & N 37.698263 & W 122.193760 & E 571,112.3m & N $4,172,317.8 m$ \\
\hline & N 37.695326 & W 122.193373 & E $571,327.1 \mathrm{~m}$ & $\mathrm{~N} 4,172,154.5 \mathrm{~m}$ \\
\hline & N 37.693838 & W 122.190953 & E $571,388.5 m$ & $\mathrm{~N} 4,172,155.5 \mathrm{~m}$ \\
\hline & N 37.693842 & W 122.190256 & E 571,573.0m & $\mathrm{N} 4,171,839.1 \mathrm{~m}$ \\
\hline & N 37.690976 & W 122.188195 & E 571,736.8m & N $4,171,795.0 m$ \\
\hline & N 37.690566 & W 122.186341 & E $571,863.3 m$ & $\mathrm{~N} 4,171,887.0 \mathrm{~m}$ \\
\hline & N 37.691385 & W 122.184898 & E $572,126.0 \mathrm{~m}$ & $\mathrm{~N} 4,171,971.1 \mathrm{~m}$ \\
\hline & N 37.692122 & W 122.181910 & E 572,403.6m & $\mathrm{N} 4,171,876.1 \mathrm{~m}$ \\
\hline & N 37.691244 & W 122.178771 & E $570,556.1 \mathrm{~m}$ & N $4,170,852.4 m$ \\
\hline & N 37.682162 & W 122.199823 & E $567,289.3 m$ & $\mathrm{~N} 4,169,081.5 \mathrm{~m}$ \\
\hline & N 37.666447 & W 122.237032 & E $567,858.1 \mathrm{~m}$ & $\mathrm{~N} 4,171,148.7 \mathrm{~m}$ \\
\hline \multirow[t]{9}{*}{ SFB33 } & N 37.628125 & W 122.368838 & E 555,963.3m & $\mathrm{N} 4,164,743.3 \mathrm{~m}$ \\
\hline & N 37.620122 & W 122.374645 & E $555,186.8 m$ & $\mathrm{~N} 4,163,852.0 \mathrm{~m}$ \\
\hline & N 37.609945 & W 122.359816 & E 556,503.1m & $\mathrm{N} 4,162,731.7 \mathrm{~m}$ \\
\hline & N 37.619515 & W 122.313502 & E $560,583.1 \mathrm{~m}$ & $\mathrm{~N} 4,163,822.3 \mathrm{~m}$ \\
\hline & N 37.637061 & W 122.252913 & E $565,914.7 m$ & N 4,165,809.9m \\
\hline & N 37.666447 & W 122.237032 & E $567,289.3 m$ & $\mathrm{~N} 4,169,081.5 \mathrm{~m}$ \\
\hline & N 37.660170 & W 122.252151 & E $565,961.5 m$ & N $4,168,374.3 m$ \\
\hline & N 37.642223 & W 122.312069 & E $560,691.1 \mathrm{~m}$ & $\mathrm{~N} 4,166,342.7 \mathrm{~m}$ \\
\hline & N 37.628125 & W 122.368838 & E 555,963.3m & N $4,164,743.3 \mathrm{~m}$ \\
\hline \multirow[t]{7}{*}{ SFB34 } & E 37.666447 & W 122.237032 & E $567,289.3 m$ & N $4,169,081.5 m$ \\
\hline & E 37.682162 & W 122.199823 & E $570,556.1 \mathrm{~m}$ & $\mathrm{~N} 4,170,582.4 \mathrm{~m}$ \\
\hline & E 37.691244 & W 122.178771 & E $572,403.6 m$ & $\mathrm{~N} 4,171,876.1 \mathrm{~m}$ \\
\hline & E 37.675263 & W 122.158441 & E $574,211.9 m$ & $\mathrm{~N} 4,170,118.9 \mathrm{~m}$ \\
\hline & E 37.656345 & W 122.199823 & E $570,580.6 m$ & N $4,167,988.0 m$ \\
\hline & E 37.637061 & W 122.252913 & E $565,914.7 m$ & N $4,165,809.9 m$ \\
\hline & E 37.666447 & W 122.237032 & E $567,289.3 m$ & $\mathrm{~N} 4,169,081.5 \mathrm{~m}$ \\
\hline \multirow[t]{8}{*}{ SFB35 } & N 37.605640 & W 122.279218 & E $563,602.5 m$ & N 4,162,305.6m \\
\hline & N 37.609311 & W 122.275685 & E $563,929.3 m$ & N $4,162,715.3 m$ \\
\hline & N 37.637061 & W 122.252913 & E $565,914.7 m$ & $\mathrm{~N} 4,165,809.9 \mathrm{~m}$ \\
\hline & N 37.656345 & W 122.199823 & E $570,580.6 m$ & N 4,167,988.0m \\
\hline & N 37.675263 & W 122.158441 & E $574,211.9 m$ & $\mathrm{~N} 4,170,118.9 \mathrm{~m}$ \\
\hline & N 37.670808 & W 122.155321 & E $574,491.5 m$ & $\mathrm{~N} 4,169,627.1 \mathrm{~m}$ \\
\hline & N 37.658259 & W 122.154111 & E $574,610.8 m$ & $\mathrm{~N} 4,168,235.8 \mathrm{~m}$ \\
\hline & N 37.635781 & W 122.205236 & E $570,122.4 m$ & $\mathrm{~N} 4,165,702.4 \mathrm{~m}$ \\
\hline
\end{tabular}




\begin{tabular}{|c|c|c|c|c|}
\hline \multirow[t]{12}{*}{ SFB36 } & N 37.605640 & W 122.279218 & E $563,602.5 \mathrm{~m}$ & $\mathrm{~N} 4,162,305.6 \mathrm{~m}$ \\
\hline & N 37.609311 & W 122.275685 & E 563,929.3m & N $4,162,715.3 m$ \\
\hline & N 37.637061 & W 122.252913 & E $565,914.7 m$ & $\mathrm{~N} 4,165,809.9 \mathrm{~m}$ \\
\hline & N 37.619515 & W 122.313502 & E 560,583.1m & N $4,163,822.3 m$ \\
\hline & N 37.609945 & W 122.359816 & E $556,503.1 \mathrm{~m}$ & $\mathrm{~N} 4,162,731.7 \mathrm{~m}$ \\
\hline & N 37.620122 & W 122.374645 & E 555,186.8m & N $4,163,852.0 m$ \\
\hline & N 37.606284 & W 122.392370 & E 553,632.5m & N 4,162,306.4m \\
\hline & N 37.585377 & W 122.370138 & E $555,610.4 m$ & N 4,159,999.8m \\
\hline & N 37.574576 & W 122.331736 & E 559,009.5m & N $4,158,824.9 m$ \\
\hline & N 37.582390 & W 122.322208 & E 559,844.6m & N 4,159,697.9m \\
\hline & N 37.589693 & W 122.318244 & E $560,188.7 m$ & $\mathrm{~N} 4,160,510.6 \mathrm{~m}$ \\
\hline & N 37.605640 & W 122.279218 & E 563,602.5m & N 4,162,305.6m \\
\hline \multirow[t]{13}{*}{ SFB37 } & N 37.582390 & W 122.322208 & E $559,844.6 m$ & $\mathrm{~N} \mathrm{4,159,697.9m}$ \\
\hline & N 37.576051 & W 122.313280 & E 560,638.0m & N $4,159,000.3 m$ \\
\hline & N 37.569244 & W 122.279517 & E 563,625.1m & N $4,158,267.4 m$ \\
\hline & N 37.572467 & W 122.263491 & E 565,037.6m & N $4,158,636.0 m$ \\
\hline & N 37.589947 & W 122.245028 & E $566,652.4 \mathrm{~m}$ & N 4,160,588.3m \\
\hline & N 37.609197 & W 122.180088 & E $572,367.1 \mathrm{~m}$ & $\mathrm{~N} 4,162,772.1 \mathrm{~m}$ \\
\hline & N 37.621099 & W 122.142525 & E $575,670.4 m$ & $\mathrm{~N} 4,164,122.2 \mathrm{~m}$ \\
\hline & N 37.651755 & W 122.148969 & E 575,070.9m & N $4,167,518.2 m$ \\
\hline & N 37.658259 & W 122.154111 & E $574,610.8 m$ & N 4,168,235.8m \\
\hline & N 37.635781 & W 122.205236 & E $570,122.4 m$ & $\mathrm{~N} 4,165,702.4 \mathrm{~m}$ \\
\hline & N 37.605640 & W 122.279218 & E $574,620.5 m$ & $\mathrm{~N} \mathrm{4,162,305.6m}$ \\
\hline & N 37.589693 & W 122.318244 & E $560,188.7 m$ & N 4,160,510.6m \\
\hline & N 37.582390 & W 122.322208 & E $559,844.6 m$ & N $4,159,697.9 m$ \\
\hline \multirow[t]{11}{*}{ SFB38 } & N 37.568012 & W 122.259025 & E $565,435.9 m$ & $\mathrm{~N} 4,158,144.8 \mathrm{~m}$ \\
\hline & N 37.548937 & W 122.244749 & E 566,713.6m & N $4,156,038.5 m$ \\
\hline & N 37.547887 & W 122.239617 & E $567,167.9 m$ & $\mathrm{~N} 4,155,925.7 \mathrm{~m}$ \\
\hline & N 37.565627 & W 122.208102 & E $569,935.2 m$ & N 4,157,916.9m \\
\hline & N 37.587162 & W 122.166082 & E 573,625.0m & N 4,160,338.2m \\
\hline & N 37.600081 & W 122.139024 & E $576,000.8 m$ & $\mathrm{~N} 4,161,793.1 \mathrm{~m}$ \\
\hline & N 37.621099 & W 122.142525 & E $575,670.4 m$ & $\mathrm{~N} 4,164,122.2 \mathrm{~m}$ \\
\hline & N 37.609197 & W 122.180088 & E $572,367.1 \mathrm{~m}$ & $\mathrm{~N} 4,162,772.1 \mathrm{~m}$ \\
\hline & N 37.589947 & W 122.245028 & E 566,652.4m & N $4,160,588.3 m$ \\
\hline & N 37.572467 & W 122.263491 & E 565,037.6m & N 4,158,636.0m \\
\hline & N 37.568012 & W 122.259025 & E 565,435.9m & N $4,158,144.8 m$ \\
\hline \multirow[t]{9}{*}{ SFB39 } & N 37.547887 & W 122.239617 & E $567,167.9 m$ & N $4,155,925.7 m$ \\
\hline & N 37.521524 & W 122.208739 & E 569,920.1m & $\mathrm{N} 4,153,023.3 \mathrm{~m}$ \\
\hline & N 37.539017 & W 122.177542 & E 572,659.9m & N $4,154,987.8 m$ \\
\hline & N 37.557772 & W 122.147619 & E $575,284.7 m$ & $\mathrm{~N} 4,157,092.1 \mathrm{~m}$ \\
\hline & N 37.567909 & W 122.130747 & E $576,764.5 m$ & N $4,158,230.4 m$ \\
\hline & N 37.600081 & W 122.139024 & E $576,000.8 m$ & $\mathrm{~N} 4,161,793.1 \mathrm{~m}$ \\
\hline & N 37.587162 & W 122.166082 & E 573,625.0m & $\mathrm{N} 4,160,338.2 \mathrm{~m}$ \\
\hline & N 37.565627 & W 122.208102 & E 569,935.2m & N 4,157,916.9m \\
\hline & N 37.547887 & W 122.239617 & E $567,167.9 m$ & N 4,155,925.7m \\
\hline
\end{tabular}




\begin{tabular}{|c|c|c|c|c|}
\hline \multirow[t]{13}{*}{ SFB40 } & N 37.521524 & W 122.208739 & E 569,920.1m & N 4,153,023.3m \\
\hline & N 37.516556 & W 122.212021 & E 569,634.7m & N 4,152,469.7m \\
\hline & N 37.515136 & W 122.207360 & E 570,047.9m & N 4,152,315.6m \\
\hline & N 37.498282 & W 122.197600 & E $570,926.4 \mathrm{~m}$ & $\mathrm{~N} 4,150,453.1 \mathrm{~m}$ \\
\hline & N 37.504282 & W 122.184227 & E 572,102.8m & N $4,151,128.9 m$ \\
\hline & N 37.519243 & W 122.158443 & E 574,366.9m & N 4,152,808.8m \\
\hline & N 37.535469 & W 122.134886 & E $576,432.1 \mathrm{~m}$ & N 4,154,627.9m \\
\hline & N 37.548168 & W 122.117926 & E $577,917.3 \mathrm{~m}$ & N $4,156,050.8 m$ \\
\hline & N 37.556414 & W 122.123442 & E $577,421.5 m$ & N 4,156,961.1m \\
\hline & N 37.567909 & W 122.130747 & E $576,764.5 m$ & N 4,158,230.4m \\
\hline & N 37.557772 & W 122.147619 & E $575,284.7 m$ & $\mathrm{~N} 4,157,092.1 \mathrm{~m}$ \\
\hline & N 37.539017 & W 122.177542 & E 572,659.9m & N $4,154,987.8 m$ \\
\hline & N 37.521524 & W 122.208739 & E 569,920.1m & N 4,153,023.3m \\
\hline \multirow[t]{11}{*}{ SFB42 } & N 37.498282 & W 122.197600 & E $570,926.4 m$ & N 4,150,453.1m \\
\hline & N 37.484174 & W 122.167655 & E 573,587.2m & N $4,148,910.8 m$ \\
\hline & N 37.491479 & W 122.156262 & E $574,587.2 m$ & N $4,149,730.3 m$ \\
\hline & N 37.512436 & W 122.124878 & E $577,340.1 \mathrm{~m}$ & N 4,152,080.7m \\
\hline & N 37.523273 & W 122.108187 & E $578,803.8 m$ & N 4,153,296.9m \\
\hline & N 37.524174 & W 122.108220 & E 578,799.9m & N 4,153,396.8m \\
\hline & N 37.548168 & W 122.117926 & E $577,917.3 \mathrm{~m}$ & N 4,156,050.8m \\
\hline & N 37.535469 & W 122.134886 & E $576,432.1 \mathrm{~m}$ & N 4,154,627.9m \\
\hline & N 37.519243 & W 122.158443 & E $574,366.9 m$ & N $4,152,808.8 m$ \\
\hline & N 37.504282 & W 122.184227 & E $572,102.8 m$ & N $4,151,128.9 m$ \\
\hline & N 37.498282 & W 122.197600 & E $570,926.4 \mathrm{~m}$ & N 4,150,453.1m \\
\hline \multirow[t]{11}{*}{ SFB43 } & N 37.484174 & W 122.167655 & E 573,587.2m & N $4,148,910.8 m$ \\
\hline & N 37.468493 & W 122.125785 & E 577,305.2m & N $4,147,204.7 m$ \\
\hline & N 37.482373 & W 122.105648 & E $579,071.3 m$ & N $4,148,761.3 m$ \\
\hline & N 37.492925 & W 122.090772 & E $580,375.2 \mathrm{~m}$ & N 4,149,944.6m \\
\hline & N 37.502899 & W 122.077347 & E $571,551.1 \mathrm{~m}$ & N 4,151,062.7m \\
\hline & N 37.515843 & W 122.062839 & E 582,819.2m & N 4,152,511.5m \\
\hline & N 37.518187 & W 122.084479 & E 580,904.2m & N $4,152,752.7 m$ \\
\hline & N 37.523273 & W 122.108187 & E 578,803.8m & N 4,153,296.9m \\
\hline & N 37.512436 & W 122.124878 & E $577,340.1 \mathrm{~m}$ & N 4,152,080.7m \\
\hline & N 37.491479 & W 122.156262 & E $574,587.2 m$ & N $4,149,730.3 m$ \\
\hline & N 37.484174 & W 122.167655 & E 573,587.2m & N 4,148,910.8m \\
\hline \multirow[t]{12}{*}{ SFB44 } & N 37.468493 & W 122.125785 & E $577,305.2 m$ & N $4,147,207.7 m$ \\
\hline & N 37.441074 & W 122.114650 & E $578,318.4 m$ & N 4,144,171.9m \\
\hline & N 37.431080 & W 122.081994 & E 581,218.1m & $\mathrm{N} 4,143,090.7 \mathrm{~m}$ \\
\hline & N 37.438937 & W 122.074682 & E 581,856.4m & N 4,143,968.7m \\
\hline & N 37.447235 & W 122.067007 & E 582,526.3m & N 4,144,896.0m \\
\hline & N 37.470374 & W 122.047232 & E 584,249.5m & N 4,147,480.7m \\
\hline & N 37.486507 & W 122.051379 & E 583,864.8m & N 4,149,266.9m \\
\hline & N 37.498010 & W 122.048828 & E $584,077.4 \mathrm{~m}$ & N $4,150,545.4 m$ \\
\hline & N 37.515843 & W 122.062839 & E 582,819.2m & N 4,152,511.5m \\
\hline & N 37.502899 & W 122.077347 & E 581,551.1m & N 4,151,062.7m \\
\hline & N 37.492925 & W 122.090772 & E 580,375.2m & N 4,149,944.6m \\
\hline & N 37.482373 & W 122.105648 & E 579,071.3m & N $4,148,761.3 m$ \\
\hline
\end{tabular}




\begin{tabular}{|c|c|c|c|c|}
\hline \multirow{9}{*}{ SFB46 } & N 37.470011 & W 122.047504 & E $584,249.5 m$ & N $4,147,480.7 m$ \\
\hline & N 37.472976 & W 122.030905 & E 585,690.3m & $\mathrm{N} 4,147,784.1 \mathrm{~m}$ \\
\hline & N 37.458517 & W 122.033082 & E $585,514.3 m$ & $\mathrm{~N} 4,146,178.0 \mathrm{~m}$ \\
\hline & N 37.455360 & W 122.035877 & E 585,270.7m & N $4,145,825.2 m$ \\
\hline & N 37.449261 & W 122.041246 & E $584,802.7 m$ & $\mathrm{~N} 4,145,143.7 \mathrm{~m}$ \\
\hline & N 37.436902 & W 122.059948 & E $583,162.1 \mathrm{~m}$ & N $4,143,755.9 m$ \\
\hline & N 37.438937 & W 122.074682 & E 581,856.4m & N $4,143,968.7 m$ \\
\hline & N 37.447235 & W 122.067007 & E $582,526.3 m$ & N 4,144,896.0m \\
\hline & N 37.470011 & W 122.047504 & E 584,249.5m & $\mathrm{N} 4,147,480.7 \mathrm{~m}$ \\
\hline \multirow[t]{8}{*}{ SFB47 } & N 37.458517 & W 122.033082 & E $585,514.3 m$ & N $4,146,178.0 m$ \\
\hline & N 37.458281 & W 122.023516 & E 586,360.6m & $\mathrm{N} 4,146,160.5 \mathrm{~m}$ \\
\hline & N 37.459315 & W 122.018656 & E $586,789.2 m$ & $\mathrm{~N} 4,146,279.7 \mathrm{~m}$ \\
\hline & N 37.461336 & W 122.014387 & E $587,164.4 m$ & N 4,146,507.9m \\
\hline & N 37.471135 & W 122.015780 & E $587,029.9 m$ & $\mathrm{~N} 4,147,593.8 \mathrm{~m}$ \\
\hline & N 37.473146 & W 122.023226 & E 586,369.1m & $\mathrm{N} 4,147,810.0 \mathrm{~m}$ \\
\hline & N 37.472976 & W 122.030905 & E $585,690.3 m$ & $\mathrm{~N} 4,147,784.1 \mathrm{~m}$ \\
\hline & N 37.458517 & W 122.033082 & E 585,514.3m & $\mathrm{N} 4,146,178.0 \mathrm{~m}$ \\
\hline \multirow[t]{7}{*}{ SFB48 } & N 37.461336 & W 122.014387 & E $587,164.4 m$ & N 4,146,507.9m \\
\hline & N 37.460431 & W 122.001558 & E 588,300.1m & N 4,146,419.4m \\
\hline & N 37.458860 & W 121.984872 & E $589,777.7 m$ & N 4,146,260.9m \\
\hline & N 37.464261 & W 121.983656 & E $589,878.8 m$ & N 4,146,861.3m \\
\hline & N 37.468779 & W 121.985457 & E $589,714.1 \mathrm{~m}$ & N 4,147,360.8m \\
\hline & N 37.471438 & W 121.998542 & E 588,553.8m & N 4,147,643.5m \\
\hline & N 37.471135 & W 122.015780 & E 587,029.9m & N 4,147,593.8m \\
\hline \multirow[t]{7}{*}{ SFB49 } & N 37.464261 & W 121.983656 & E $589,878.8 m$ & N 4,146,861.3m \\
\hline & N 37.465794 & W 121.976980 & E $590,467.3 m$ & N 4,147,037.8m \\
\hline & N 37.465743 & W 121.964919 & E 591,534.0m & N 4,147,043.8m \\
\hline & N 37.468324 & W 121.961948 & E $591,793.6 m$ & N 4,147,333.0m \\
\hline & N 37.471061 & W 121.962514 & E $591,740.2 m$ & $\mathrm{~N} 4,147,636.1 \mathrm{~m}$ \\
\hline & N 37.472437 & W 121.976285 & E $590,520.8 m$ & $\mathrm{~N} 4,147,775.4 \mathrm{~m}$ \\
\hline & N 37.468779 & W 121.985457 & E $589,714.1 \mathrm{~m}$ & N 4,147,360.8m \\
\hline \multirow[t]{7}{*}{ SFB50 } & N 37.458860 & W 121.984872 & E $589,777.7 m$ & N 4,146,260.9m \\
\hline & N 37.456583 & W 121.974138 & E $590,729.8 m$ & N 4,146,018.6m \\
\hline & N 37.460755 & W 121.965464 & E $591,491.9 m$ & N 4,146,489.8m \\
\hline & N 37.464298 & W 121.964655 & E $591,559.1 \mathrm{~m}$ & $\mathrm{~N} 4,146,883.7 \mathrm{~m}$ \\
\hline & N 37.465743 & W 121.964919 & E $591,534.0 m$ & $\mathrm{~N} 4,147,043.8 \mathrm{~m}$ \\
\hline & N 37.465794 & W 121.976980 & E $590,467.3 m$ & N 4,147,037.8m \\
\hline & N 37.464261 & W 121.983655 & E $589,878.8 m$ & N 4,146,861.3m \\
\hline \multirow[t]{9}{*}{ SFB51 } & N 37.468324 & W 121.961948 & E 591,793.6m & N 4,147,333.0m \\
\hline & N 37.470575 & W 121.955826 & E 592,332.2m & $\mathrm{N} 4,147,588.7 \mathrm{~m}$ \\
\hline & N 37.471229 & W 121.949575 & E $592,884.1 \mathrm{~m}$ & $\mathrm{~N} 4,147,667.4 \mathrm{~m}$ \\
\hline & N 37.472538 & W 121.941619 & E 593,589.0m & $\mathrm{N} 4,147,820.5 \mathrm{~m}$ \\
\hline & N 37.475306 & W 121.938524 & E 593,856.2m & $\mathrm{N} 4,148,130.7 \mathrm{~m}$ \\
\hline & N 37.478829 & W 121.941050 & E 593,628.5m & $\mathrm{N} 4,148,519.1 \mathrm{~m}$ \\
\hline & N 37.476966 & W 121.950901 & E 592,759.8m & N 4,148,302.6m \\
\hline & N 37.476513 & W 121.957152 & E 592,207.6m & $\mathrm{N} 4,148,246.2 \mathrm{~m}$ \\
\hline & N 37.471061 & W 121.962514 & E $591,740.2 m$ & $\mathrm{~N} 4,147,636.1 \mathrm{~m}$ \\
\hline
\end{tabular}




\begin{tabular}{|c|c|c|c|c|}
\hline \multirow[t]{8}{*}{ SFB52 } & N 37.464298 & W 121.964655 & E 591,559.1m & N 4,146,883.7m \\
\hline & N 37.465089 & W 121.955448 & E 592,372.3m & N $4,146,980.4 m$ \\
\hline & N 37.465089 & W 121.944460 & E 593,344.1m & N 4,146,991.3m \\
\hline & N 37.460320 & W 121.943363 & E 593,447.0m & N 4,146,463.3m \\
\hline & N 37.455023 & W 121.946733 & E 593,155.5m & N 4,145,872.2m \\
\hline & N 37.455475 & W 121.954123 & E 592,501.4m & N $4,145,915.1 \mathrm{~m}$ \\
\hline & N 37.460912 & W 121.961510 & E 591,841.4m & N $4,146,511.1 \mathrm{~m}$ \\
\hline & N 37.460755 & W 121.965464 & E 591,491.9m & N $4,146,489.8 m$ \\
\hline \multirow[t]{7}{*}{ SFB53 } & N 37.460912 & W 121.961510 & E 591,841.4m & N $4,146,511.1 \mathrm{~m}$ \\
\hline & N 37.456734 & W 121.964414 & E 591,589.6m & N $4,146,044.7 m$ \\
\hline & N 37.453409 & W 121.964155 & E 591,616.6m & N $4,145,676.1 \mathrm{~m}$ \\
\hline & N 37.453031 & W 121.968180 & E 591,261.0m & N $4,145,630.2 m$ \\
\hline & N 37.456583 & W 121.969529 & E $591,137.4 \mathrm{~m}$ & N 4,146,023.0m \\
\hline & N 37.459049 & W 121.967508 & E 591,313.2m & N 4,146,298.6m \\
\hline & N 37.460755 & W 121.965464 & E 591,491.9m & N $4,146,489.8 m$ \\
\hline \multirow[t]{7}{*}{ SFB54 } & N 37.453409 & W 121.964155 & E 591,616.6m & N 4,145,676.1m \\
\hline & N 37.450592 & W 121.964414 & E 591,597.1m & N $4,145,363.3 m$ \\
\hline & N 37.442940 & W 121.957847 & E $592,187.4 \mathrm{~m}$ & N 4,144,520.7m \\
\hline & N 37.441329 & W 121.961320 & E $591,882.1 \mathrm{~m}$ & N 4,144,338.6m \\
\hline & N 37.444199 & W 121.969845 & E $591,124.5 m$ & N 4,144,648.7m \\
\hline & N 37.447924 & W 121.970160 & E 591,092.1m & N $4,145,061.7 m$ \\
\hline & N 37.453031 & W 121.968180 & E 591,261.0m & N $4,145,630.2 m$ \\
\hline \multirow[t]{8}{*}{ SFB55 } & N 37.458281 & W 122.023516 & E 586,360.6m & N $4,146,160.5 m$ \\
\hline & N 37.448188 & W 122.022823 & E 586,433.5m & N $4,145,041.4 m$ \\
\hline & N 37.443563 & W 122.017255 & E 586,931.4m & N $4,144,533.4 m$ \\
\hline & N 37.444185 & W 122.008960 & E $587,664.4 \mathrm{~m}$ & $\mathrm{~N} 4,144,610.1 \mathrm{~m}$ \\
\hline & N 37.449748 & W 122.005468 & E 587,966.8m & N $4,145,230.5 m$ \\
\hline & N 37.451055 & W 122.014005 & E $587,210.2 m$ & N $4,145,367.6 m$ \\
\hline & N 37.454477 & W 122.014934 & E $587,124.0 m$ & N $4,145,746.4 m$ \\
\hline & N 37.459315 & W 122.018656 & E 586,789.2m & N $1,146,279.7 m$ \\
\hline \multirow[t]{6}{*}{ SFB56 } & N 37.444185 & W 122.008960 & E $587,664.4 \mathrm{~m}$ & N $4,144,610.1 m$ \\
\hline & N 37.436284 & W 122.000655 & E 588,408.4m & N $4,143,741.3 m$ \\
\hline & N 37.431331 & W 121.989823 & E 589,372.5m & N 4,143,202.0m \\
\hline & N 37.434635 & W 121.986153 & E 589,693.3m & N 4,143,572.0m \\
\hline & N 37.441713 & W 121.990454 & E 589,304.4m & N $4,144,353.2 m$ \\
\hline & N 37.449748 & W 122.005468 & E 587,966.8m & N $4,145,230.5 m$ \\
\hline \multirow[t]{10}{*}{ SFB57 } & N 37.431331 & W 121.989823 & E $589,372.5 \mathrm{~m}$ & $\mathrm{~N} 4,143,202.0 \mathrm{~m}$ \\
\hline & N 37.426777 & W 121.984494 & E 589,849.5m & N $4,142,701.8 m$ \\
\hline & N 37.421943 & W 121.980390 & E $590,218.4 m$ & $\mathrm{~N} 4,142,169.4 \mathrm{~m}$ \\
\hline & N 37.418870 & W 121.978394 & E $590,398.7 m$ & N $4,141,830.4 m$ \\
\hline & N 37.418770 & W 121.975844 & E 590,624.5m & N $4,141,821.7 m$ \\
\hline & N 37.421238 & W 121.970918 & E $591,057.4 m$ & N $4,142,100.3 m$ \\
\hline & N 37.425569 & W 121.971487 & E 591,001.8m & N 4,142,580.2m \\
\hline & N 37.427986 & W 121.976412 & E 590,563.1m & N 4,142,843.6m \\
\hline & N 37.429597 & W 121.980643 & E 590,186.8m & N $4,143,018.3 m$ \\
\hline & N 37.434635 & W 121.986153 & E 589,693.3m & N 4,143,572.0m \\
\hline
\end{tabular}




\title{
SECTION 8
}

\author{
APPENDIX
}

\section{ACOUSTIC CLASSIFICATION SURVEY SOUTH SAN FRANCISCO BAY}

\author{
Prepared by:
}

Quester Tangent Corporation 


\section{Acoustic Seabed Classification Survey}

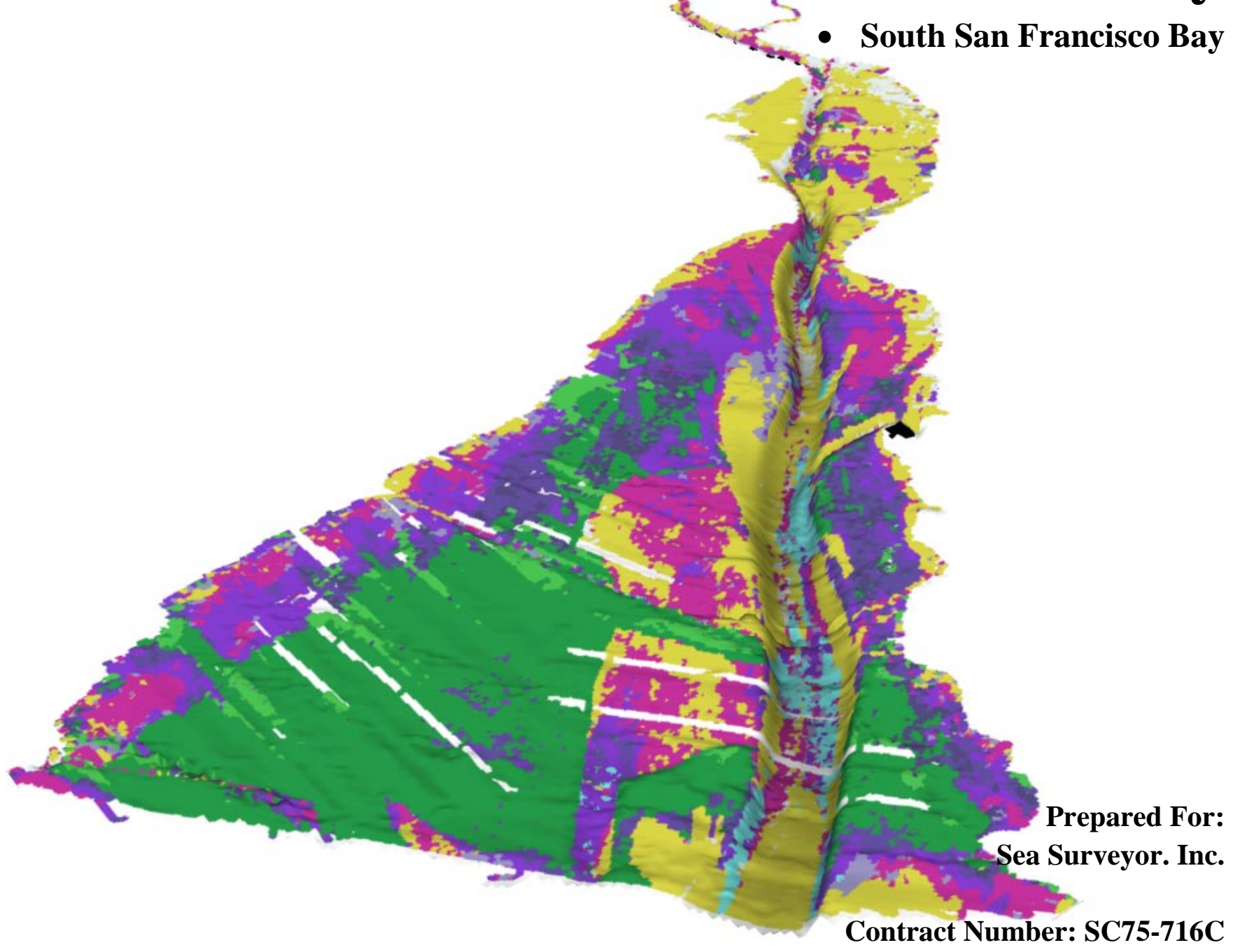

Issue Date: March 24, 2005

Document Number: SS-SC75-716C-00 


\begin{tabular}{|c|l|l|}
\hline DATE & \multicolumn{1}{|c|}{ REVISION } & DESCRIPTION \\
\hline 03.24 .2005 & R00 & Original Issue \\
\hline & & \\
\hline
\end{tabular}

The QTC VIEW, QTC IMPACT, QTC CLAMS and surrounding acoustic seabed classification technology is the sole property of Quester Tangent Corporation. Caris HIPS/SIPS technology is the sole property of Universal Systems, Ltd.

\section{REPORT PREPARED BY:}

Quester Tangent Corporation

Marine Technology Centre

201-9865 West Saanich Road

Sidney, B.C., Canada V8L 5 Y8

Tel: 1-250-656-6677

Fax: 1-250-655-4696

info@questertangent.com

www.questertangent.com 


\section{Table of Contents}

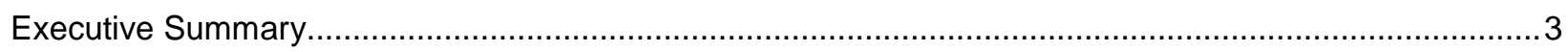

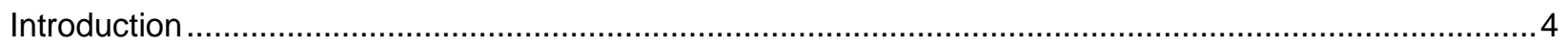

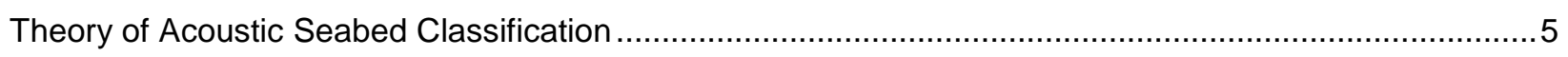

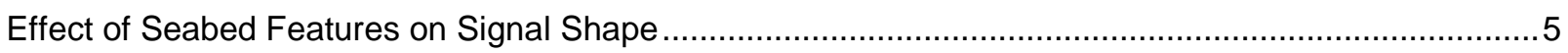

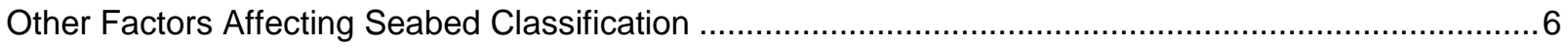

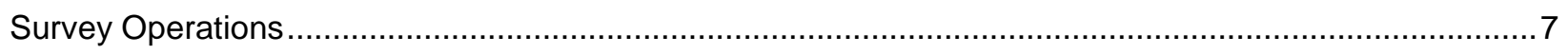

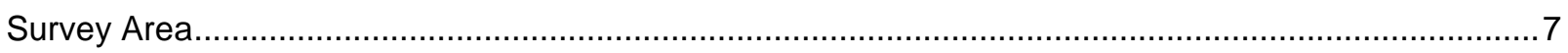

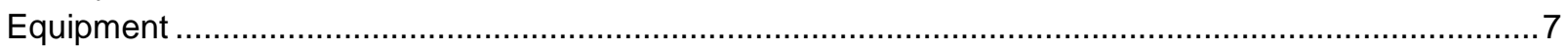

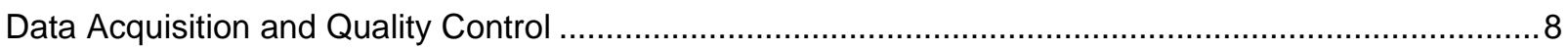

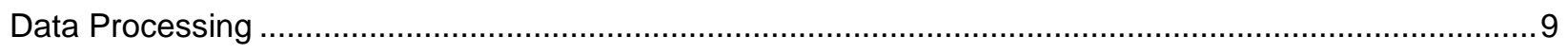

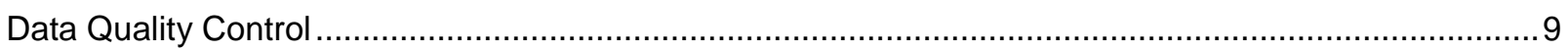

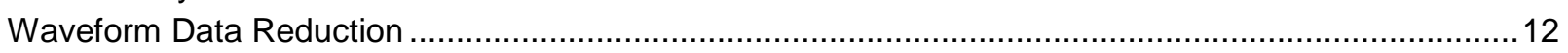

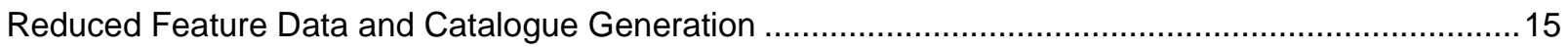

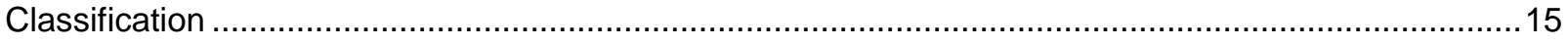

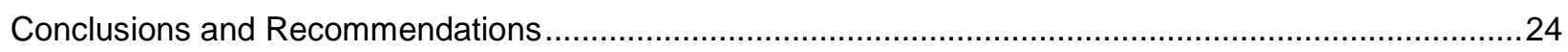

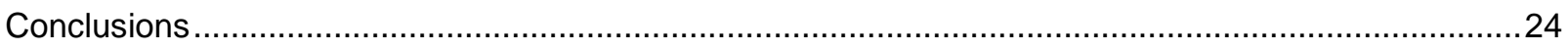

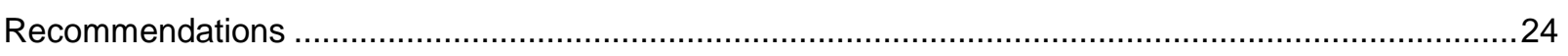

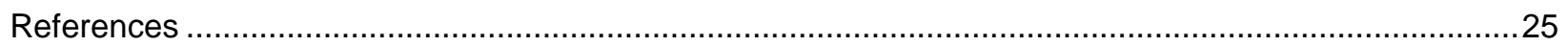




\section{List of Figures}

Figure 1. Comparison of echo traces from two representative seabeds.........................................................

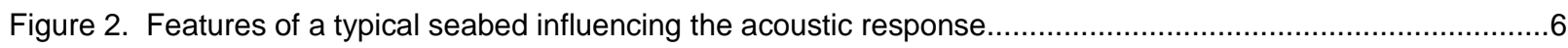

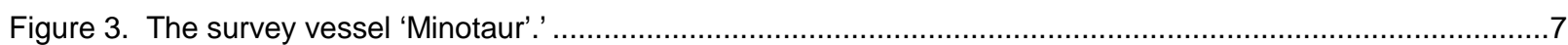

Figure 4. Interconnection diagram for the QTC VIEW TM system.

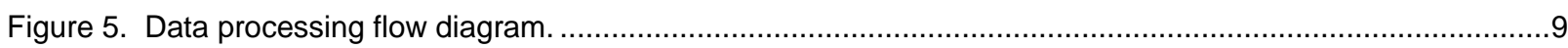

Figure 6. Waveform Editor showing high quality envelope data from February 19, 2005..............................10

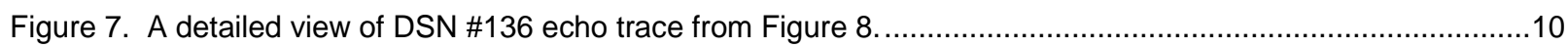

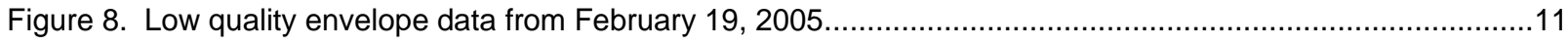

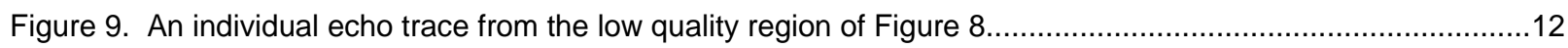

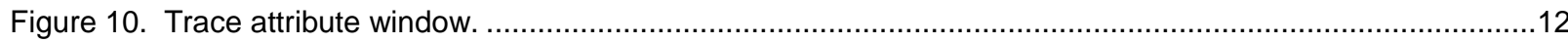

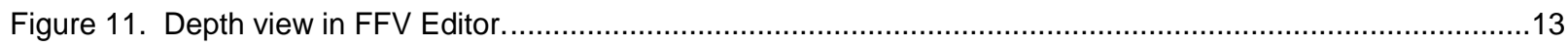

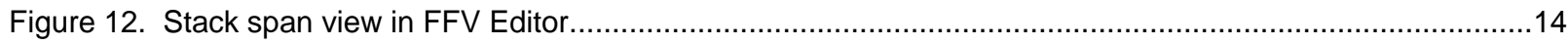

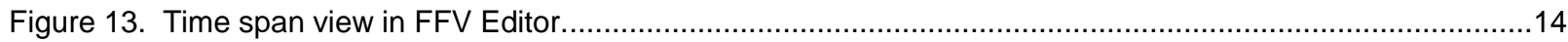

Figure 14. Plot of $Q$-space with ten acoustic classes plotted in similarity colours. ........................................15

Figure 15. Acoustic classification data displayed with similarity colours.......................................................17

Figure 16. Interpolated classes over sun illuminated bathymetry. ......................................................... 18

Figure 17. Alternate view of interpolated classes over sun illuminated bathymetry........................................19

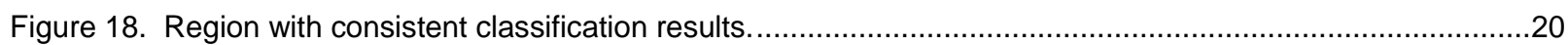

Figure 19. Classification in the region of the San Mateo-Hayward Bridge...................................................

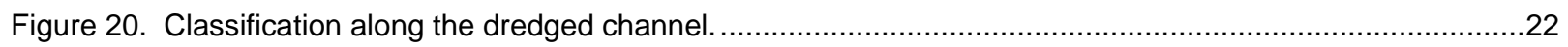

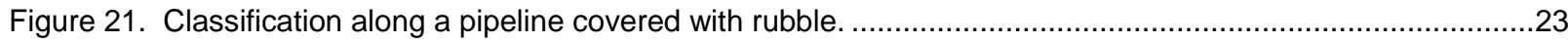

\section{List of Tables}

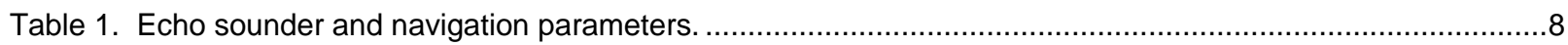

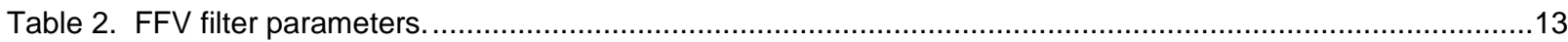

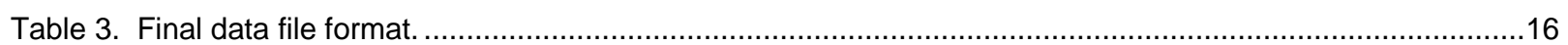




\section{EXECUTIVE SUMMARY}

The transmitted signal from the echo sounder and the first returning echo are captured and digitized by QTC VIEW ${ }^{\mathrm{TM}}$. The digital signal is then processed by a series of algorithms sensitive to different components of the echo shape. This processing generates 166 features of the echo trace, which make up a Full Feature Vector record describing the trace. Statistical analysis provides a means by which the 166 features can be reduced to three so-called Q-values. Each echo, as represented by three Qvalues, can be plotted in three-dimensional Q-space. Echoes from acoustically similar seabeds will form discrete and definable clusters when plotted in Q-space. The information used to reduce the 166 feature elements to the three Q-values are stored in a catalogue. Full Feature Vectors, describing echo traces, are then classified according to the classes defined in the catalogue.

Acoustic seabed classification data were collected in South San Francisco Bay using the QTC VIEWTM seabed classification system. The survey was performed by Sea Surveyor, Inc. for several federal and local regulatory agencies from January until March of 2005. The area of study was surveyed using a QTC VIEW ${ }^{T M}$ connected to a normal-incidence, single-frequency echo sounder. These data were then post-processed using Quester Tangent's acoustic waveform processing toolkit QTC IMPACT ${ }^{\mathrm{TM}}$. An unsupervised catalogue was generated by analysing a representative subset of the population of echoes to determine logical groupings or echo classes. The data were classified with respect to the catalogue and plotted as colour points along the vessel track. 


\section{INTRODUCTION}

Acoustic seabed classification is the organization of seabeds into discrete units based on characteristic acoustic responses generated by an echo sounder (Collins and McConnaughey, 1998). The echo signal shape is the profile, over time, of the acoustic energy redirected to the echo sounder transducer. This energy is influenced by features of the seabed and immediate subsurface.

This report consists of an introduction to acoustic seabed classification followed by a description of the survey operations, the survey area and the equipment used. Data processing techniques are presented including data description, data reduction, catalogue generation and classification. 


\section{THEORY OF ACOUSTIC SEABED CLASSIFICATION}

The amplitude and shape of an acoustic signal reflected from the sea floor is determined by the sea bottom roughness, the contrast in acoustic impedance between water and sea floor, and perturbations caused by inhomogeneities in the substrate's volume. Remote seabed classification requires an acoustic data acquisition system, an algorithm set to analyze the data, an implementation method to determine the seabed type, and ground truth to relate the acoustic classification to seabed features.

The QTC VIEW ${ }^{\mathrm{TM}}$ seabed classification system typically uses the signal from a normal incidence, single-frequency echo sounder (Collins et al., 1996). The system is connected in parallel with the echo sounder transducer and digitally extracts the echo trace. Pre-processing involves identification of the sea floor in the echo trace and filtering to suppress noise.

Echo description is accomplished using several algorithms to extract 166 echo shape features, known as full feature vectors (FFVs), from each trace. Multivariate statistical analysis then identifies the best feature combinations to distinguish groups of echoes representing different seabeds. The feature combinations are reduced to three primary values, known as Q-values, which describe each echo.

Echo classification is accomplished using the three Q-values; it is assumed the acoustic response from like seabeds will be similar. When Q1, Q2 and Q3 are plotted in orthogonal Q-space, seabeds with similar acoustic responses will form clusters. An echo is classified using its position in Q-space with respect to the clusters generated from calibration data; the echo being classed the same as the closest cluster.

The echo classification in Q-space was done without prior knowledge of the sediment at the sites. Therefore, without a catalogue associating clusters to sediment type, unsupervised classification was used to statistically generate clusters from Q-values alone.

The final step was to use these results to generate a catalogue, and to reprocess the echoes from each area according to this catalogue.

\section{Effect of Seabed Features on Signal Shape}

The primary role of an echo sounder is to measure water depth. Details of the echo are usually ignored. Quester Tangent bottom classification is based on these details, which contain information about the bottom type. This necessitates considerations with the returning echo's shape when mapping the sea floor. For example, the echo from a smooth, simple seabed has a sharp rise and a peak followed by a short tail. The response from a rough, complicated seabed will be a peak followed by a slower decay in the signal represented by a longer tail (Figure 1).
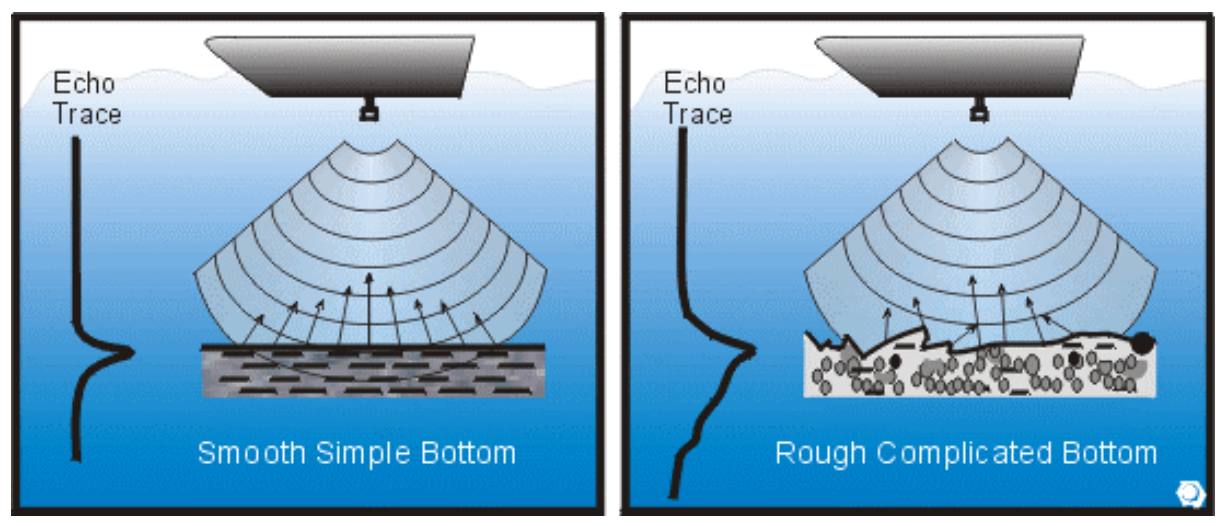

Figure 1. Comparison of echo traces from two representative seabeds. 
While the shape of the returning waveform is related to the target (i.e., sea floor sediments), there are numerous characteristics accounting for the seabed's variability (Figure 2). These include organisms living on or in the seabed. Sedimentary bedforms, such as ripple marks, will influence the echo as will sediment properties including grain size and index properties, such as porosity and density. The signal's shape will be a composite of the above features averaged over the footprint.

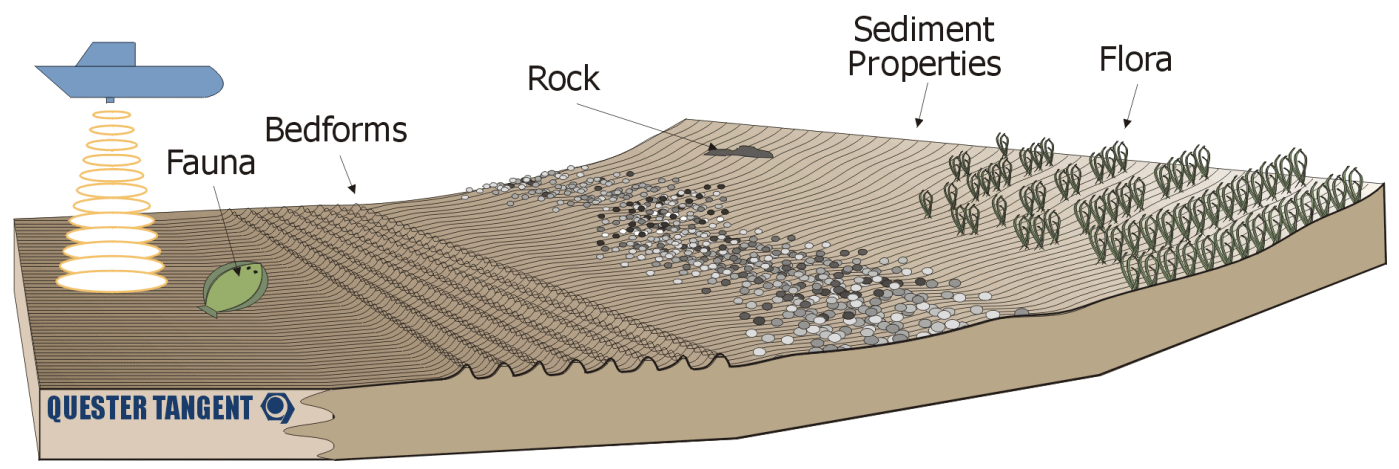

Figure 2. Features of a typical seabed influencing the acoustic response.

\section{Other Factors Affecting Seabed Classification}

Sounder parameters such as beam width and frequency influence classification results (Collins and Rhynas, 1998). Beam width is a measure of the size of the conical shaped path of the transmitted echo pulse. The size of the seabed acoustic footprint is a function of the beam width and the water depth. Frequency is a characteristic of the carrier signal used for insonification. Frequency governs the passage of the acoustic pulse through both water and sediments, and determines the resolution of the data returning to the sounder. High frequency signals $(>100 \mathrm{kHz})$, typically provide greater resolution, suffer greater attenuation in the water column and penetrate centimetres into the seabed depending largely on substrate reflectivity. High frequency transducers have typically smaller beamwidths $\left(10^{\circ}\right.$ $20^{\circ}$ ). Low frequencies, $10 \mathrm{kHz}$ to $100 \mathrm{kHz}$, resolve less than the higher frequencies, exhibit smaller signal losses in the water, and will penetrate tens of centimetres into the seabed. Low frequency transducers generally have larger beamwidths $\left(15^{\circ}-30^{\circ}\right)$. 


\section{SURVEY OPERATIONS}

\section{Survey Area}

The survey area is located in South San Francisco Bay. Water depths range from approximately one to forty meters. The data were collected for bathymetry purposes as well as acoustic seabed classification analysis.

\section{Equipment}

This survey was performed using the Survey Vessel, Minotaur (Figure 3). It is fully equipped for surveying including an echo sounder with an over-the-side mounted transducer, a data management and navigation software package, and a GPS which provided positioning to a QTC View Series V seabed classification system and its management software running on a PC.

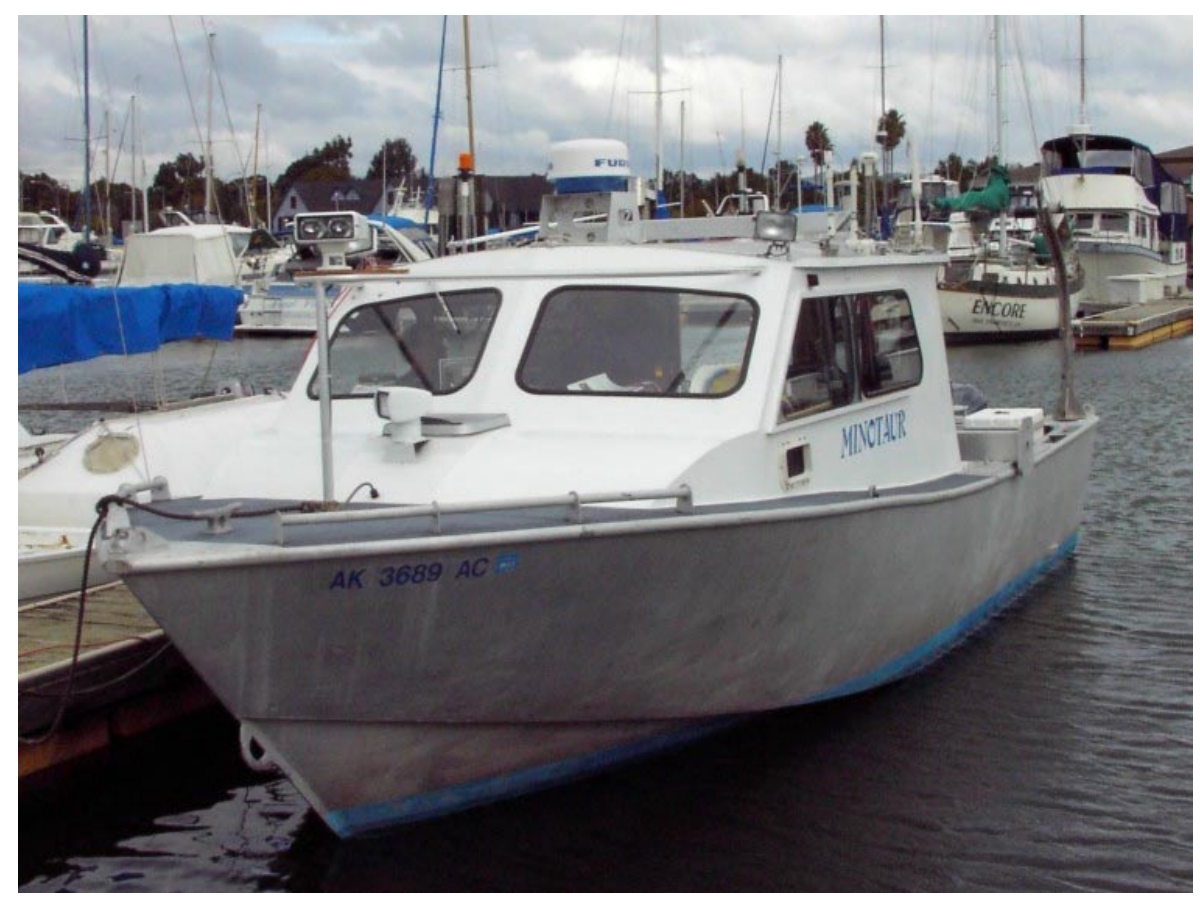

Figure 3. The survey vessel 'Minotaur'.' 


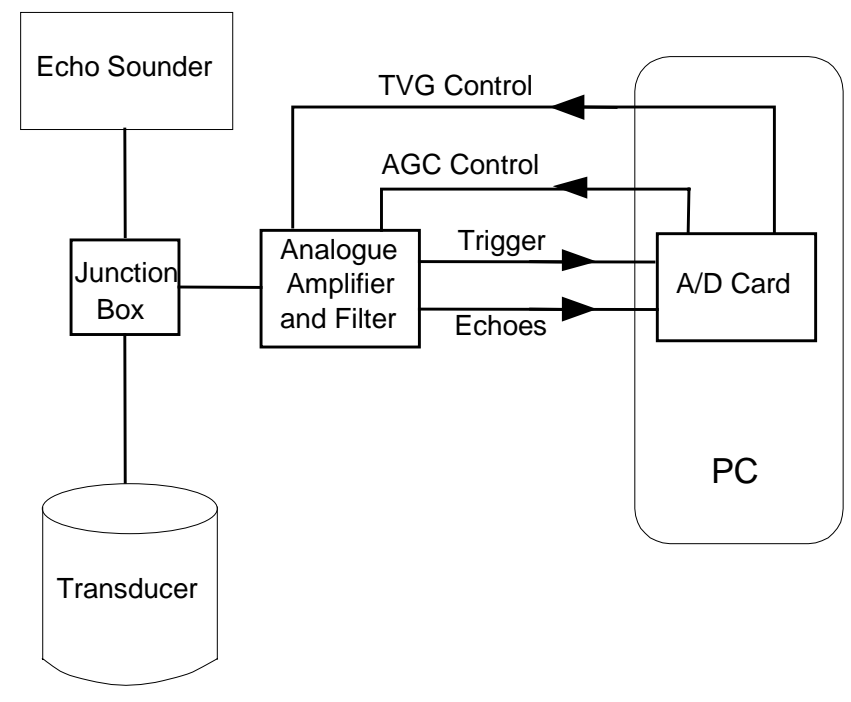

Figure 4. Interconnection diagram for the QTC VIEW ${ }^{T M}$ system.

A Suzuki 2025 echosounder was used for surveying. Table 1 outlines the relevant parameters for seabed classification of this echo sounder.

A QTC VIEW ${ }^{\text {тм }}$ Sounder Interface Module (SIM) was connected in parallel to the echo sounder's transducer (Figure 4). The SIM was also connected to the seabed classification system's computer via a SCSI-like connection to an A/D card. During acquisition both the navigation and sonar data were simultaneously time-stamped and logged to the computer.

\begin{tabular}{|l|l|}
\hline \multicolumn{2}{|c|}{ ECHO SOUNDER PARAMETERS } \\
\hline Frequency & $50 \mathrm{kHz}$ \\
\hline Depth Range & 0 to 40 metres \\
\hline Ping Rate & 3 pings per second \\
\hline Pulse Duration & $0.3 \mathrm{~ms}$ \\
\hline Beam Width & 24 \\
\hline \multicolumn{2}{|c|}{ NAVIGATION PARAMETERS } \\
\hline Update Rate & 1 per second \\
\hline Record Type & \$GPGGA \\
\hline
\end{tabular}

Table 1. Echo sounder and navigation parameters.

\section{Data Acquisition and Quality Control}

The area was surveyed from January 10 to March 12, 2005 with the QTC VIEW ${ }^{\mathrm{TM}}$ acoustic seabed classification system. The system digitally acquired each raw echo at a rate of approximately three per second and logged the waveform for post-processing. GPS navigation data were simultaneously logged as comma-delimited ASCII records which in this case were a NMEA GPGGA string. In postprocessing, the sonar and navigation records were merged based on a high resolution time-stamp tagged to each record at the time of logging. Both the full waveform (FWF) and envelope data were logged by the system. The sonar data were stored in a QTC proprietary format. 


\section{DATA PROCESSING}

Following data acquisition the navigation and sonar data were loaded into QTC IMPACT ${ }^{\text {TM }}$ for processing. Data from the echo sounder were processed and classified.

The flow of data processing is displayed in Figure 5. The seabed classification process includes quality assurance by viewing the raw echo traces, extraction of feature set to be used as echo description, principal components analysis for data reduction and cluster analysis to identify acoustic regimes which were then assigned to an acoustic class.

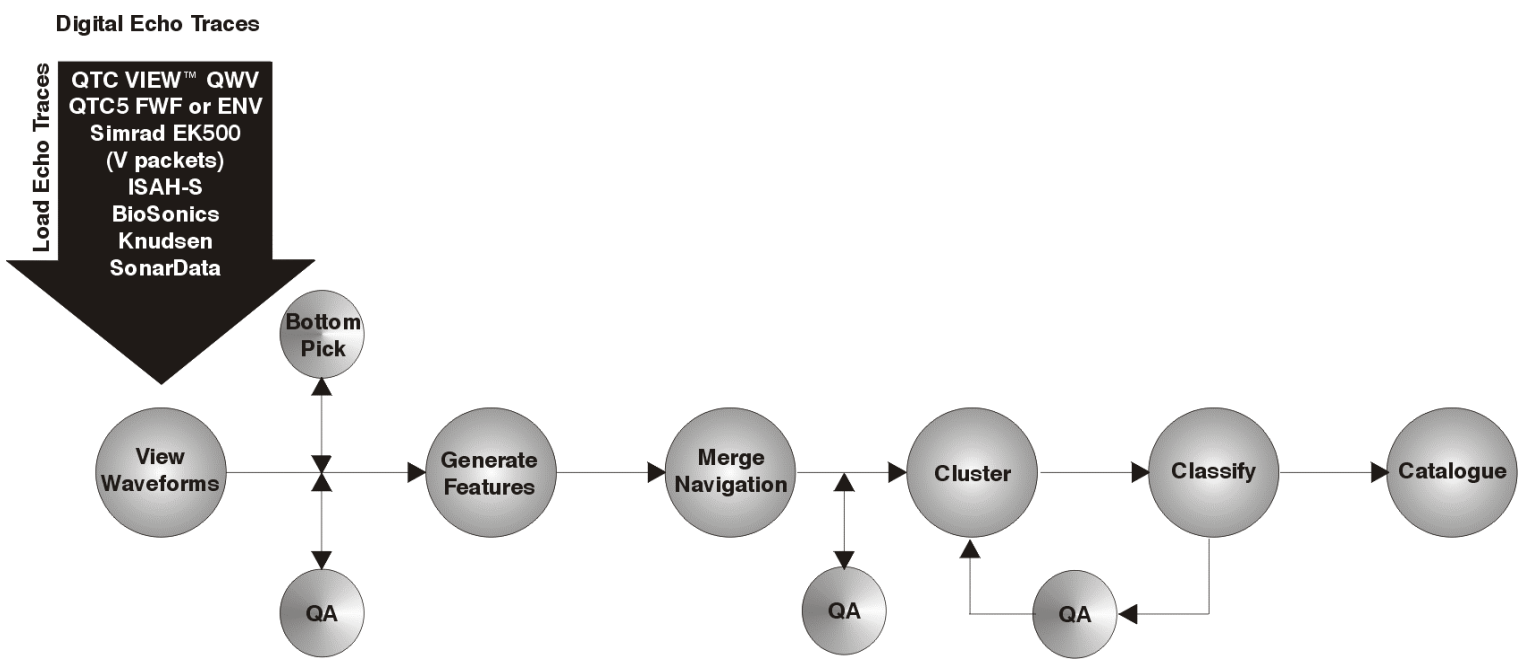

Figure 5. Data processing flow diagram.

\section{Data Quality Control}

A critical step in processing the data prior to classification is quality assessment. The envelope data were loaded into QTC IMPACT and the waveforms were visually evaluated using the Waveform Editor

All of the following figures, including the screen captures from the Waveform Editor and FFV Editor, display actual data from the analyzed data set.

The group of waveforms in Figure 6 represent good quality full waveform data with a red line indicating the depth the waveform was recorded. Figure 7 shows the waveform DSN \#136 from Figure 6 in a single trace viewer. In this view a user can see the details of the waveform and also the amplitude of the signal in samples. QTC VIEW ${ }^{\mathrm{TM}}$ Series V data is 12 bit data so the maximum signal amplitude is 2048 samples.

Figures 8 and 9 show poor quality envelope data. The envelope trace in Figure 9 on of the echoes that are represented in Figure 8. 


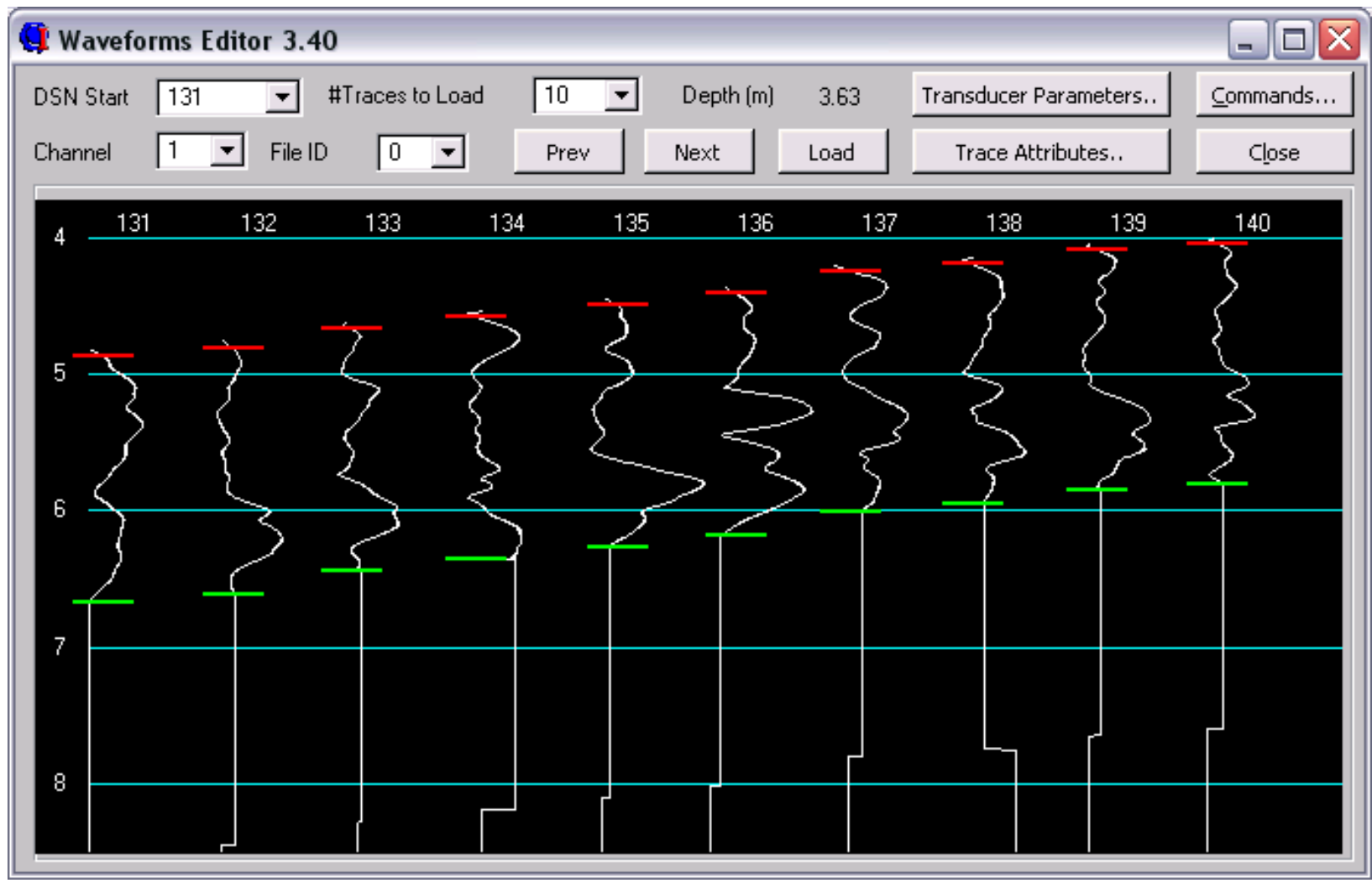

Figure 6. Waveform Editor showing high quality envelope data from February 19, 2005.

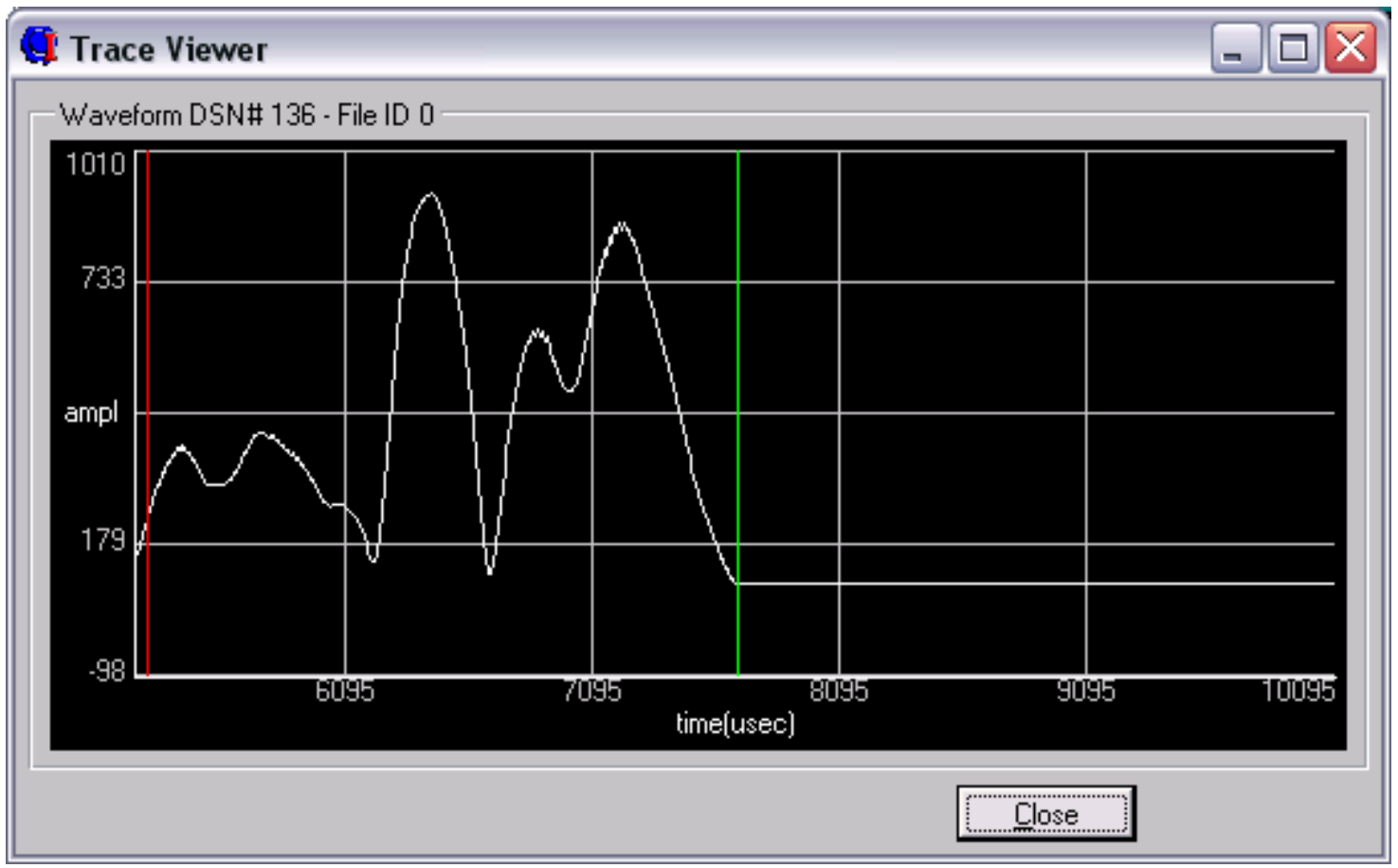

Figure 7. A detailed view of DSN \#136 echo trace from Figure 8. 


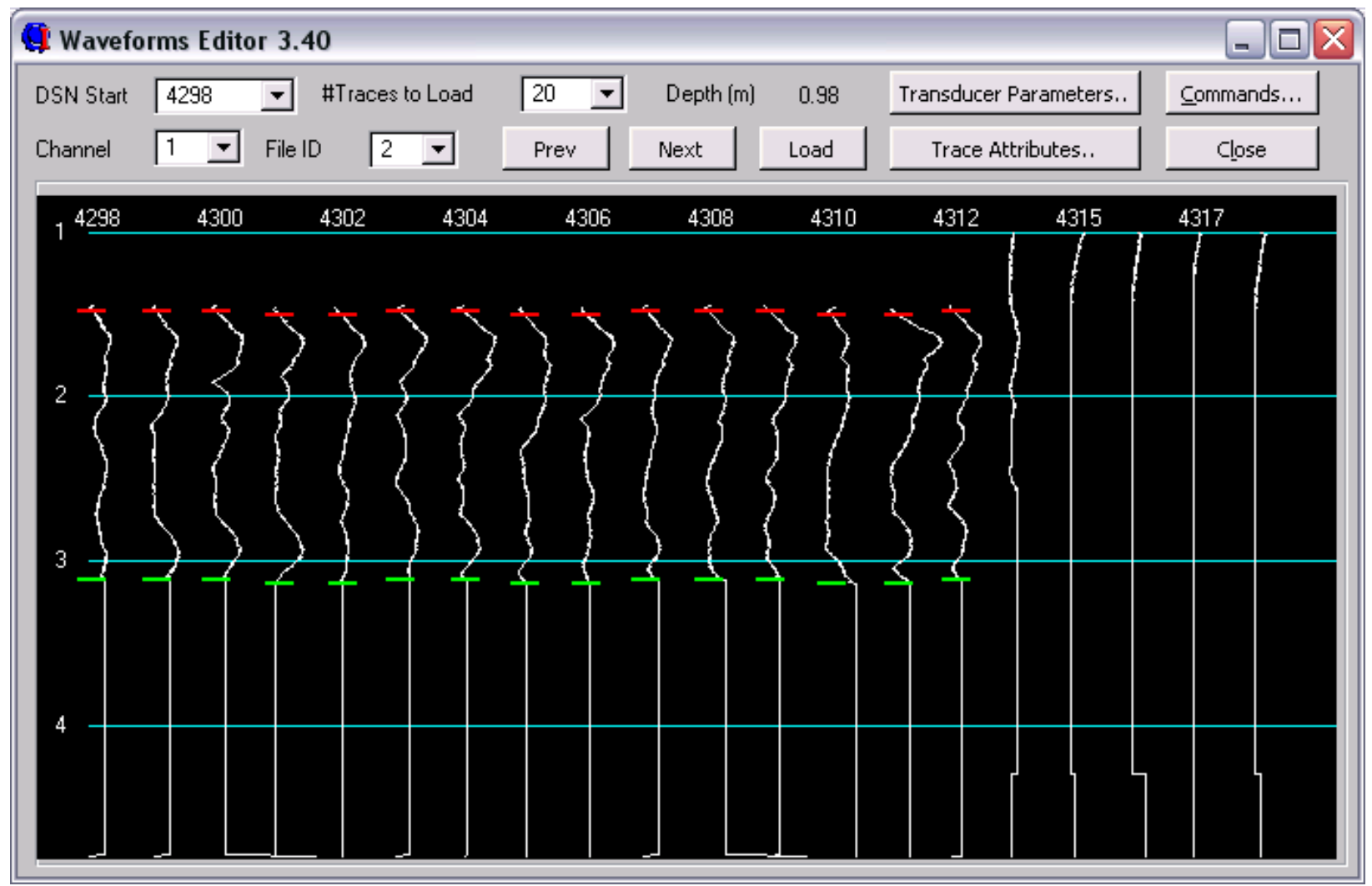

Figure 8. Low quality envelope data from February 19, 2005. DSN \#4313 - 4318 represent low quality data.

Figures 8 and 9 are examples of poor quality envelope data. Figure 9 displays waveform DSN \#4315 from Figure 8. It appears that the depth has gone shallower than the blanking depth resulting in low quality, low signal strength echoes. 


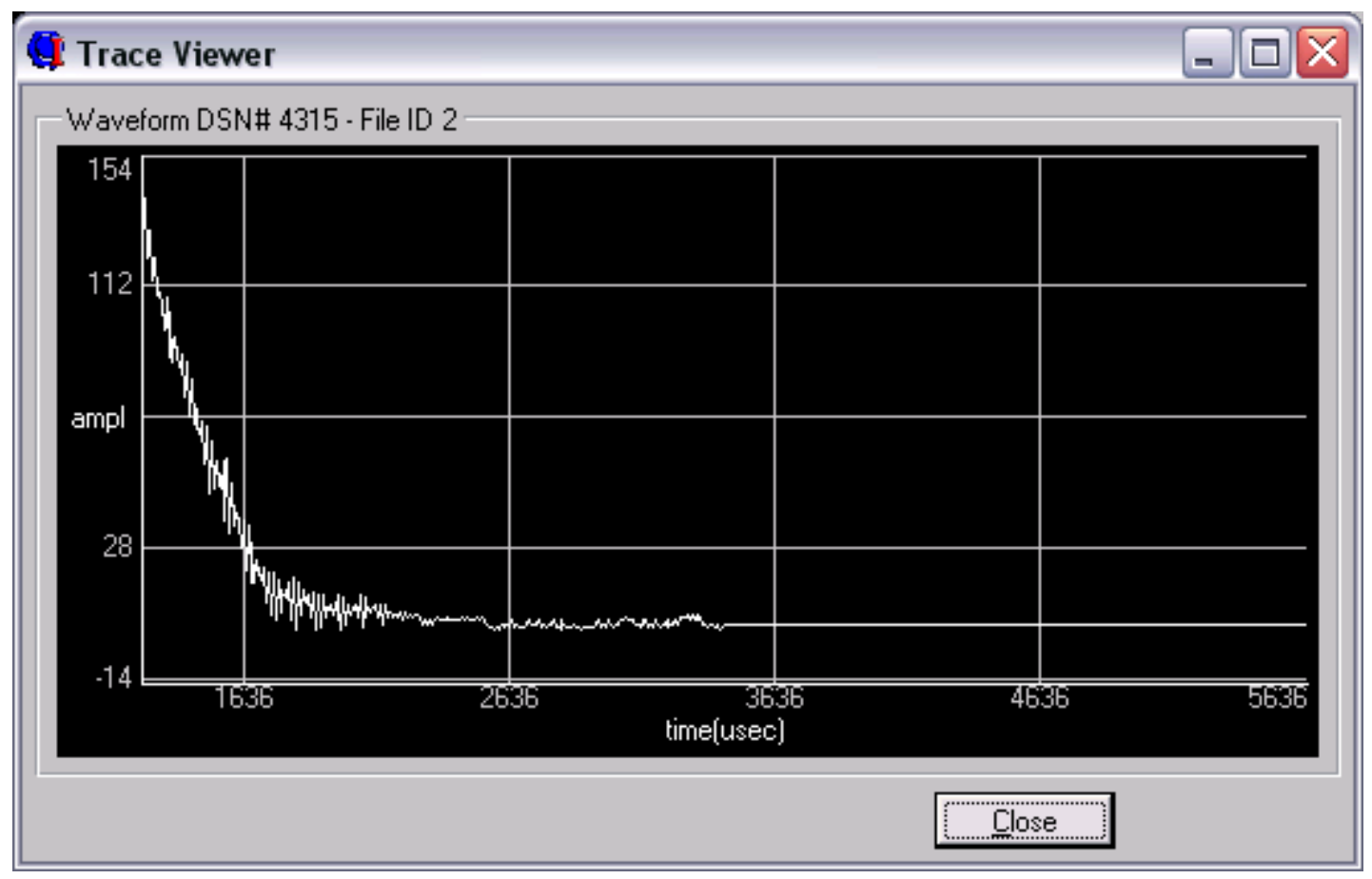

Figure 9. An individual echo trace from the low quality region of Figure 8

Figure 10 is the trace attributes window which is available in the Waveform Editor. This window gives a user valuable qualitative and quantitative information on each waveform. The time stamps can be used to determine how fast the system logged data, or by using the signal strength as a percentage, the signal amplitude as a ratio of the maximum signal possible can be seen.

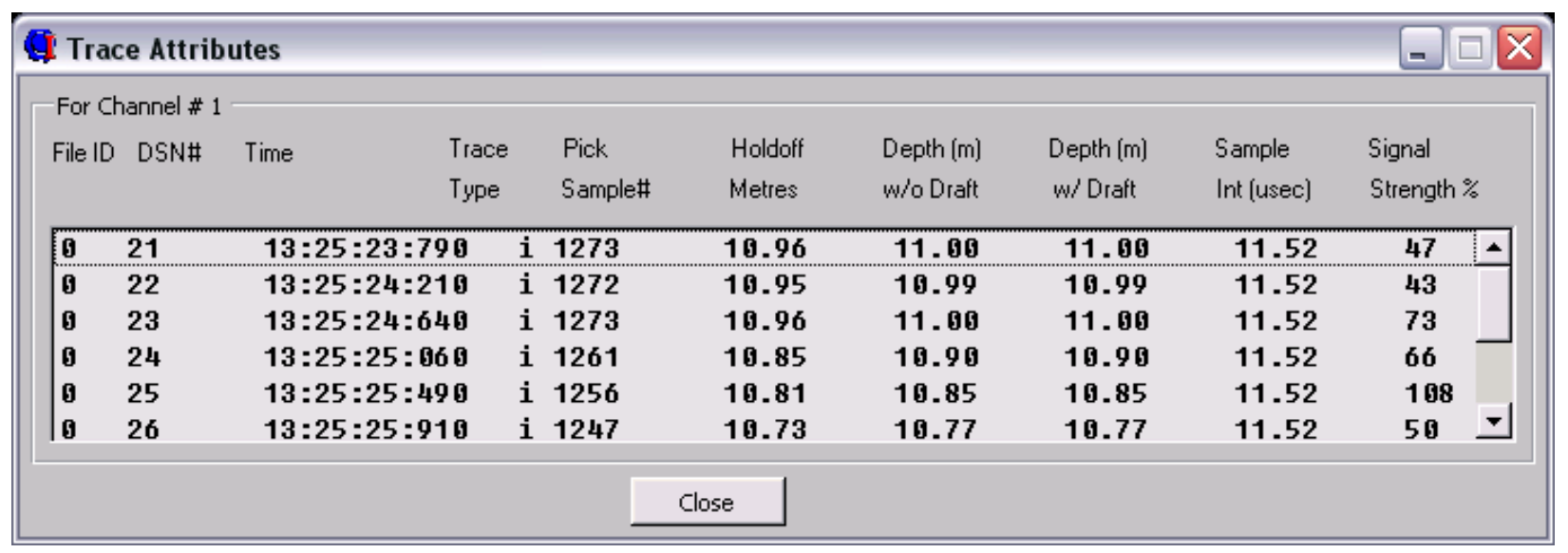

Figure 10. Trace attribute window.

\section{Waveform Data Reduction}

This process reduced over 2.5 million sonar envelopes to approximately 515,000 records called Full Feature Vectors (FFV). Each FFV is comprised of 166 parameters that describe each individual echo and were derived from Quester Tangent's suite of algorithms. In preparation for the next level of data cleaning each FFV was merged with the closest position record. 
The next step of quality assessment occurs after Full Feature Vectors (FFVs) are created. Using the FFV editor, the FFVs were viewed with respect to different parameters. These data were viewed by depth (Figure 11), stack span (Figure 12) and time span (Figure 13). The FFVs can be readily cleaned in either the FFV Editor or by utilising the FFV Filter. The FFV records are flagged as rejected or filtered and then excluded from classification. Data displayed as green dots are good quality data. Data displayed as yellow or red have been flagged and will not be carried any further in the classification process. The parameters used for FFV filtering are outlined in Table 2. In addition to these filters, some manual rejecting was performed to eliminate some erroneous depths. The resulting file was used to define a reference set for making a catalogue of seabed classes across the survey site.

There were over 515,000 FFVs before the editing was performed. Over 60,000 data points (approximately 12\%) were filtered or rejected. Typically, $10 \%$ of the data are rejected so $12 \%$ data loss is reasonable.

\begin{tabular}{|l|l|}
\hline Filter & \multicolumn{1}{|c|}{ Value } \\
\hline Depths & Excluded depths between 0 and 1 metre. \\
\hline Stack Span & Excluded stack spans greater than 1.00 meters \\
\hline Time Span & Excluded time spans greater than $2000 \mathrm{~ms}$ \\
\hline
\end{tabular}

Table 2. FFV filter parameters.

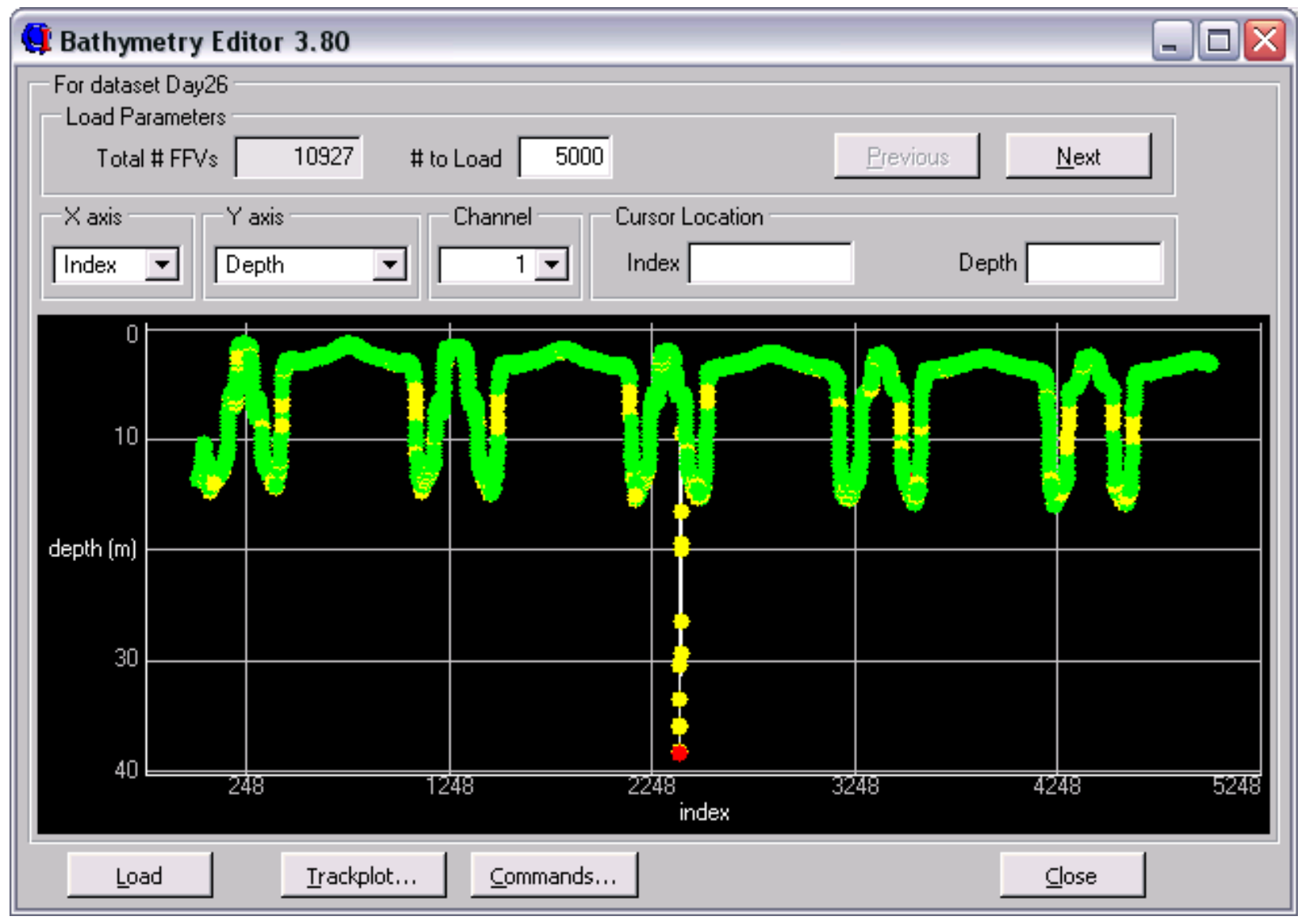

Figure 11. Depth view in FFV Editor.

The data displayed are from February 8, 2005. Regions with poor quality data have been filtered or rejected. 


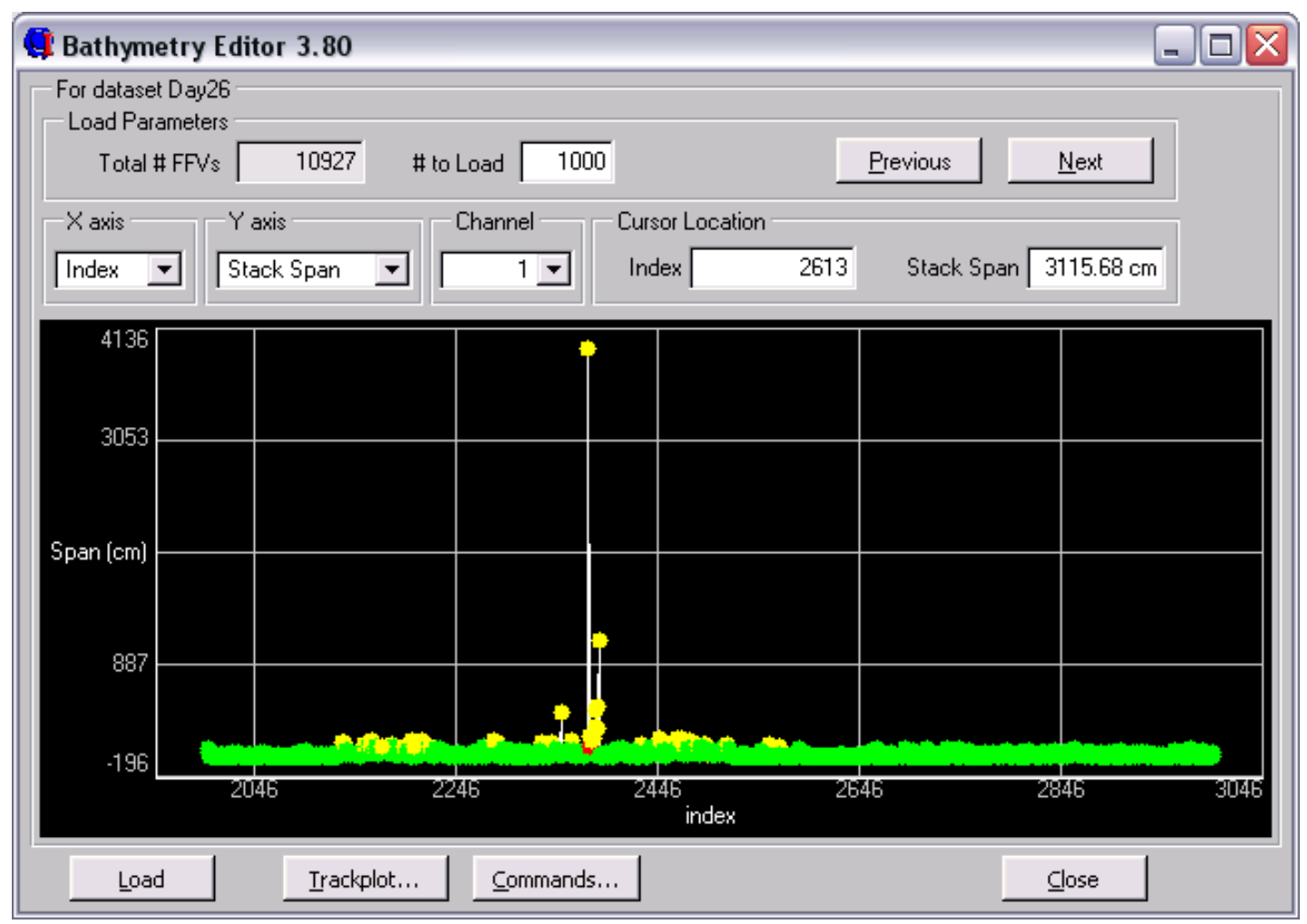

Figure 12. Stack span view in FFV Editor.

The data displayed are from February 9, 2005.

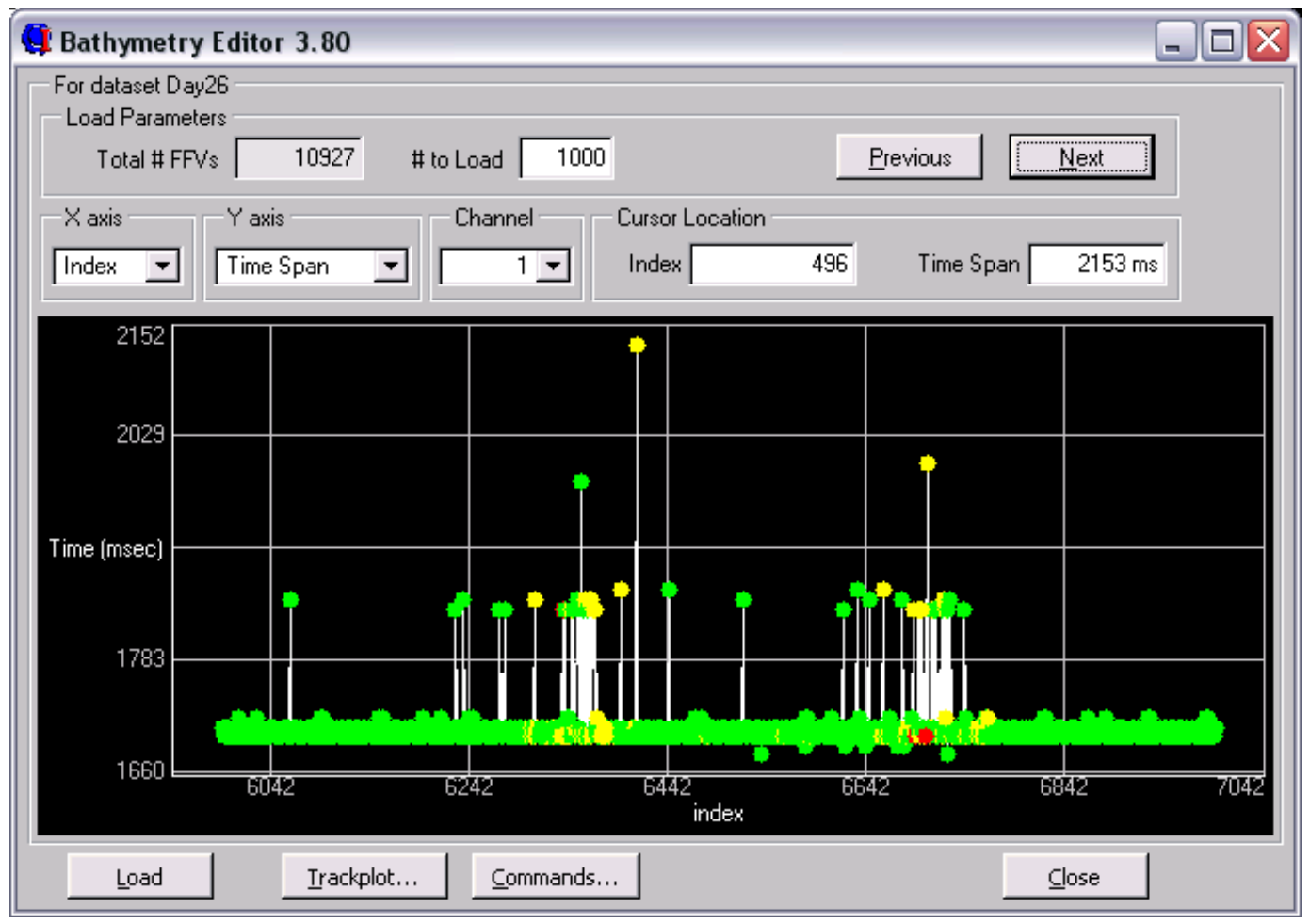

Figure 13. Time span view in FFV Editor.

The data displayed are from February 9, 2005. 


\section{Reduced Feature Data and Catalogue Generation}

Each FFV record from the reference set was reduced to three Q-values using a multivariate statistical technique. The Q-values were then submitted to a proprietary cluster tool to identify logical populations of echoes. Twelve populations of echoes were identified in the data. The data were displayed in Q-space as coloured points, each colour representing an acoustic class (Figure 14). Wiremesh ellipsoids representing a surface one standard deviation from the mean of each cluster were also shown to indicate class covariance.

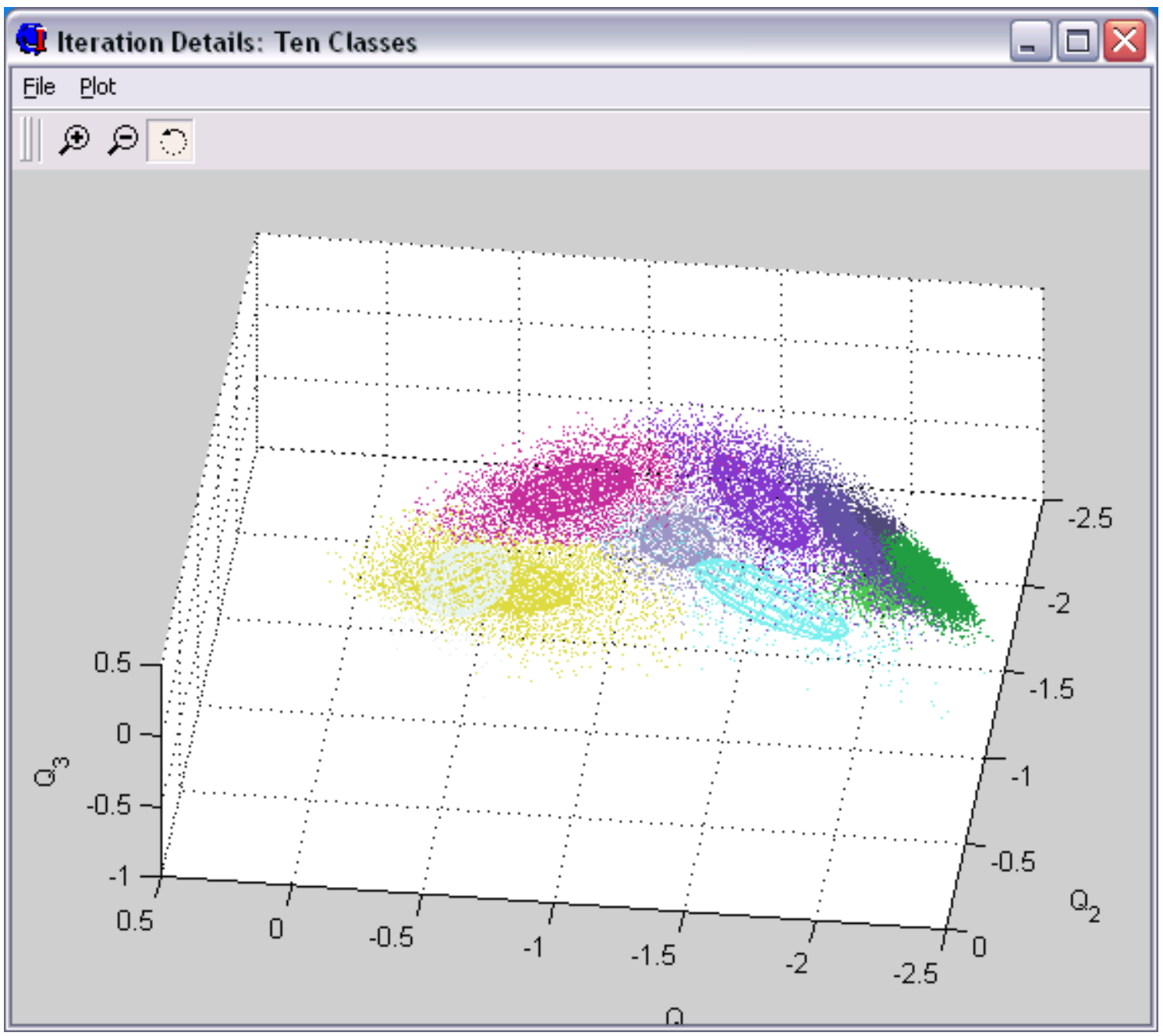

Figure 14. Plot of Q-space with ten acoustic classes plotted in similarity colours.

Similarity colours means that similar acoustic classes are displayed with similar colours.

Once the clusters were determined, their mathematical descriptions were stored with the results from the multivariate analysis, used to reduce the FFV information to the three Q-values, to comprise the catalogue. This catalogue was then used in preparing the final classification map.

\section{Classification}

The analysis consisted of defining twelve classes using the raw echoes collected during the survey. The resulting data file was merged with the position information to generate a geo-referenced classification data set constituting the final data product. The file format is a comma-delimited text file, known as a seabed file. It contains processing date, time stamp, latitude and longitude in decimal 
degrees, depth, $\mathrm{Q}_{1}, \mathrm{Q}_{2}, \mathrm{Q}_{3}$, confidence, probability, classification number, classification name, source survey name, source date stamp, source data set name, source FFV file channel, and source FFV file record index. Table 3 presents a section of this seabed file. A map of the ten classes was produced (Figure 15). The classes are plotted with the same similarity colours shown in the Q-space in Figure 14.

Absolute ground types have not been assigned to the acoustic classification. When the ground truth data becomes available, association of acoustic class with sediment type will be possible.

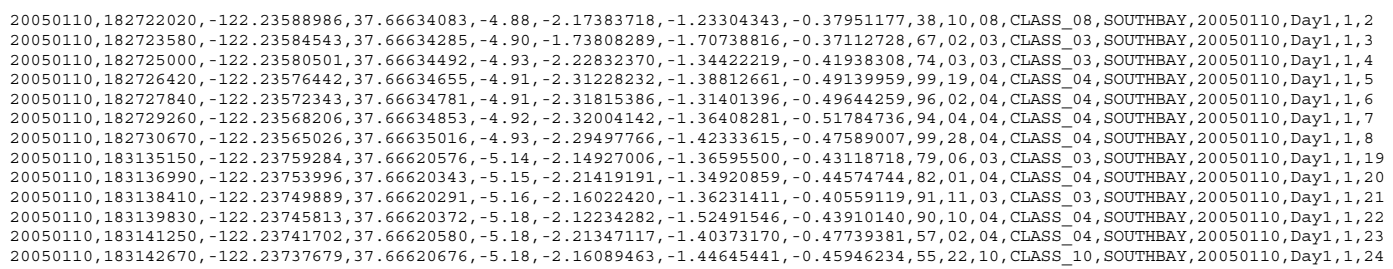

Table 3. Final data file format.

Examples of consistent classification are also displayed in Figures 18. Consistent classification is where there are areas of homogeneity with distinct borders between classes. Another example of classification consistency is crossing tracklines that have the same class at the crossing point. Figures 19 through 21 show areas of interest with discrete features showing prominently in the classification.

Please note, the seabed files in both lat/long and UTM (Zone 10, WGS84) are included on the data report CD. In addition, figures 14 through 18 have been included in Surfer ${ }^{\mathrm{TM}}$ format. 


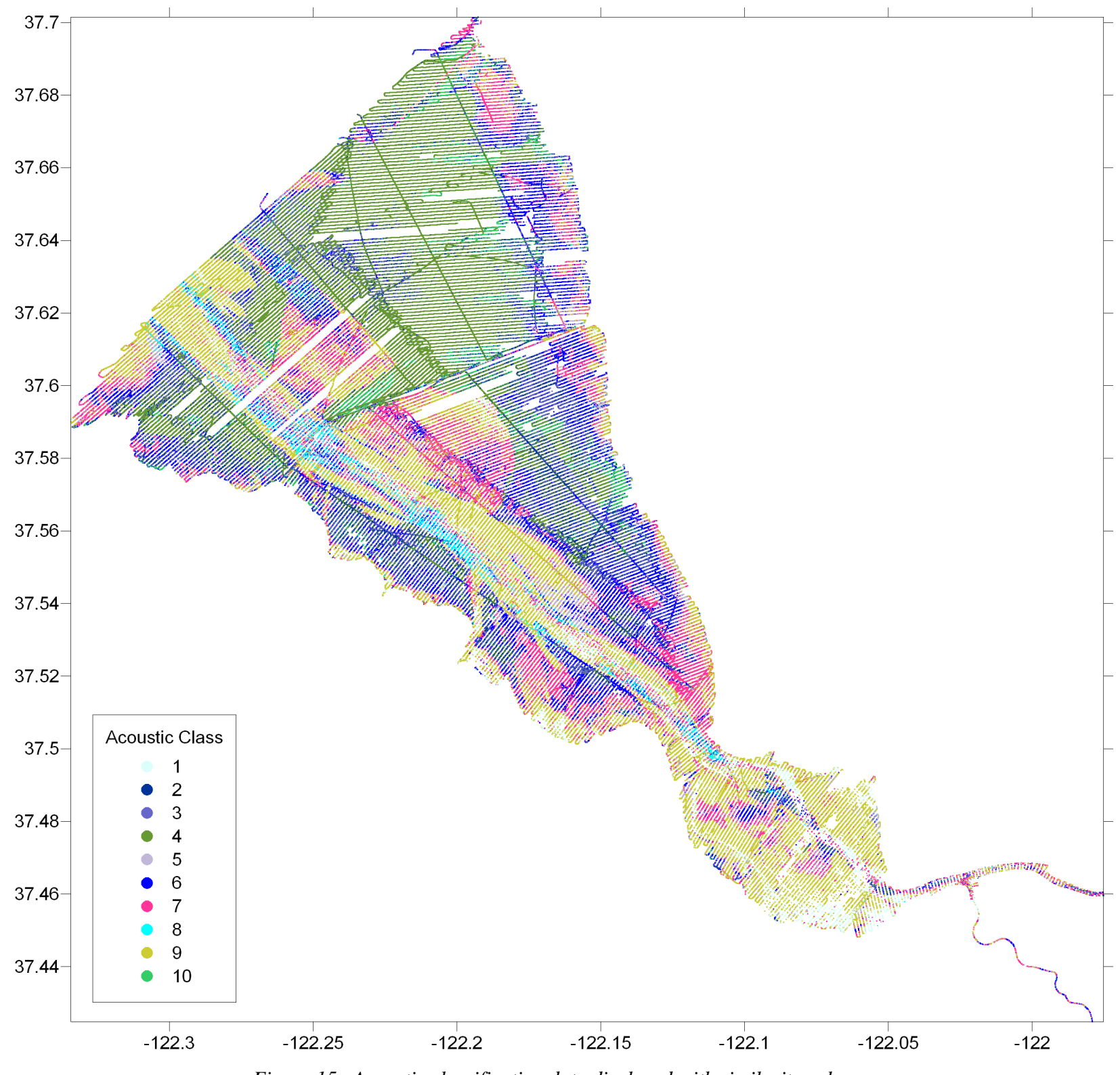

Figure 15. Acoustic classification data displayed with similarity colours. 


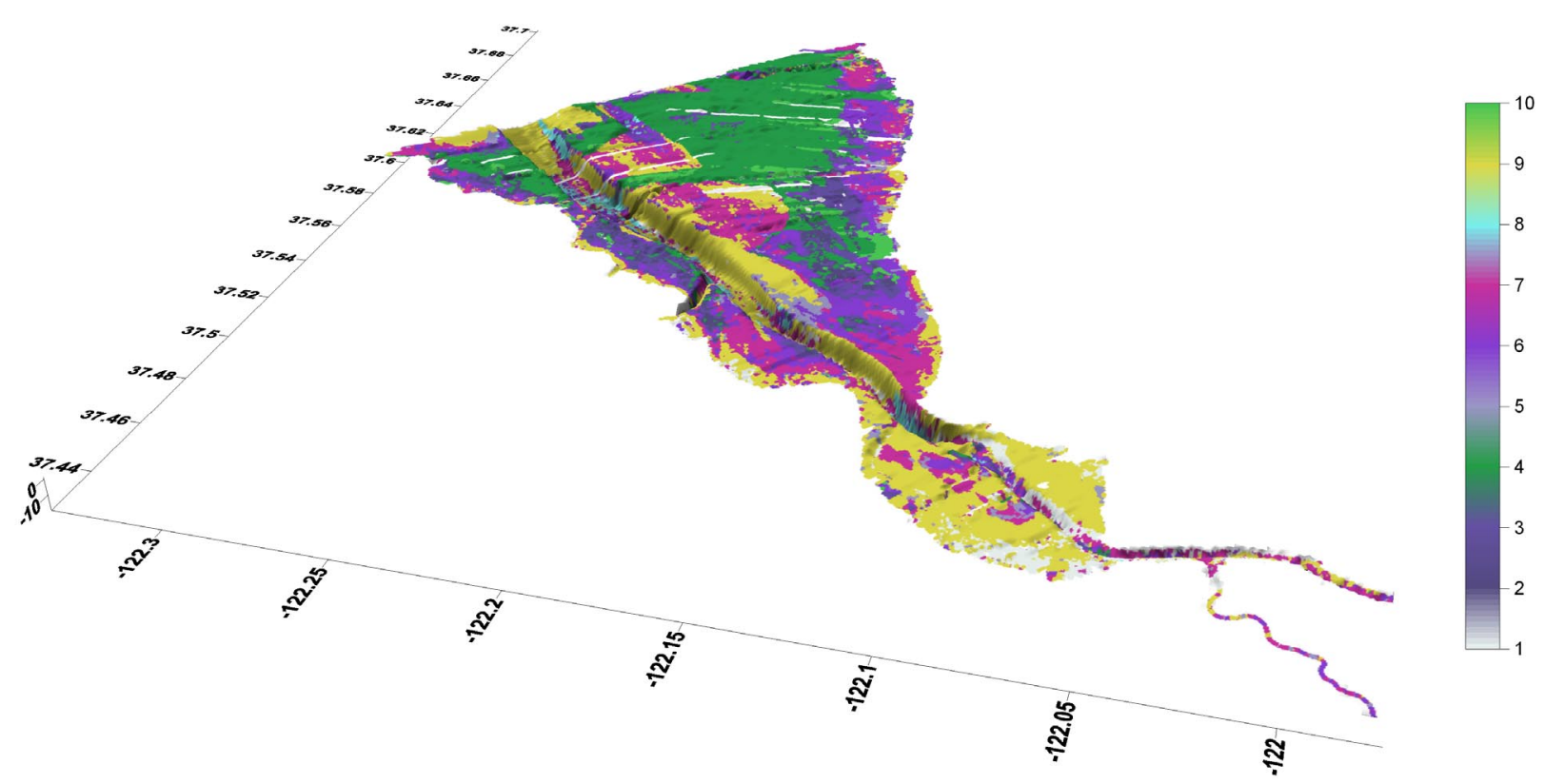

Figure 16. Interpolated classes over sun illuminated bathymetry.

Interpolated with colours painted using similarity colours (acoustically similar classes have similar colours). The gridding was accomplished in QTC CLAMS with a grid size of $25 \mathrm{~m}$, a search radius of $75 \mathrm{~m}$ utilizing a maximum of 100 points per buffer. 


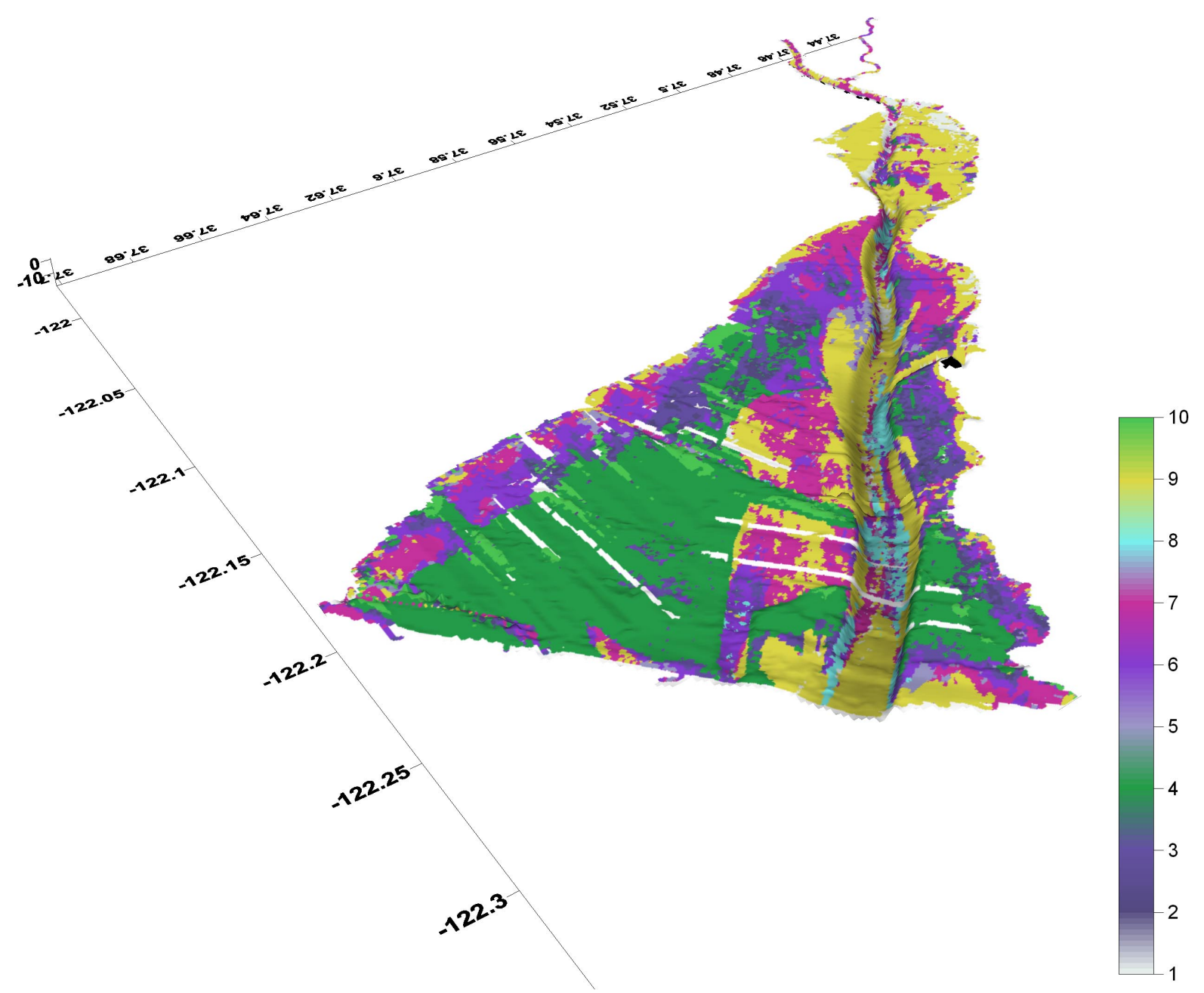

Figure 17. Alternate view of interpolated classes over sun illuminated bathymetry. 


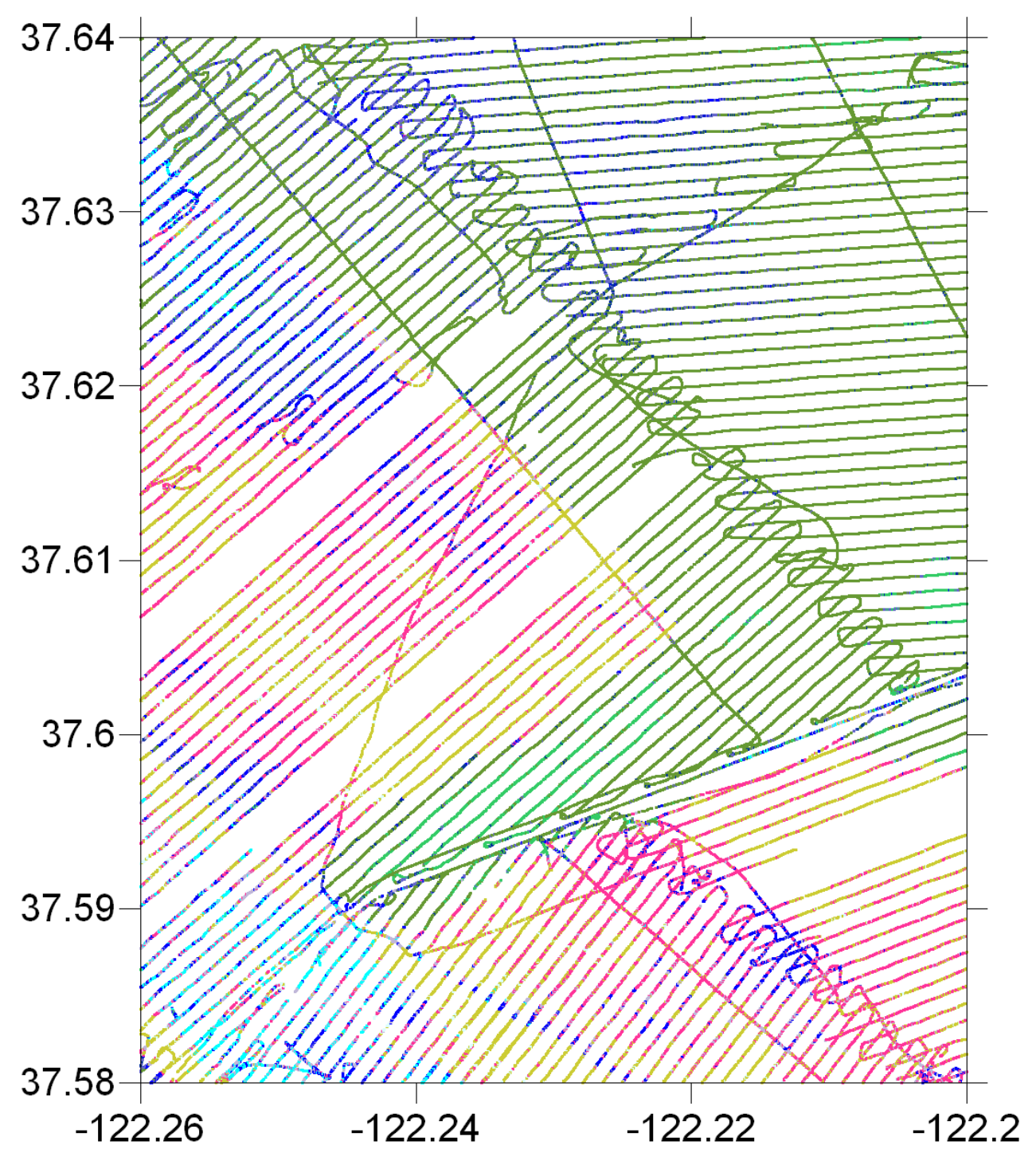

Figure 18. Region with consistent classification results. 


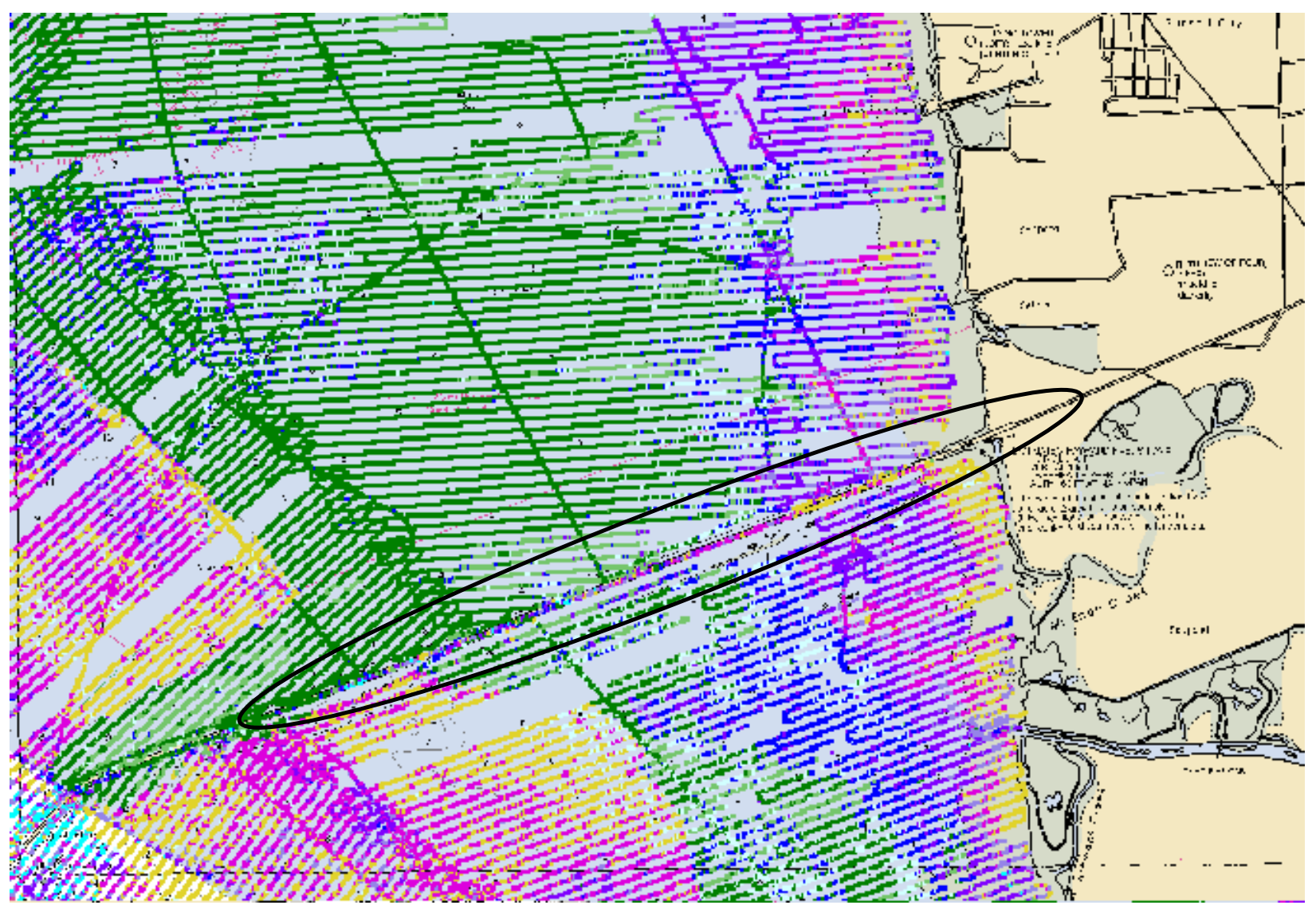

Figure 19. Classification in the region of the San Mateo-Hayward Bridge. Image produced using Caris $^{T M}$ HIPS/SIPS. 


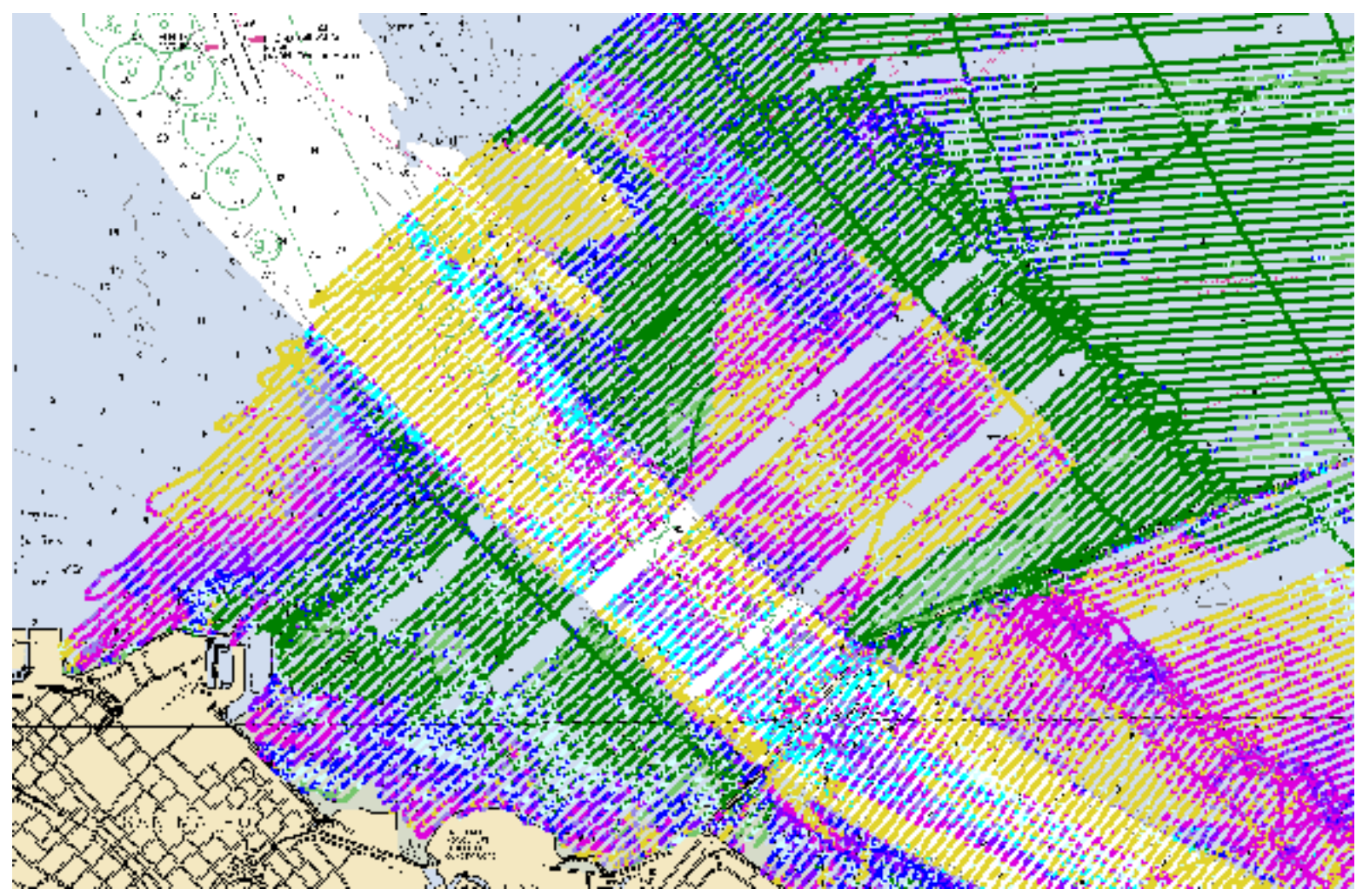

Figure 20. Classification along the dredged channel. Image produced using Caris $^{T M}$ HIPS/SIPS. 


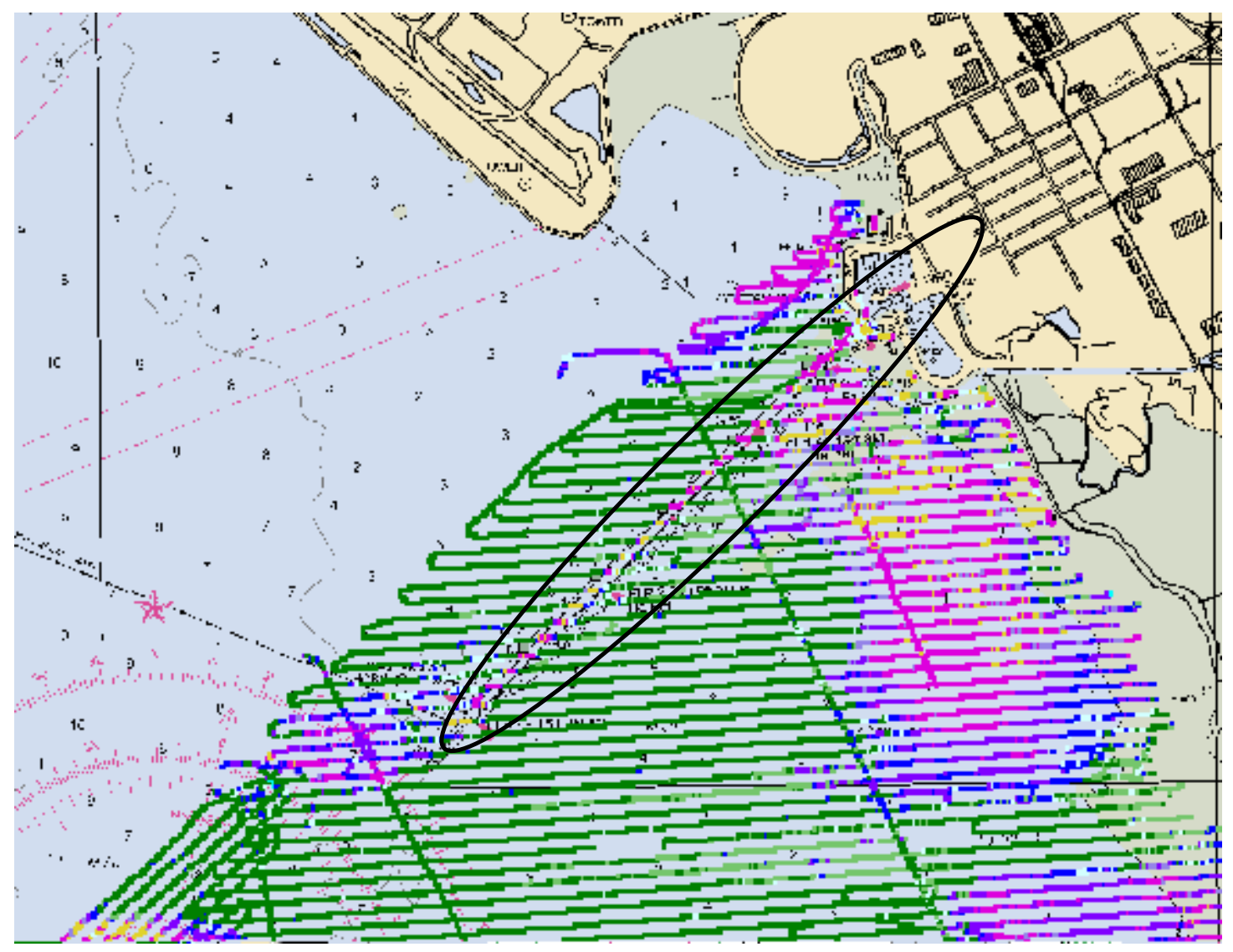

Figure 21. Classification along a pipeline covered with rubble. Image produced using Caris ${ }^{T M}$ HIPS/SIPS. 


\section{CONCLUSIONS AND RECOMMENDATIONS}

\section{Conclusions}

1. We conclude that acquisition of acoustic data for the purpose of seabed classification can be carried out simultaneous to a standard bathymetry survey.

2. We conclude that acquisition of acoustic data was an effective means to classifying sediments.

3. We conclude that acoustic seabed classification was able to identify 10 distinct acoustic classes using $50 \mathrm{kHz}$.

\section{Recommendations}

1. We recommend that correlation analysis be undertaken to identify sediments now represented by acoustic classes.

2. We recommend that the collection of acoustic seabed classification data be specified in future contract surveys. 


\section{REFERENCES}

Collins, W.T., Gregory, R.S. and Anderson, J.T. (1996), “A Digital Approach to Seabed Classification”, Sea Technology, pp. 83-87, Vol. 37, No. 8.

Collins, W.T. and Rhynas, K. (1998), “Acoustic Seabed Classification Using Echo Sounders: Operational Considerations and Strategies", Proceedings from the 1998 Canadian Hydrographic Conference, Victoria, B.C., Canada, March 1998.

Collins, W.T. and R. McConnaughey (1998), “Acoustic Classification as Synoptic Environmental Data to Address Essential Fish Habitat Requirements”, Abstract, Western Groundfish Conference, Pacific Grove, California, February 2-5, 1998.

Freitas, R., Silva, S., Quintino, V., Rodrigues, A.M., Rhynas, K., and Collins, W.T., "Acoustic seabed classification of marine habitats: studies in the western coastal-shelf area of Portugal," ICES J. of Marine Science vol. 60, pp. 599608 (2003).

Preston, J.M., and Collins, W.T., "Bottom classification in very shallow water by high-speed data acquisition", Proceedings IEEE Oceans 'O0, vol. 2, pp. 1277-1282 (2000).

Preston, J., Collins, W.T., Mosher, D.C., Poeckert, R.H., and Kuwahara, R.H., "The strength of correlations between geotechnical variables and acoustic classifications," Proceedings IEEE Oceans '99, vol. 3, pp. 1123-1127 (1999).

All of these references can be found at www.questertangent.com. 


\section{Appendix II}




\title{
SUMMARY OF PROCEDURES AND RESULTS SOUTH SAN FRANCISCO BAY VERTICAL DATUM DETERMINATION AND CONVERSION STUDY
}

\author{
Supporting the 2005 USGS South San Francisco Bay Bathymetric Survey
}

South Bay Salt Pond Restoration Project

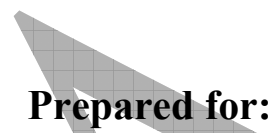

Dr. Bruce Jaffe

United States Geological Survey

400 Natural Bridges Drive Santa Cruz, CA 95060

By:

The Center for Operational Oceanographic Products and Services

NOAA National Ocean Service

SSMC4 1305 East West Highway

Silver Spring, MD 20910

November 2005 


\section{INTRODUCTION:}

In August of 2004, Dr. Bruce Jaffe, United States Geological Survey (USGS) Santa Cruz, CA requested assistance from the National Ocean Service (NOS) in providing tidal datum vertical control and geodetic conversions for a new bathymetric survey planned for South San Francisco Bay. The Bathymetric Survey, in support of the South Bay Salt Pond Restoration Project, was to be integrated with previous LIDAR surveys for the purpose of determining the extent of geomorphic changes over time in South San Francisco Bay and the amount of sediment available for restoration purposes throughout the designated Salt Pond study region.

\section{BACKGROUND:}

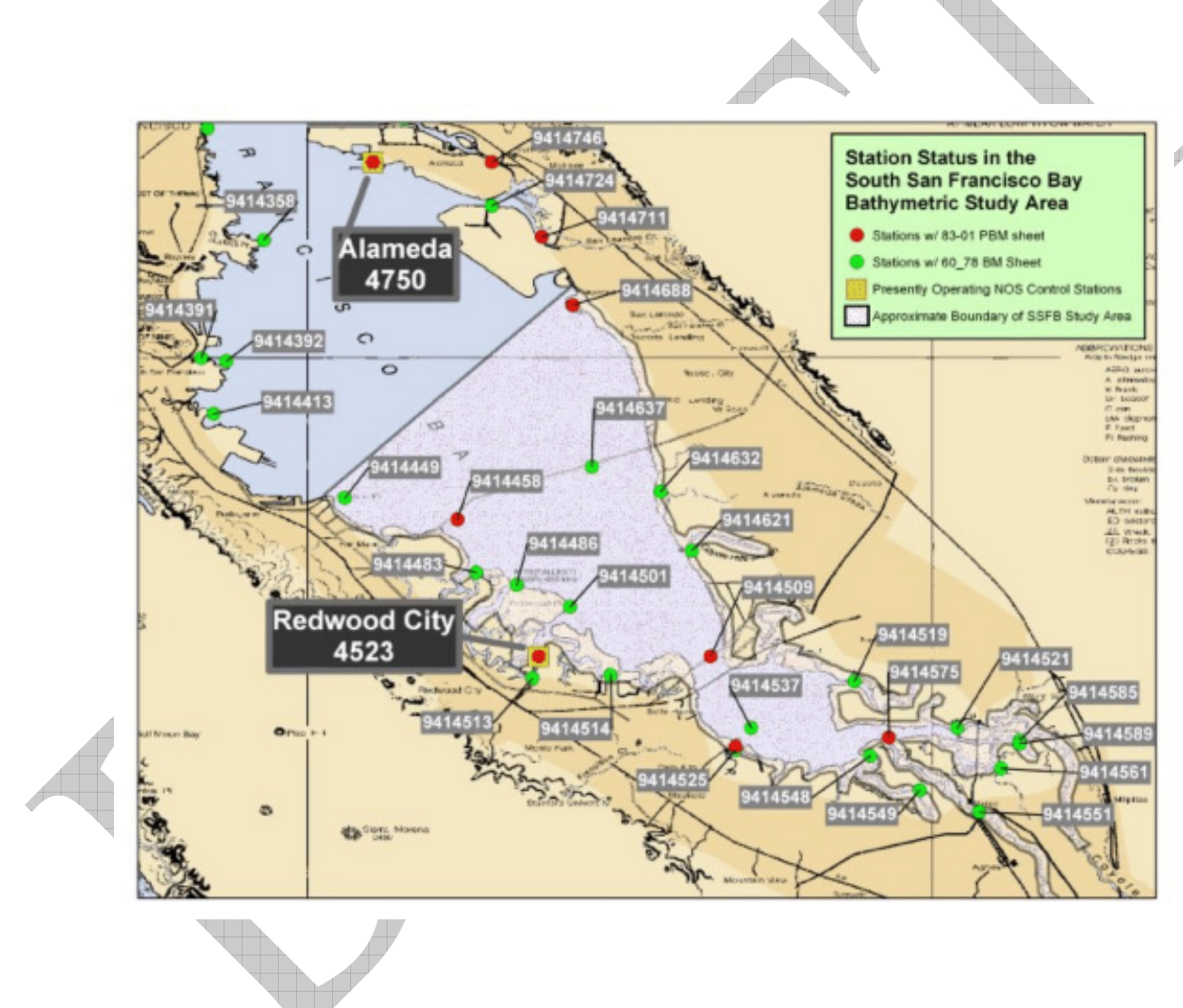

Following the request from Dr. Jaffe's office for assistance in scoping tidal requirements for a planned bathymetric survey of South San Francisco Bay, Oceanographers in the NOS Center for Operational Oceanographic Products and Services (CO-OPS) responded in September 2005 with recommendations for providing tidal datum vertical control in the South San Francisco Bay, from the area just below San Mateo Bridge to the lower regions of the bay in Coyote Creek and Alviso Slough. Recommendations were based on analysis of tidal characteristics at historic tide stations in the area and NOS accepted standards and criteria for hydrographic survey tide control. Four stations were selected at 9414688 San Leandro Marina, 9414458 San Mateo Bridge, West Side, 9414509 Dumbarton Bridge and 9414575 Coyote Creek. It was also suggested that short duration 


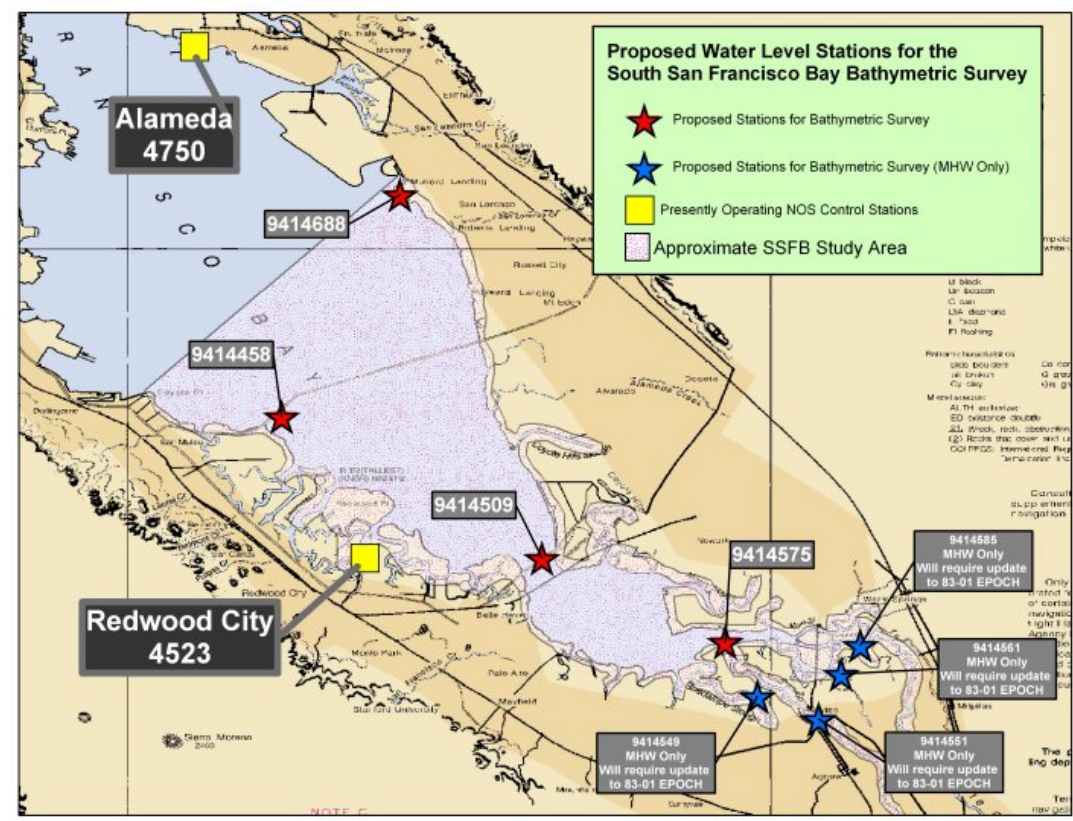

tide stations would have to be installed in other regional sloughs if bathymetric surveys were to extend into the lower reaches of the project area, and that in some of these locations, Mean High Water (MHW) could only be determined. The NOS Primary tide station at 9414750 Alameda, was designated for vertical tidal datum control

\section{BATHYMETRIC SURVEY:}

\section{Tide Gauge Installation}

In October, 2004, the USGS entered into a property loan agreement with CO-OPS to obtain transducers and other hardware for tide gauge installations in support of the South Bay bathymetric survey. The USGS contractor, Sea Surveyor, Inc, was responsible for installation and maintenance of tide gauges, including establishing benchmarks and leveling. The GOES linked Sutron 8210 data loggers and Model 9210 Aquatrak acoustic water level sensors were used specifically for the South Bay bathymetric survey. COOPS field personnel provided assistance and training to Sea Surveyor sub contractors for calibration of water level sensors and tide gauge installation and operation.

It was essential to set each of the four tide gauges to the recently updated (1983-2001 NTDE) Mean Lower Low Water (MLLW) datum. This was accomplished through differential leveling surveys which utilized official published tidal bench mark elevations at each site. Levels were run to each tide gauge upon installation and removal to assure stability during operation, CO-OPS provided the MLLW offsets at each gauge site for determining the original staff zero or datum of tabulation, this allowed the new tide data to be compared directly with the historic data series. 


\section{Tide Gauges}

Tide gauges were installed at the following locations:

Station 9414688 San Leandro Marina

Primary Bench Mark NOS Tidal BM 4, 1974: 6.784m above NOS historic station datum.

Station 9414458 San Mateo Fishing Pier (West Side)

Primary Bench Mark VM8127 stamped 1: 9.576m above NOS historic station datum

Station 9414509 Dumbarton Bridge(East Side)

Primary Bench Mark U553 1956: 10.968m above NOS historic station datum

Station 9414575 Coyote Creek, Alviso Slough

\section{Data Collection and Quality Assurance}

Tide data collection began in January, 2005 in support of the South Bay Bathymetric Survey. Three of the four designated gauge sites were operational at the time of the survey, 9414688 San Leandro Marina, 9414458 San Mateo Fishing Pier (West Side) and 9414509 Dumbarton Bridge. The fourth station, 9414575 Coyote Creek, Alviso Slough developed problems with the original Sutron transducer and never became operational during the survey. Tide data was transmitted via GOES satellite to the CO-OPS Silver Spring, MD headquarters for quality assurance review and data processing. The final data products from each gauge included 6-minute data series, times and heights of high and low waters, monthly means and hourly heights relative to station datum, MLLW. The quality of the tide data obtained from the three operational gauges was assured through a datum recovery procedure which compared the computed datums from the one month data set in January, 2005 with the long term accepted datums used in the reduction of soundings. The datum recovery was $0.1 \mathrm{ft}$ or less at all three stations which is well within the expected generalized accuracy limits for a one month data series $\left(+_{-} 0.13 \mathrm{ft}\right)$ on the West Coast( Swanson 1974).

\section{Tidal Zoning}

Sea Surveyor, Inc began the bathymetric survey, at the northern survey limits(between Coyote Point and San Leandro) on January $10^{\text {th }}, 2005$ and proceeded south until completion in early March, 2006. To account for spatial and temporal changes in the tidal prism throughout the survey area, a tidal zoning scheme was developed by CO-OPS for adjusting tide correctors applied to the bathymetric soundings. The entire South Bay was divided into 59 polygons which are discrete tidal zones with designated tide control reference gauges and time and height corrections. CO-OPS personnel worked closely with Sea Surveyor, Inc contractor, Steve Sullivan to refine the tidal zoning which was completed at the end of May, 2005. The tidal zoning scheme was converted to an Autocad format for easy integration with the bathymetric sounds and tide data. 


\begin{tabular}{|l|c|c|c|c|c|c|c|c|}
\hline Zone & $\begin{array}{c}\text { Time } \\
\text { Corrector }\end{array}$ & $\begin{array}{c}\text { Range } \\
\text { Corrector }\end{array}$ & $\begin{array}{c}\text { Tide } \\
\text { Station }\end{array}$ & & $\underline{\text { Zone }}$ & $\begin{array}{c}\text { Time } \\
\text { Corrector }\end{array}$ & $\begin{array}{c}\text { Range } \\
\text { Corrector }\end{array}$ & $\begin{array}{c}\text { Tide } \\
\text { Station }\end{array}$ \\
\hline SBF28 & -24 & $\mathrm{x} 0.93$ & 9414688 & & SFB43 & 6 & $\mathrm{x} 1.00$ & 9414509 \\
\hline SBF29 & -18 & $\mathrm{x} 0.95$ & 9414688 & & SFB44 & 18 & $\mathrm{x} 1.03$ & 9414509 \\
\hline SFB30 & -12 & $\mathrm{x} 0.95$ & 9414688 & & SBF45 & 24 & $\mathrm{x} 1.03$ & 9414509 \\
\hline SBF31 & -6 & $\mathrm{x} 0.97$ & 9414688 & & SFB46 & 24 & $\mathrm{x} 1.06$ & 9414509 \\
\hline SBF31A & 0 & $\mathrm{x} 1.00$ & 9414688 & & SBF47 & 24 & $\mathrm{x} 1.07$ & 9414509 \\
\hline SBF32 & -18 & $\mathrm{x} 0.97$ & 9414688 & & SBF48 & 30 & $\mathrm{x} 1.08$ & 9414509 \\
\hline SFB33 & -18 & $\mathrm{x} 0.99$ & 9414688 & & SBF49 & 36 & $\mathrm{x} 1.09$ & 9414509 \\
\hline SFB34 & -6 & $\mathrm{x} 0.99$ & 9414688 & & SBF50 & 36 & $\mathrm{x} 1.09$ & 9414509 \\
\hline SBF35 & -6 & $\mathrm{x} 1.01$ & 9414688 & & SBF51 & 48 & $\mathrm{x} 1.09$ & 9414509 \\
\hline SBF36 & -12 & $\mathrm{x} 1.01$ & 9414688 & & SBF52 & 48 & $\mathrm{x} 1.09$ & 9414509 \\
\hline SFB37 & 0 & $\mathrm{x} 0.98$ & 9414458 & & SBF53 & 48 & $\mathrm{x} 1.09$ & 9414509 \\
\hline SFB38 & 6 & $\mathrm{x} 1.01$ & 9414458 & & SBF54 & 54 & $\mathrm{x} 1.09$ & 9414509 \\
\hline SFB39 & 12 & $\mathrm{x} 1.03$ & 9414458 & & SBF55 & 30 & $\mathrm{x} 1.08$ & 9414509 \\
\hline SFB40 & -6 & $\mathrm{x} 0.94$ & 9414509 & & SBF56 & 36 & $\mathrm{x} 1.10$ & 9414509 \\
\hline SBF41 & -6 & $\mathrm{x} 0.95$ & 9414509 & & SBF57 & 42 & $\mathrm{x} 1.12$ & 9414509 \\
\hline SFB42 & 0 & $\mathrm{x} 0.97$ & 9414509 & & SBF58 & 30 & $\mathrm{x} 1.07$ & 9414509 \\
\hline & & & & & SBF59 & 42 & $\mathrm{x} 1.09$ & 9414509 \\
\hline
\end{tabular}
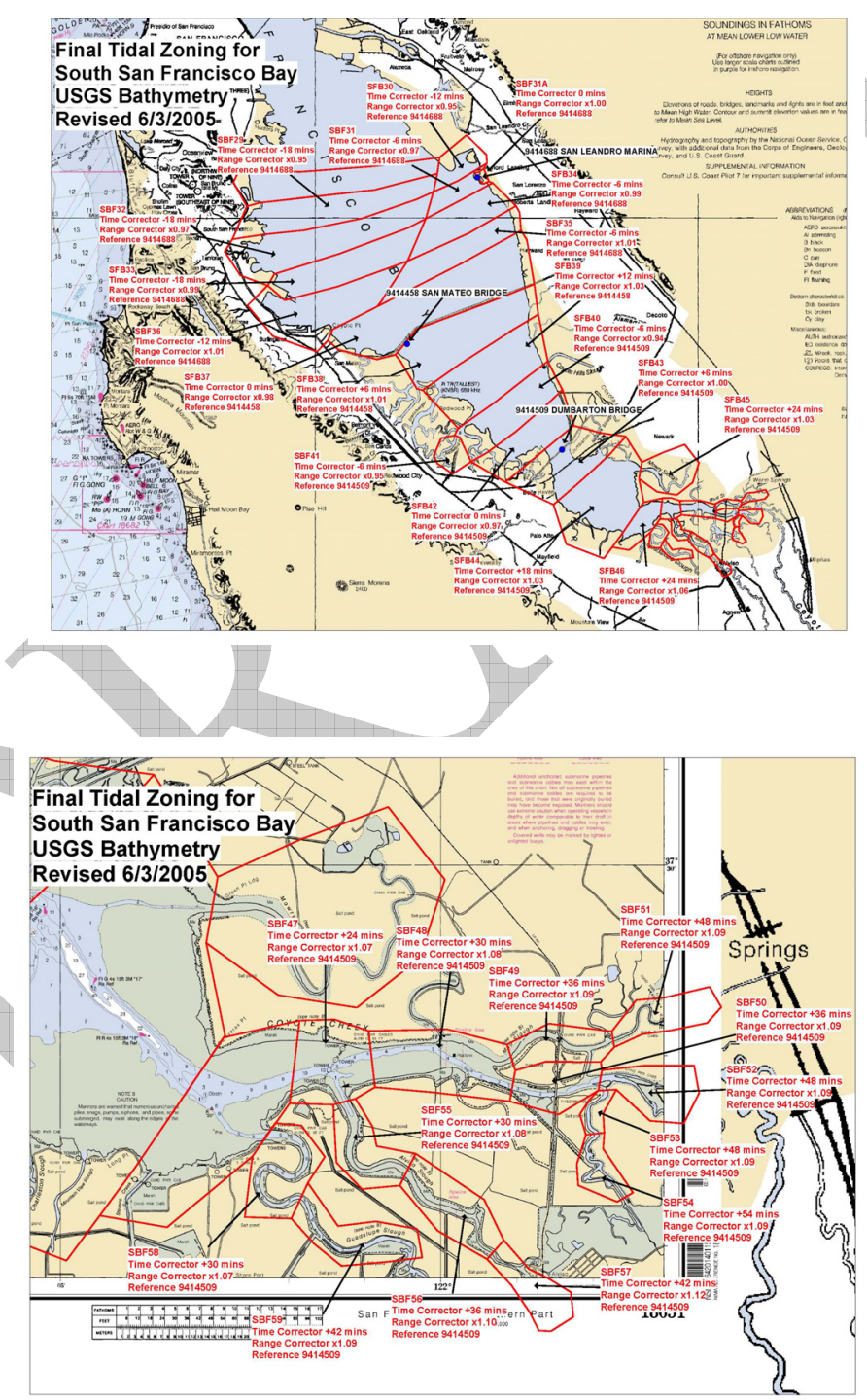


\section{GEODETIC DATUMS:}

\section{NAVD 88}

Following the completion of the South San Francisco Bay bathymetric survey, and adjustment of the soundings to Mean Lower Low Water(1983-2001 National Tidal Datum Epoch), the USGS contractor, Sea Surveyor Inc, requested on May 24, 2004 assistance from CO-OPS in the conversion of bathymetric soundings to the geodetic referenced North American Vertical Datum of 1988. (NAVD 88). It was determined that the most efficient and reliable procedure was to adjust each tidal zone used in the survey with a computed offset between NAVD 88 and MLLW. Thanks to previous tidal surveys from a Federal /State cooperative marine boundary program in the late 1970's and early 1980 's, there were approximately 30 historic tide station locations within the project area where the MLLW was already determined and the tide ranges were well defined. Many of these former tide stations originally had geodetic level ties to the now superseded National Geodetic Vertical Datum of 1929 (NGVD 29), but not to the newly adopted NAVD 88. Therefore, only through VERTCON, a geographic based model program, developed by the National Geodetic Survey (NGS) which computes the difference between both datums, was it possible to convert to NAVD 88. The inaccuracies associated with the VERTCON data made it unacceptable for NAVD 88/MLLW conversions required for the South Bay project.

The ongoing NGS Height Modernization program in California has resulted in more accurate GPS derived orthometric NAVD 88 heights in the South Bay/Salt Pond survey area and in addition, Sea Surveyor Inc obtained GPS observations at selected tide gauge sites. This information provided the basis for determining NAVD 88/MLLW conversions used throughout the South Bay Bathymetric survey project area.

\section{TIDAL CHARACTERISTICS IN SOUTH SAN FRANCISCO BAY:}

\section{Description}

The San Francisco Bay is a shallow estuary carved by narrow channels with many tributaries and sloughs. The bay is basically divided into three distinct regions. The lower estuary, with a direct ocean or marine connection, a middle estuary subject to mixing of salt and fresh water flow and an upper estuary characterized by strong freshwater influence of the Sacramento and San Joaquin Rivers, but still retaining daily tidal action. Tides are characterized as a mixed type with relatively large low water diurnal inequalities of $1.20 \mathrm{ft}$ in the South bay. The diurnal range of tide changes dramatically from the Golden Gate south to the lower reaches of South San Francisco Bay from $5.8 \mathrm{ft}$ to nearly $9.5 \mathrm{ft}$. In some locations, tides in the lower sloughs and creeks below Coyote Creek become completely dry during Spring tide conditions. 


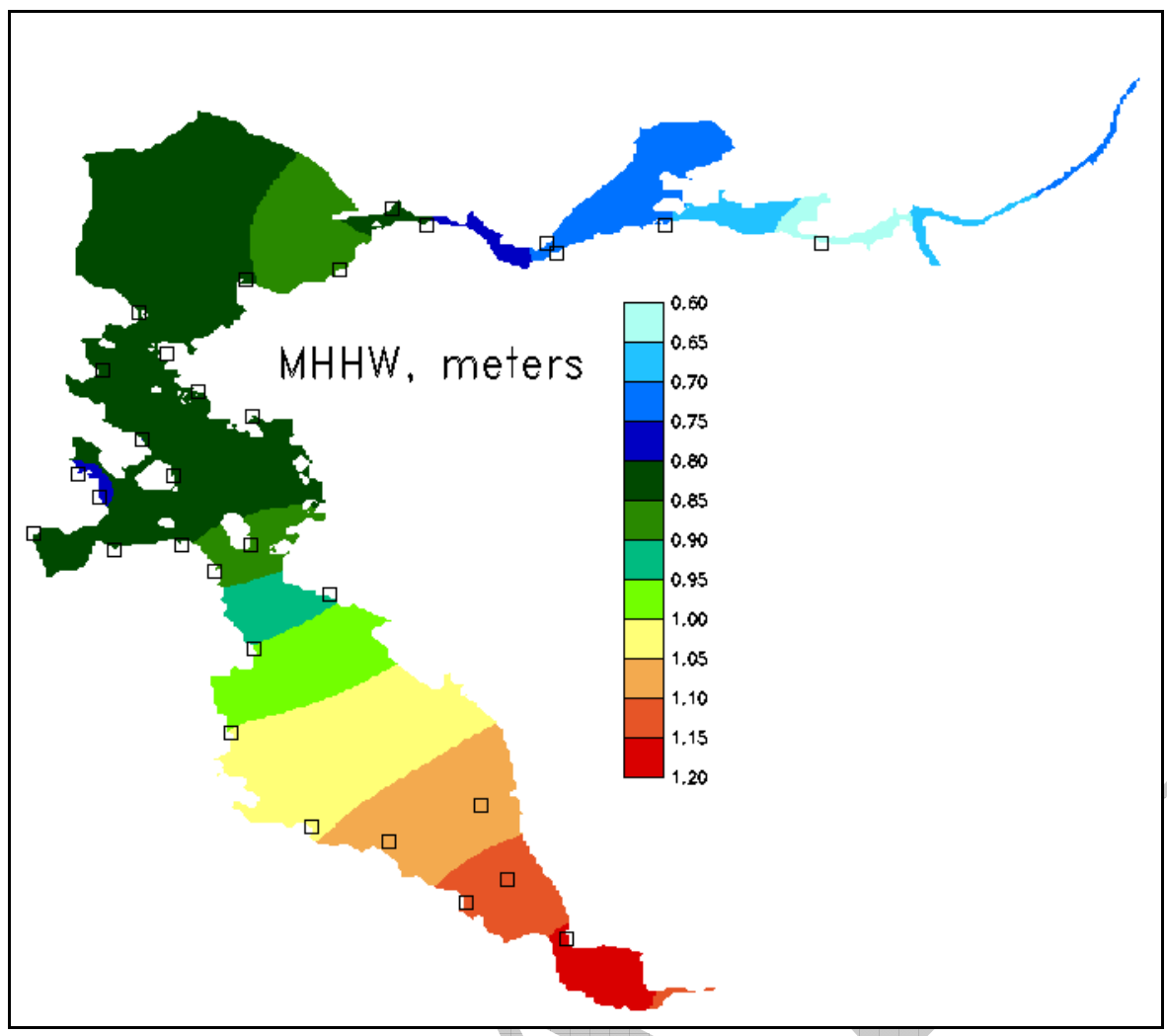

\section{TIDAL DATUMS:}

\section{Mean Lower Low Water (MLLW)}

The MLLW is defined as a tidal datum, which is the arithmetic mean of all Lower Low Waters observed over a 19 year National Tidal Datum Epoch (NTDE). Only the lower low water of each tidal day is included in the mean. The 19 year NTDE is re-computed approximately every 20-25 years, and not only takes into account the changes in the moon's declination cycle, but also changes in local sea level. Soundings shown on NOAA nautical charts and the tide predictions nation wide are referred to MLLW. The most recent NTDE is for the 19 year period ,1983-2001 and all tidal datums, including those short term tide observations used for correcting soundings during the time of the bathymetric survey, are based on this latest NTDE. The NOAA Primary control station at Alameda was used as the 19 reference station for adjusting tidal datums at subordinate or short term stations to the NTDE through standard mathematical comparison procedures. Up until the 1980's, the NOAA gauge at Golden Gate was used for long term NTDE datum control for marine boundaries and hydrographic surveys in the South San Francisco Bay. It wasn't until the 1960-78 NTDE that the Alameda gauge became the Primary tide control for computing short term tidal datums. In general, tidal datums compute approximately $0.1 \mathrm{ft}$ higher using Alameda for datum control.

\section{Mean Sea Level (MSL)}

Local Mean Sea Level (LMSL) is defined as a tidal datum, which is the arithmetic mean of hourly heights observed over a 19 year NTDE. LMSL is the most accurately determined tidal datum which can be used to approximate a geopotential surface within a 
limited region for the purpose of interpolation when adjusted to a fixed geodetic reference like NAVD 88. Long term sea level measurements are not available in the South Bay, but the NOS Primary tide station at Alameda shows a relative sea level trend of $+0.89 \mathrm{~mm} /$ year or relative sea level rise of $(0.29 \mathrm{ft} / \mathrm{century})$. This trend differs substantially from that of the Golden Gate $(0.70 \mathrm{ft} /$ century $)$ and is a good indication of the localized nature of geomorphological changes occurring in the Bay region.

\section{VERTICAL DATUM CONVERSION:}

The conversion of soundings from MLLW to NAVD 88 was accomplished by CO-OPS personnel through applying computed NAVD88-MLLW offsets to each tide zone generated for the bathymetric survey. Computed datum offsets were based on analysis of all available tide and geodetic data in the lower bay. Using a combination of new GPS surveys (performed under contract to Sea Surveyor, Inc.) and NGS Height Modernization bench marks at historic NOS tide stations ( Oyster Point south to Guadalupe and Alviso Sloughs in the lower bay), a linear interpolation was modeled between stations with known NAVD 88-MLLW relationships and adjusted for changes in diurnal tide range. Conversions from MLLW to NAVD 88 were not computed for 6 zones in the region of lower Coyote Creek, due to the loss of a substantial number of lower low water observations at existing NOS stations in the area. This was due, in most part, to the bottom hydrographic features baring before the full lower range of tide was reached. Further data processing is required at these NOS stations in addition to analysis of third party data, and new GPS observations before reliable NAVD 88-MLLW conversions are made available.

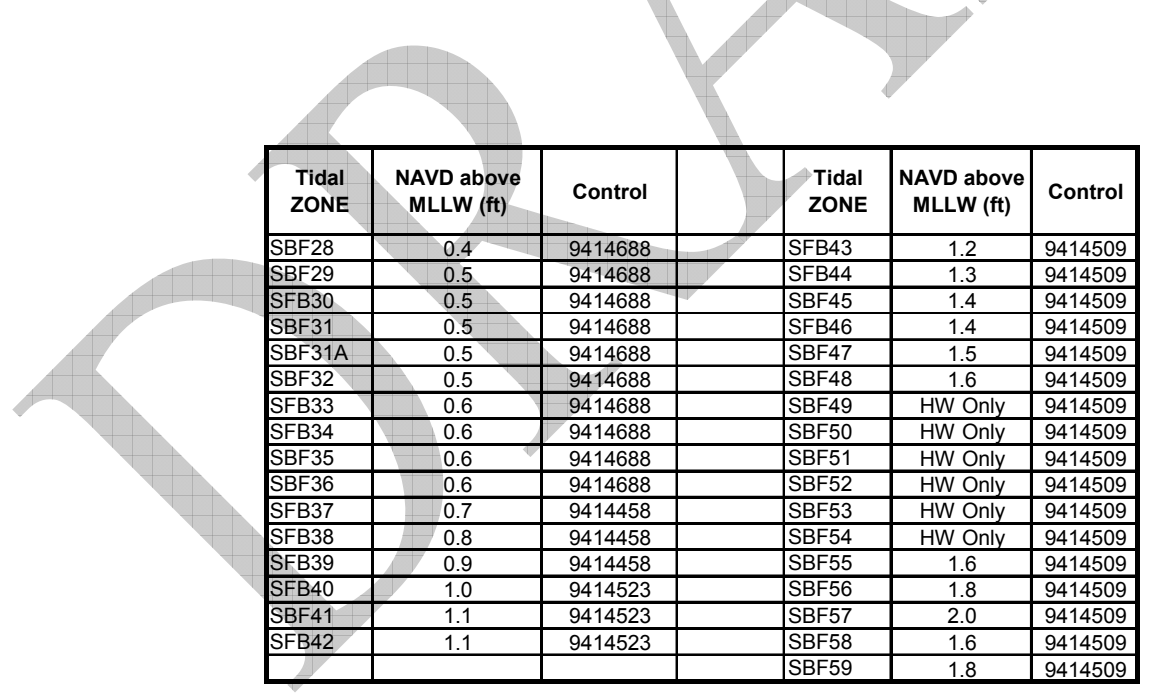



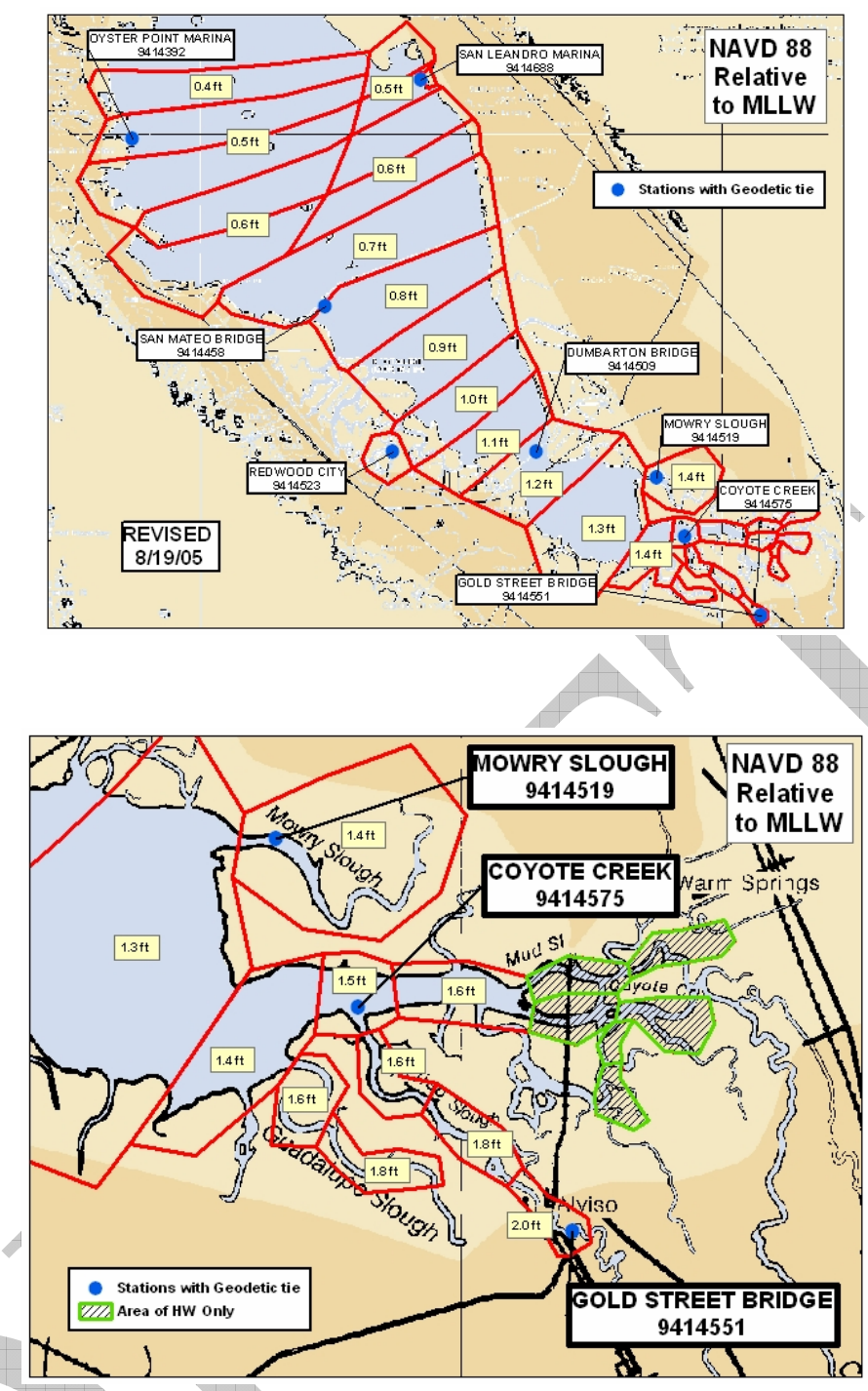


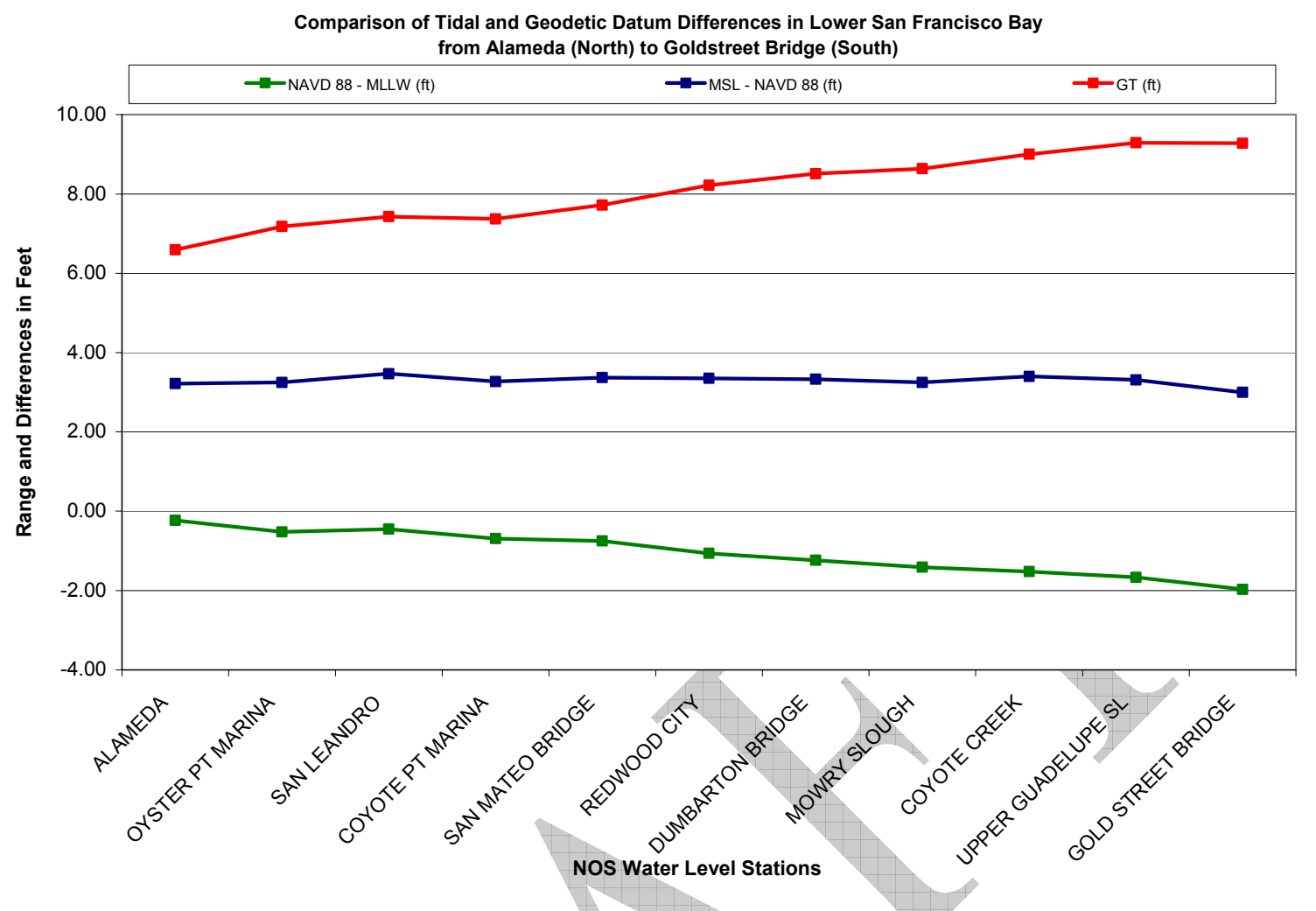

\section{SUMMARY:}

With the inclusion of updated tidal datums, adjusted for the latest sea level trends( NTDE 1983-2001), and new contracted GPS surveys combined with updated geodetic NAVD 88 Height Modernization elevations, NOS/CO-OPS played a key role in supporting the USGS integrated LIDAR and bathymetric surveys of the South San Francisco Bay region which are necessary in establishing baseline bathymetric conditions and documenting historical changes for salt pond restoration activities. The cooperative assistance was highlighted by a property loan agreement for tide gauge installations, COOPS expertise provided for hydrographic project planning, data collection, processing, benchmark leveling, datum computation and vertical datum conversion from MLLW to NAVD 88. Throughout the bathymetric survey project, CO-OPS personnel worked closely with the USGS contractor, Sea Surveyor Inc. to assure that the highest quality data was obtained. Any correspondence, gauge installation reports, tide data, and leveling information produced by the contractor pertinent to the project and used in the final derivation of tidal and geodetic relationships are maintained in official CO-OPS files.

\section{References}

Computations Techniques for Tidal Datums http://tidesandcurrents.noaa.gov/publications/ Computational_Techniques_for_Tidal_Datums_handbook.pdf 
Specifications and Deliverables for Installation, Operation, and Removal of Water $\underline{\text { Level Stations }}$

http://tidesandcurrents.noaa.gov/publications/

wl_gauge_install_operation_removal_specs.pdf

New Technology for Shallow Water Hydrographic Surveys

http://chartmaker.ncd.noaa.gov/hsd/ihr 9 98.pdf

Contractor Partnership Specifications

http://chartmaker.ncd.noaa.gov/hsd/IHR June 00.htm

Specifications and Deliverables

http://chartmaker.ncd.noaa.gov/hsd/specs/specs.htm 